ORNL/TM-13568

\title{
Prediction of External Corrosion for Steel Cylinders - 1998 Report
}

\author{
B.F. Lyon
}


This report has been reproduced directly from the best available copy.

Available to DOE and DOE contractors from the Office of Scientific and Technical Information, P.O. Box 62, Oak Ridge, TN 37831; prices available from 615-576-8401, FTS 626-8401.

Available to the public from the National Technical Information Service, U.S. Department of Commerce, 5285 Port Royal Rd., Springfield, VA 22161.

This report was prepared as an account of work sponsored by an agency of the United States Government. Neither the United States Government nor any agency thereof, nor any of their employees, makes any warranty, express or implied, or assumes any legal liability or responsibility for the accuracy, completeness, or usefulness of any information, apparatus, product, or process disclosed, or represents that its use would not infringe privately owned rights. Reference herein to any specific commercial product, process, or service by trade name, trademark, manufacturer, or otherwise, does not necessarily constitute or imply its endorsement, recommendation, or favoring by the United States Government or any agency thereof. The views and opinions of authors expressed herein do not necessarily state or reflect those of the United States Government or any agency thereof. 
ORNL/TM-13568

\title{
PREDICTION OF EXTERNAL CORROSION FOR STEEL STORAGE CYLINDERS - 1998 REPORT
}

\author{
B. F. Lyon
}

Date Issued--February 1998

Prepared by

Toxicology and Risk Analysis Section

Life Sciences Division

Oak Ridge National Laboratory

Prepared for

U.S. Department of Energy

Office of Environmental Restoration and Waste Management

under budget and reporting code EW 20

OAK RIDGE NATIONAL LABORATORY

Oak Ridge, Tennessee 37831-6285

managed by

LOCKHEED MARTIN ENERGY SYSTEMS, INC.

under contract no. DE-AC05-96OR22464

with the U.S. DEPARTMENT OF ENERGY 


\section{CONTENTS}

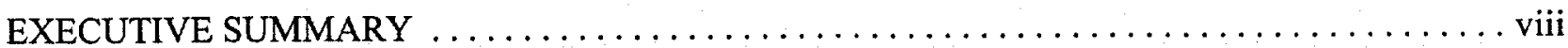

1. INTRODUCTION $\ldots \ldots \ldots \ldots \ldots \ldots \ldots \ldots \ldots \ldots \ldots \ldots \ldots \ldots \ldots \ldots \ldots \ldots \ldots$

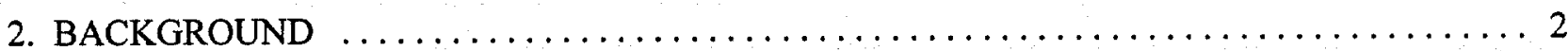

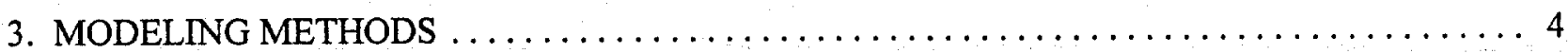

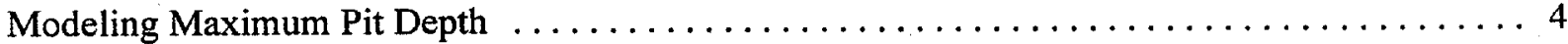

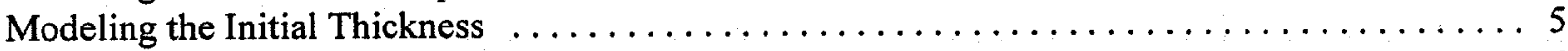

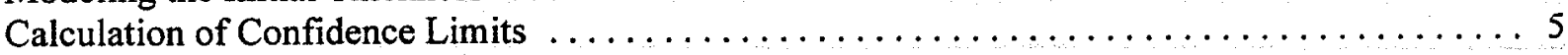

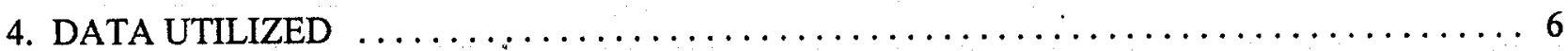

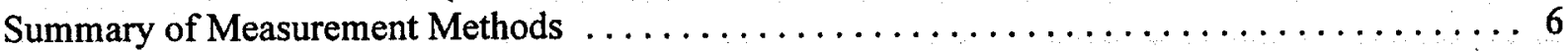

Summary of Data Collection Efforts by Fiscal Year $\ldots \ldots \ldots \ldots \ldots \ldots \ldots \ldots \ldots \ldots \ldots$

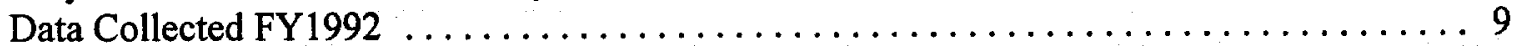

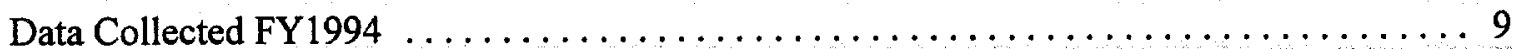

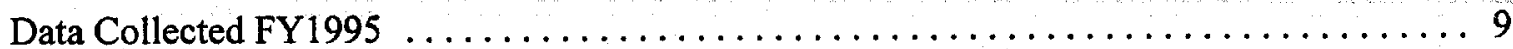

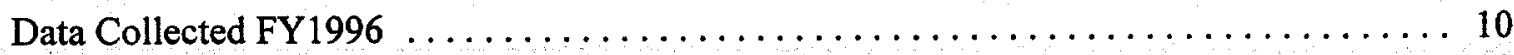

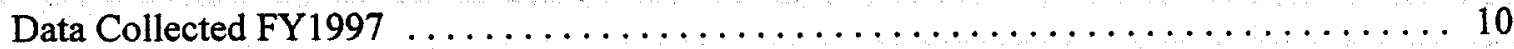

Summary of Data Utilized by Subpopulation $\ldots \ldots \ldots \ldots \ldots \ldots \ldots \ldots \ldots \ldots \ldots \ldots$

$\mathrm{K}$ Yard at Oak Ridge, Thin-Walled Cylinders $\ldots \ldots \ldots \ldots \ldots \ldots \ldots \ldots \ldots \ldots \ldots \ldots \ldots$

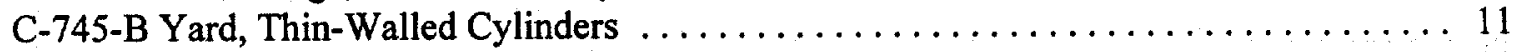

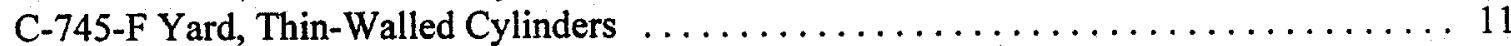

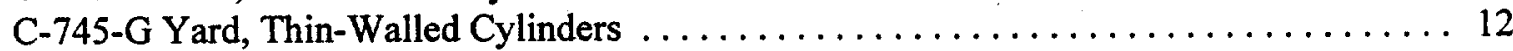

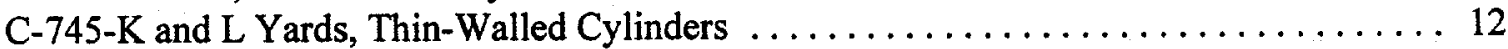

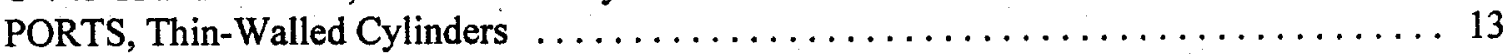

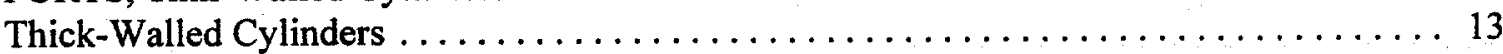

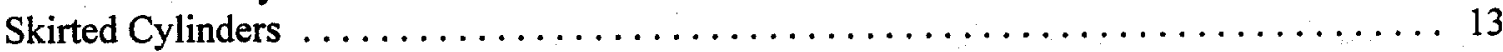

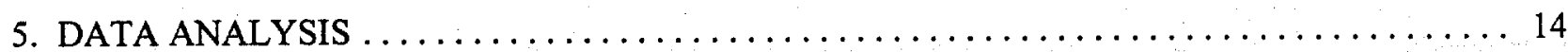

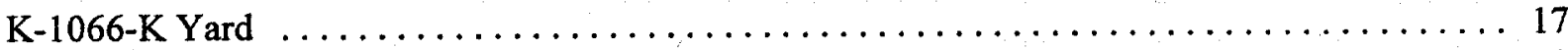

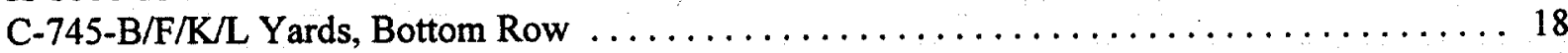

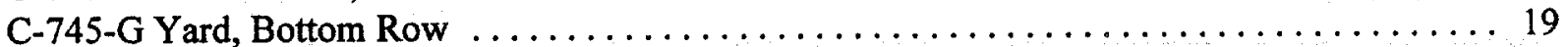

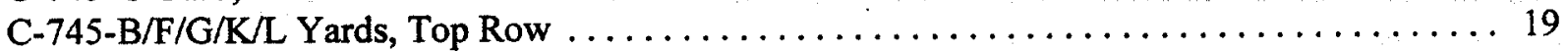

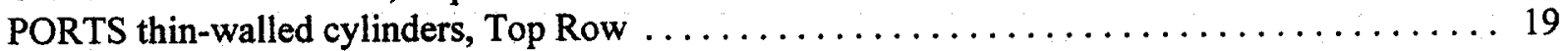

PORTS thin-walled cylinders, Bottom Row $\ldots \ldots \ldots \ldots \ldots \ldots \ldots \ldots \ldots \ldots \ldots \ldots$

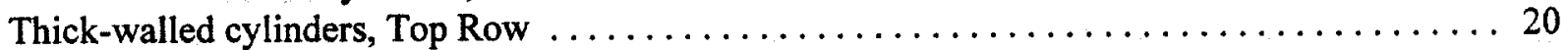

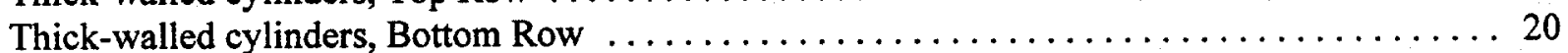

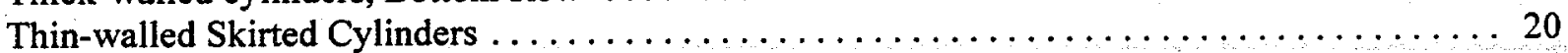

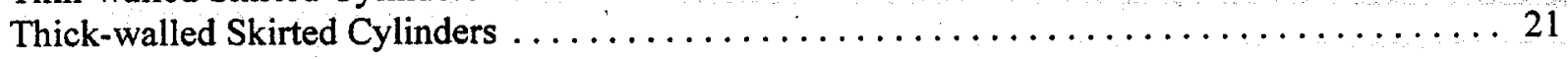

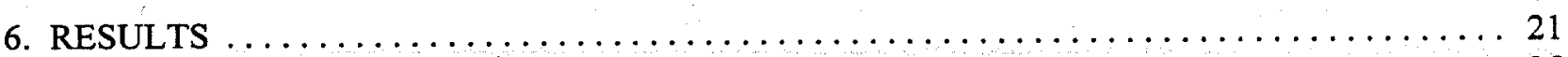

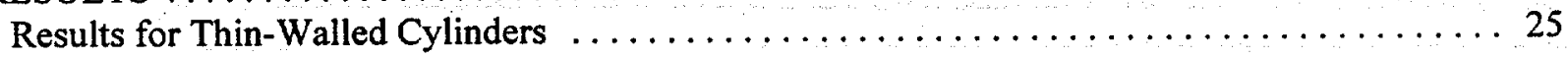




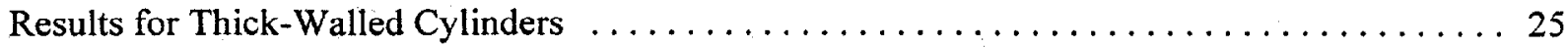

Results at the Head/Skirt Interface for Skirted Cylinders $\ldots \ldots \ldots \ldots \ldots \ldots \ldots \ldots \ldots \ldots$

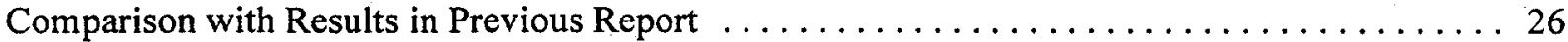

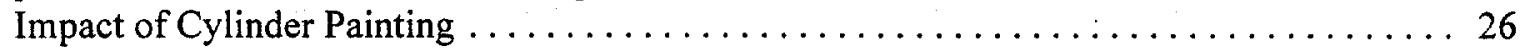

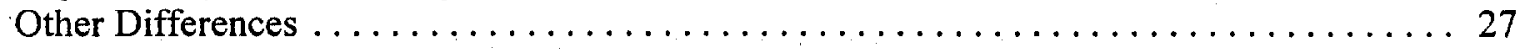

7. UNCERTAINTIES AND LIMITATIONS $\ldots \ldots \ldots \ldots \ldots \ldots \ldots \ldots \ldots \ldots \ldots \ldots \ldots \ldots$

8. CONCLUSIONS AND RECOMMENDATIONS $\ldots \ldots \ldots \ldots \ldots \ldots \ldots \ldots \ldots \ldots \ldots \ldots$

9. REFERENCES ..................................... 29

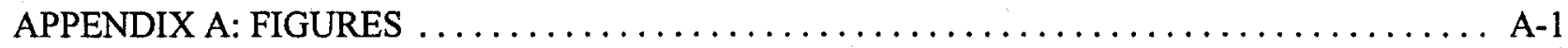

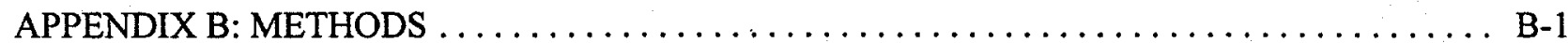

Calculating the cumulative distribution function for the difference of two distributions ...... B-1

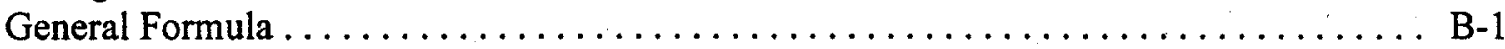

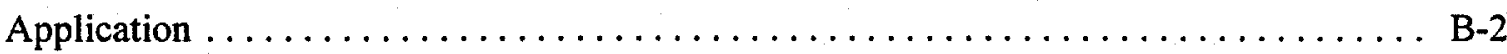

Calculation of Upper Confidence Limits $\ldots \ldots \ldots \ldots \ldots \ldots \ldots \ldots \ldots \ldots \ldots \ldots \ldots \ldots \ldots \ldots \ldots \ldots \ldots$

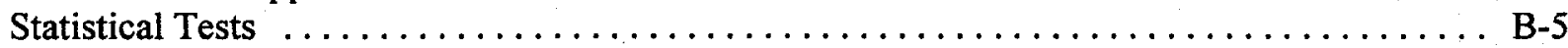

Kolmogorov-Smirnov Goodness-of-Fit Test $\ldots \ldots \ldots \ldots \ldots \ldots \ldots \ldots \ldots \ldots \ldots$ B-5

T-Test with Unequal Variances $\ldots \ldots \ldots \ldots \ldots \ldots \ldots \ldots \ldots \ldots \ldots \ldots \ldots \ldots \ldots \ldots \ldots \ldots$

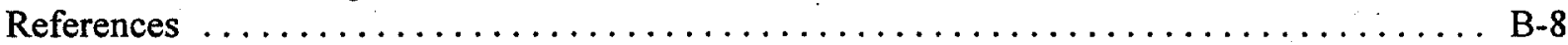

APPENDIX C: SIMULTANEOUS CONFIDENCE LIMITS ON THE PERCENTILES OF A NORMAL

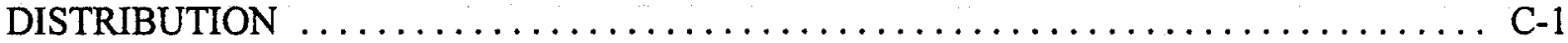

Numerical Methods . . . . . . . . . . . . . . .

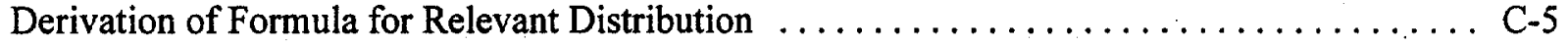

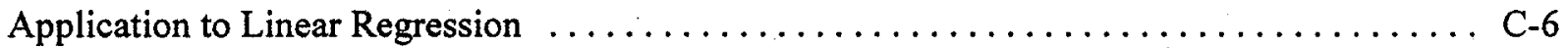

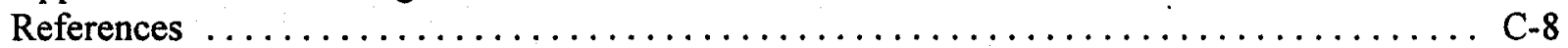




\section{TABLES}

1. Chronological summary of data for estimating minimum wall thicknesses at a point, not including the

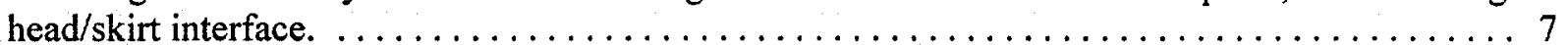

2. Summary of data utilized for estimating wall thickness at head/skirt interface. . . . . . . 8

3. Summary of thin-walled cylinder data utilized, not including data at the head/skirt interface (numbers in parenthesis are the ages, or range of ages, of the cylinders when evaluated) $\ldots \ldots \ldots \ldots \ldots$

4. Summary of thick-walled cylinder data utilized, not including data at the head/skirt interface (numbers in parenthesis are the ages, or range of ages, of the cylinders when evaluated) $\ldots \ldots \ldots \ldots .9$

5. Summary of population datasets and modeling assumptions for thin-walled cylinders. . . . . . 15

6. Summary of population datasets and modeling assumptions for thick-walled cylinder populations, skirted

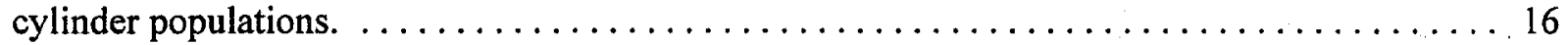

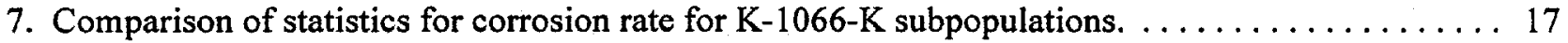

8. Summary results for thin-walled cylinder populations (nominal initial thickness 312.5 mils). . . 23

9. Summary results for thick-walled cylinder populations (nominal initial thickness 625 mils) . . . . 24

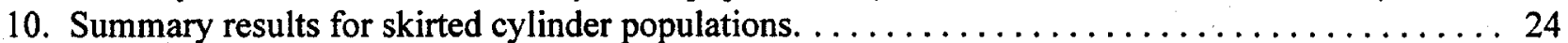

11. Illustration of impact of current painting program on $C-745-G$ yard bottom row cylinders. . . . 26 


\section{EXECUTIVE SUMMARY}

The United States Department of Energy (DOE) currently manages the $\mathrm{UF}_{6}$ Cylinder Project. The project was formed to maintain and safely manage the depleted uranium hexafluoride $\left(\mathrm{UF}_{6}\right)$ stored in approximately 50,000 carbon steel cylinders. The cylinders are located at three DOE sites: the K-25 site (K-25) at Oak Ridge, Tennessee; the Paducah Gaseous Diffusion Plant (PGDP) in Paducah, Kentucky, and the Portsmouth Gaseous Diffusion Plant (PORTS) in Portsmouth, Ohio.

The System Requirements Document (SRD) (LMES 1997a) delineates the requirements of the project. The appropriate actions needed to fulfill these requirements are then specified within the System Engineering Management Plan (SEMP) (LMES 1997b). The report presented herein documents activities that in whole or in part satisfy specific requirements and actions stated in the $\mathrm{UF}_{6}$ Cylinder Project SRD and SEMP with respect to forecasting cylinder conditions. The wall thickness projections made in this report are based on the assumption that the corrosion trends noted will continue. Some activities planned may substantially reduce the rate of corrosion, in which case the results presented here are conservative. The results presented here are intended to supercede those presented previously. (Lyon 1995,1996, 1997), as the quality of several of the datasets has improved.

For thin-walled cylinders (design nominal initial wall thickness 312.5 mils), the minimum wall thicknesses of interest used in this report are $0,62.5 \mathrm{mils}$, and $250 \mathrm{mils}(1 \mathrm{mil}=0.001 \mathrm{in}$.). For thick-walled cylinders (design nominal initial wall thickness 625 mils), the minimum wall thicknesses of interest used in this report are $0,62.5$ mils, and 500 mils. These thicknesses are preliminary boundaries identified within the project that indicate loss of material, safe handling and stacking operations, and standards for off-site transport and contents transfer criteria, respectively. In general, these criteria are based on area of wall thinning. However, the minimum thickness predicted in this report is for a region with an area of about $0.01 \mathrm{sq}$. in, because this is the type of data used. Using minimum point thickness adds a considerable degree of conservatism to the results in this report.

The most recently collected data, which were not available for last year's report (Lyon 1997), consisted of evaluations of the wall loss in the head/skirt interface of skirted 48" thin- and thick-walled cylinders, and additional cylinder body evaluations. The head/skirt data had no impact on the previous results, as this was the first effort to collect data of this type. Inclusion of the other data resulted in minor modifications of the fitted curves for penetration depth. When combined with the impacts of the cylinder painting program and refinement of the relevant age distributions for the modeled cylinders, there is either no change, or a slight decrease in the total number of thin-walled cylinders that do not meet the various thickness criteria, when compared to the previous year's report.

The summary results are provided in Tables 8,9 and 10 of this report. Most of the cylinders predicted to have a minimum thickness less than 250 mils in 1998 are located in K-1066-K yard at K-25 or were in the bottom row of C-745-G yard at PGDP. Of the few cylinders predicted to have a minimum thickness less than 62.5 mils or have a point breach by 1998 (using expected values), all are in these same two yards. Both of these yards have had a large fraction of cylinders that were in ground contact at one time, although they have been relocated. Using conservative upper confidence limits, a single breach is predicted by 1998 in the PGDP bottom row population that is treated separately from C-745-G yard; however, this is an implication of the small sample size for this population. 
The painting program has reduced the forecasted number of cylinders that do not meet the specified wall thickness criteria. For example, for the $\mathrm{C}-745-\mathrm{G}$ yard bottom row cylinders, it is predicted that the painting already completed will prevent almost 200 cylinders from falling below the Standards limit for off-site transport and contents transfer criterion by 2008 (assuming that painting halts corrosion for approximately 10 years).

Based on data for the cylinder body, few of the approximately 2000 thick-walled cylinders are predicted to have a minimum point thickness below any of the thickness criteria by 2020 . In particular, less than 50 are predicted to have a minimum wall thickness below 500 mils by 2020 , and none are predicted to have a breach or minimum point thickness less than 62.5 mils by 2020 .

A preliminary analysis of data specifically collected at the head/skirt interface during FY1997 tentatively confirmed the accelerated nature of corrosion in the skirt crevice compared to the general body. In particular, some thick-walled cylinders, all of which are skirted, were predicted to have a minimum thickness below 62.5 mils, or even a breach, at the interface by 2020 . 
THIS PAGE INTENTIONALLY LEFT BLANK 


\section{INTRODUCTION}

The United States Department of Energy (DOE) currently manages the UF 6 Cylinder Project. The project was formed to maintain and safely manage depleted uranium hexafluoride $\left(\mathrm{UF}_{6}\right)$ stored in approximately 50,000 carbon steel cylinders. The cylinders located at three DOE sites: the K-25 site at Oak Ridge, Tennessee (K-25); the Paducah Gaseous Diffusion Plant in Paducah, Kentucky (PGDP), and the Portsmouth Gaseous Diffusion Plant (PORTS) in Portsmouth, Ohio.

The System Requirements Document (SRD) (LMES 1997a) delineates the requirements of the project. The appropriate actions needed to fulfill these requirements are then specified within the System Engineering Management Plan (SEMP) (LMES 199.7b). The report presented herein documents activities that in whole or in part satisfy specific requirements and actions stated in the UF ${ }_{6}$ Cylinder Project SRD and SEMP with respect to forecasting cylinder conditions. The wall thickness projections made in this report are based on the assumption that the corrosion trends noted will continue. Some activities planned may substantially reduce the rate of corrosion, in which case the results presented here are conservative. The results presented here are intended to supercede and enlarge the scope of those presented previously (Lyon 1995,1996, 1997). In particular, projections are made for thin-walled cylinders (nominal initial thickness 312.5 mils) and thick-walled cylinders (nominal initial thickness $625 \mathrm{mils}$ ). In addition, a preliminary analysis is conducted for the minimum thickness at the head/skirt interface for skirted cylinders.

System Requirement 1.2.2 states that performance shall be monitored and evaluated to identify potential risks within the project. The related SEMP Action 2.1.2 is to model corrosion to project cylinder integrity. This report establishes the technique for modeling corrosion rates used in the project to forecast cylinder wall thickness conditions in the future.

System Requirement 4.1.2 calls for cylinder conditions to be monitored. The related SEMP Action 3.1.2 is to statistically determine the baseline condition of cylinder populations by obtaining quantitative data. This report contains the statistical method used in the project to apply the available quantitative data to cylinder populations. Populations have been established based on historical storage locations (yard and position) and similarity of quantitative data. Wall thickness and corrosion pit depth data have been collected for several subpopulations of cylinders.

System Requirement 4.2.2 further states that cylinder conditions shall be forecast to direct surveillance and maintenance resources. Technical Requirement 4.2.2a is that specific information, as determined by the project, shall be tracked to project the current and future conditions of the system. In addition, Technical Requirement 4.2.2.b entails the development of mechanisms to consolidate information for summary level decision-making determinations. SEMP Action 2.2.1 is to integrate cylinder condition elements to be forecast with cylinder categorization. SEMP Action 3.1 is to forecast cylinder conditions using parameters identified. Wall thickness, the subject of this report, is one parameter identified in the project to forecast cylinder conditions. The available wall thickness data are used to forecast out year conditions.

SEMP Action 3.1.1 is to project the number of non-compliant cylinders. The disposition of any particular cylinder for storage, handling, and transfer is based on the condition of the cylinder, where "condition" is ultimately reflected by the minimum wall thickness of a cylinder. The wall thickness parameters (0,62.5 mils, and 250 mils for thin-walled; $0,62.5,500$ mills for thick-walled cylinders) used in 
this report are preliminary boundaries identified within the project that indicate loss of material, safe handling and stacking operations, and standard off-site transport and contents transfer criteria, respectively. In general, these criteria are based on area of wall thinning rather than minimum thickness at any one point as used in this report. Using minimum point thickness adds a considerable degree of conservatism to the results in this report.

\section{BACKGROUND}

The basic problem addressed here is to estimate how many cylinders will have a minimum thickness below some value $z$ by time $t$. The current analyzed data only allow estimating the minimum thickness at a small point, and not the thickness over a large area. Additional analysis of the available data could provide estimates of the thickness over a larger area of structural significance.

Let $C_{0}(x)$ denote the initial wall thickness (mils) at a location $x$ on the cylinder, and let $P(t, x)$ denote the amount of corrosion that has occurred (mils) at location $x$ by time $t$. The minimum wall thickness at time $t$ for a given cylinder, denoted here by $M(t)$, is given by

$$
M(t)=\min _{x}\left\{C_{0}(x)-P(t, x)\right\}
$$

where the minimum is over all points $x$ on the cylinder.

If the only concern is about the minimum thickness for a given cylinder at a given time, then knowledge of both $C_{0}(x)$ and $P(t, x)$ is not necessary. One can simply estimate the minimum wall thickness directly, although there will be measurement error that depends on the type of equipment used, as well as uncertainty as to the exact location of the minimum wall thickness. However, in order to make predictions for unsampled cylinders, or to make predictions for future time periods, assumptions must be made about the nature of the quantities $C_{o}(x)$ and $P(t, x)$.

Because the thicknesses of the cylinder walls were not recorded when they were first delivered, it is not possible to determine $C_{0}(x)$ as a function of $x$. For this reason, the joint distribution (in $\left.x\right)$ of $C_{0}(x)$ and $P(t, x)$ cannot be known. Assumptions must then be made about $C_{0}(x)$. One such assumption is to treat it as an independent (from $P(t, x)$ ) random variable, in which case the minimum thickness $M(t)$ for a given cylinder is then also a random variable, defined by

$$
\begin{aligned}
M(t) & =C_{0}-\max _{x}\{P(t, x)\} \\
& =C_{0}-P(t)
\end{aligned}
$$

where $P(t)$ is defined as the maximum penetration depth for a given cylinder of age $t$. The corrosion rate is then $d P / d t$. Thus, even given the knowledge of the value of $P(t)$, there would be uncertainty in $M(t)$ due to uncertainty in the initial thickness where the maximum pit depth occurred, $C_{0}$, for the given cylinder. The design range for the initial thickness of thin-walled cylinders is from 302.5 to 345.5 mils (615 to 655 or 665 mils for thick-walled cylinders), and so it could be argued that, without sufficient supporting 
information, the lower end of the design range must be used to confidently bound the minimum thickness. However, if it is acceptable that where the maximum penetration depth occurs the initial thickness is actually larger than the minimum of the design range, then less conservative estimates may be possible.

The preceding discussion pertains to estimating the minimum thickness for a given cylinder. When estimating the thickness for a population of cylinders, there are two additional sources of variability: (1) variability across cylinders of the maximum penetration depth $P(t)$, and (2) variability across cylinders of the distribution of initial thickness $C_{0}$. Variability in $P(t)$ can be due to random variations in the corrosion process, and to differences in the storage history of the cylinders. Variability in the distribution of initial thickness can be due to differences in the methods used by manufacturers.

Sampling of the cylinders provides estimates of the maximum penetration depth $P(t)$, and from these data predictions must be made for the maximum penetration depth for both the unsampled cylinders and for all cylinders as a function of age. Even for a fixed age, there will be variability in the maximum penetration depth. Given the uncertainty in the storage histories for the cylinders, conservative estimation of the variability in $P(t)$ can be desirable. When approximating the distribution for $P(t)$, it is natural to restrict oneself to methods of the form $P(t)=F(\alpha(t), \beta(t))$ where $F(\alpha, \beta)$ is a two-parameter random variable (e.g., the parameters $\alpha$ and $\beta$ could be the mean and standard deviation). The goal is then to approximate what the functions $\alpha(t)$ and $\beta(t)$ are.

The minimum thickness for a given population of cylinders is then given by

$$
M(t)=C_{0}-F(\alpha(t), \beta(t))
$$

and the probability that a particular cylinder of age $t$ will have a minimum thickness below a given thickness $z$ is

$$
\operatorname{Prob}\{M(t)<z\}=\operatorname{Prob}\left\{C_{0}-F(\alpha(t), \beta(t))<z\right\}
$$

With the exception of cylinders that are being purchased now, there is no way to know the distributions $\mathrm{C}_{0}$. The data collected suggest that the wall thickness on relatively uncorroded areas of a cylinder is usually larger than the nominal design thickness.

Ultimately, for a given population of cylinders, the total number of cylinders with a minimum thickness below a given value $z$ at time $T$ is estimated by

\# Cylinders with minimum thickness below $z$ at time $T=$

$$
\sum_{i}(\# \text { cylinders of age t at time } T) \times \operatorname{Prob}\{M(t)<z\}
$$




\section{MODELING METHODS}

\section{Modeling Maximum Pit Depth}

An expected feature of the corrosion rate and penetration depths is that, in general, they decrease with time. The problem that must be addressed is defensibly quantifying just what the decrease in corrosion rate is. It may be that in many cases (i.e., many subpopulations of cylinders) the corrosion process has reached a condition in which, whatever the past corrosion history for each cylinder may have been, each cylinder is corroding at some relatively constant (over the year) rate. If this is true, then the modeling is fairly straightforward: one determines the current condition for each cylinder, estimates what the current "constant rate" is, and then projections can be made for future times. Conceptually, this idea is appealing; however, to do this successfully requires a reliable "picture" of the current conditions, and determination of the current "constant" corrosion rates for all relevant populations. Both of these factors rely on the quantity and quality of the data available.

Prediction of the distribution of penetration depths $P(t)$ across cylinders is critical to the whole process of estimating the number of cylinders that have a minimum thickness below a given level. The simplest manner in which to do this is to assume that the general shape of the distribution of penetration depths is the same for all ages, but the mean or median (measures of central tendency) and standard deviation (i.e., the amount of "spread" in the distribution) is changing in a specified fashion. Focus is then directed to determining exactly how these factors depend on age.

The main approach utilized here allows modeling of the "leveling off" commonly observed, and is of the form $P(t)=A t^{n}$ where $A$ and $n$ are constants. This is often referred to as the "linear bilogarithmic law," and there are many applications of this model in long-term corrosion prediction (Felieu et al. 1993a; Felieu et al. 1993b; Legault and Preban 1975; Pourbaix 1982; Mughabghab and Sullivan 1989; Romanoff 1957). Determination of $A$ and $n$ are performed by doing a linear regression of the form $\ln P=\ln A+n \ln$. According to Pourbaix (1982), Passano (1934) was the first to use such a relationship in corrosion prediction. This law is considered to be valid for different types of atmospheres (rural, marine, industrial) and a number of materials. The parameter $A$ can be interpreted as the corrosion in the first year, and the parameter $n$ represents the attenuation of the corrosion because of the passivation of the material in the atmosphere (Pourbaix, p.115). It is also possible to discuss this model in terms of the mean (or age-averaged) corrosion rate, since the mean corrosion rate is given by $P / t=A t^{m-1}$. If $n=I$ then this implies that the age-averaged corrosion rate is constant, while if $n<1$ (which is usually the case) then the corrosion rate decreases with time. Mechanistic interpretations of $n$ have also been made (Horton 1964). If $n=0.5$, then the relationship is said to be parabolic, with the corrosion rate controlled by diffusion through the rust layer. If $n<0.5$, then this implies that the rust layer is showing protective properties, while if $n>0.5$, then the rust layer is not protective because of factors that may be preventing the homogeneous thickening of the rust layer. This approach is used in several Department of Energy models to predict time to breach due to external corrosion for carbon steel containers in soil. This method can be rather sensitive to deviations from the "leveling off" pattern usually expected for the penetration depth, and so must be used with caution. Indeed, in cases where no "leveling off" is observed (due, for example, to a narrow age range for cylinders), the simpler method used in Lyon $(1995,1996)$ is utilized.

In order to address the variability inherent in the corrosion process, it is assumed that the penetration depths are lognormally distributed at each time. This can also be expressed as $\ln P(t) \sim N\left(\ln A+n \ln t, \sigma_{\nu}\right)$, 
where $N(\mu, \sigma)$ is the normal distribution with mean $\mu$ and standard deviation $\sigma$. For this model, the median is equal to $A t^{n}$, the arithmetic mean $\mu$ is $A t^{n} \exp \left[0.5 \sigma^{2}\right]$, and the arithmetic standard deviation is $A t^{n} \exp \left[0.5 \sigma^{2}\right]\left[\exp \left(\sigma_{L}^{2}\right)-1\right]^{1 / 2}$. The coefficient of variation (ratio of the standard deviation to the mean) is constant with time, and is equal to $\left[\exp \left(\sigma_{L}^{2}\right)-1\right]^{1 / 2}$.

Given that the data consist of what are considered to be maximum pit depths, it is natural to apply extreme-value statistics to this problem. Indeed, application of this method (without confidence limits) is discussed in several papers in the literature and has also been suggested for use within this project in Rosen and Glaser (1996). The basic premise underlying this theory is that the distribution of extreme values, under rather general assumptions, should have a specific (parametric) form. However, for the present analyses simpler methods are used because calculation of confidence limits is more straightforward, and the lognormal distribution has many of the same qualitative properties as the applicable extreme value distribution.

\section{Modeling the Initial Thickness}

The initial thickness assumed is an important feature of the analysis. In Lyon (1995 and 1996) this was dealt with in a simple fashion. In this report, the initial thickness is modeled using a distribution that accounts for the variability in the initial thickness. In this analysis, the initial thickness is approximated using a truncated normal distribution, which is a normal distribution that is defined on a finite range. The parameters for the distribution are estimated based on the data available. With the exception of the data at the head/skirt interface (see below), these data consist of wall thickness measurements made on the cylinders evaluated in relatively uncorroded regions of the cylinder. These measurements were made using either an automated scanner or a hand-held probe, depending on the particular dataset. This initial thickness estimate does not include any general corrosion that may have occurred across the entire cylinder surface. This is motivated in part by concerns within the project that the variability in initial thickness could be a critical factor (e.g., Rosen and Glaser 1995).

It has been found that the wall thickness is typically much larger in the head/skirt interface than the design specifications would indicate. When the data were collected, five manual measurements were made on the cylinder head at a distance of about one inch from the cylinder head/skirt weld (Lykins and Pawel 1997). The initial thickness was set to the measured thickness at the center of the cylinder head plus 10 mils. The extra factor was used because it was found that on several $48 \mathrm{G}$-type cylinders (these are thin-walled cylinders), the wall thickness was usually 10-20 mils less than that found beneath the plug. This difference was attributed to the forging process to form the contour of the head. That method is not used here because it was found that this does not guarantee that the initial thickness is larger than the measured wall thickness in the head/skirt area. Instead, the maximum of the five measurements plus 10 mils was used as an approximation to the initial thickness.

The lower bound of the range used to model the initial thickness is set to the lower bound of the design specifications: 302.5 mils for thin-walled cylinders, 615 mils for thick-walled cylinders. The upper bound is set to the largest observed value for initial wall thickness.

\section{Calculation of Confidence Limits}

The method used to calculate confidence limits is discussed in Appendix B. It is stressed that the confidence limits are relevant only when the samples upon which they are based come from a random 
sample. As such, because few of the datasets currently available come from a random sample, the defensibility of the confidence limits presented here is suspect, except in the case of the PORTS cylinders and perhaps to some degree $C-745-G$ bottom row cylinders, since random sampling was utilized for these data. The confidence limits are presented for all populations in this report because it may assist project management by providing an upper envelope, and implementation of the methods necessary to calculate confidence limit facilitates subsequent modeling when random sampling has been employed for all populations.

\section{DATA UTILIZED}

In this section a summary of the data sets utilized is provided. The previous report (Lyon 1997) utilized wall thickness data that had been collected through September 1996. This report includes additional data that were collected during the period October 1996 to August 1997. There are two main types of data used:

(1) data for predicting overall minimum wall thickness at a point, not including the head/skirt interface

(2) data for predicting minimum wall thickness at the head/skirt interface

Some of the data available can be used to address more general issues, such as the average wall thickness over a given region, but that is not performed in this report.

Table 1 summarizes the data collected by fiscal year. In each case, it is noted whether or not the data collected constitute a random sample. Random sampling is critical because it allows statistically defensible statements to be made about the unsampled population(s). An initial sampling plan (Lyon and Lykins 1996) was prepared that included random sampling, and recommended that it be updated to more efficiently fit within the current budgetary and logistical constraints. Table 2 summarizes the data collected at the head/skirt interface, and Tables 3 and 4 show more detail about the age ranges and yard locations of the evaluated cylinders. Plots of the data are shown in Figures 3-13 in Appendix A.

\section{Summary of Measurement Methods}

Several of the data collection efforts have used an automated scanner called a P-Scan system (see Schmidt et al. 1996 for a description of the equipment). The first effort was performed during 1994 at K1066-K yard at K-25. The second was performed during the fall of 1995 at the PGDP, the third was conducted between March and September 1996 at both the PORTS and PGDP sites as part of the cylinder relocation efforts. The most recent was conducted during FY1997, primarily at the PORTS site. The pit depth data consist of measurements made with the automated scanner for a square region of width and height of about $2.54 \mathrm{~mm}(0.1 \mathrm{in})$. The wall thickness data used for the initial thickness consisted of either data collected with the automated scanner near where the maximum pit occurred (with a width and height of approximately the same size as the pit data), or was collected using a hand-held probe for a circular region with a radius of about $2 \mathrm{~mm}(0.08 \mathrm{in})$.

Hand-held methods (Lykins and Pawel 1997) were used to collect data on the corrosion in the head/skirt interface during FY1997 for both thin- and thick-walled cylinders at the PORTS and PGDP sites. 
Table 1. Chronological summary of data for estimating minimum wall thicknesses at a point, not including the head/skirt interface.

\begin{tabular}{|c|c|c|c|c|c|c|c|}
\hline & FY1992 & FY1994 & FY1995 & \multicolumn{2}{|c|}{ FY1996 } & \multicolumn{2}{|c|}{ FY1997 } \\
\hline \multicolumn{8}{|c|}{ Thin-Walled Cylinders (nominal initial wall thickness of 312.5 mils) } \\
\hline Yard(s) & K-1066-K & $\mathrm{K}-1066-\mathrm{K}$ & $\mathrm{C}-745-\mathrm{B} / \mathrm{F} / \mathrm{K} / \mathrm{L}$ & $\mathrm{C}-745-\mathrm{F} / \mathrm{G} / \mathrm{K}$ & $\mathrm{X}-745-\mathrm{C}$ & $\mathrm{C}-745-\mathrm{G} / \mathrm{L}$ & $\mathrm{X}-745-\mathrm{C}$ \\
\hline Type of Data & Visual & PSCAN & PSCAN & PSCAN & PSCAN & PSCAN & PSCAN \\
\hline Number cylinders & 2 & 138 & 94 & 261 & 473 & 3 & 85 \\
\hline Random sampling? & No & No & No & No & Yes & No & Yes \\
\hline Comment on Sampling & $\begin{array}{l}\text { Breached } \\
\text { cylinders }\end{array}$ & $\begin{array}{l}\text { Intent was that } \\
\text { cylinders be } \\
\text { selected } \\
\text { randomly, but } \\
\text { limitations were } \\
\text { imposed by } \\
\text { scanner }\end{array}$ & $\begin{array}{l}\text { Cylinders } \\
\text { selected based on } \\
\text { judgement of } \\
\text { personnel (Blue, } \\
\text { 1995a). }\end{array}$ & $\begin{array}{l}\text { Intent was that } \\
10 \% \text { of cylinders } \\
\text { moved would be } \\
\text { evaluated. Space } \\
\text { restrictions for } \\
\text { selected cylinders } \\
\text { prevented this } \\
\text { from occurring. }\end{array}$ & $\begin{array}{l}10 \% \text { of cylinders } \\
\text { moved during } \\
\text { FY } 1996 \text { were } \\
\text { randomly } \\
\text { selected and } \\
\text { evaluated }\end{array}$ & & \\
\hline \multicolumn{8}{|c|}{ Thick-walled Cylinders (nominal initial wall thickness of 625 mils) } \\
\hline Yard(s) & & & & $X-745-C$ & & & \\
\hline Type of Data & & & & PSCAN & & & \\
\hline Number cylinders & & & & 137 & & & \\
\hline Random sampling? & & & & Yes & & & \\
\hline Comment & & & & $\begin{array}{l}10 \% \text { of cylinders } \\
\text { moved during } \\
\text { FY1996 were } \\
\text { randomly } \\
\text { selected and } \\
\text { evaluated }\end{array}$ & & . & \\
\hline
\end{tabular}




\begin{tabular}{|r|r|}
\hline \multicolumn{2}{|l|}{$\begin{array}{l}\text { Table 2. Summary of data utilized for estimating wall thickness } \\
\text { at head/skirt interface. }\end{array}$} \\
\hline \multicolumn{2}{|c|}{ FY1997 } \\
\hline $\begin{array}{r}\text { Thin-Walled Cylinders (nominal initial } \\
\text { wall thickness 312.5 mils) }\end{array}$ & \\
\hline Yard(s) & X-745-C \\
\hline Type of Data & Hand-held \\
\hline Aguber cylinders & 233 \\
\hline Random sampling? & Yes \\
\hline $\begin{array}{r}\text { Thick-walled Cylinders (nominal initial } \\
\text { wall thickness 625 mils) }\end{array}$ & $38-40$ \\
\hline Yard(s) & \\
\hline Type of Data & Hand-held \\
\hline Number cylinders & 115 \\
\hline Age Range (yr) & $36-45$ \\
\hline Random sampling? & Yes \\
\hline &
\end{tabular}

Table 3. Summary of thin-walled cylinder data utilized, not including data at the head/skirt interface (numbers in parenthesis are the ages, or range of ages, of the cylinders when evaluated).

\begin{tabular}{|c|c|c|c|c|c|c|c|}
\hline \multirow[b]{2}{*}{ Site } & \multirow[b]{2}{*}{ Yard } & \multirow[b]{2}{*}{ Row } & \multicolumn{4}{|c|}{ Number of Cylinders } & \multirow[b]{2}{*}{1997} \\
\hline & & & 1992 & 1994 & 1995 & 1996 & \\
\hline \multirow{2}{*}{$\mathrm{K}-25$} & \multirow{2}{*}{$\mathrm{K} \cdot 1066-\mathrm{K}$} & Top & $1(29)^{*}$ & $60(31-36)$ & & & \\
\hline & & Bottom & $1(34)^{*}$ & $55(31-38)$ & & & \\
\hline \multirow{10}{*}{ PGDP } & \multirow{2}{*}{ C-745-B } & Top & & & $4(39)$ & & \\
\hline & & Bottom & & & $2(39)$ & & \\
\hline & \multirow{2}{*}{$C-745-F$} & Top & & & $13(31-36)$ & & \\
\hline & & Bottom & & & $13(32-36)$ & $6(36.37)$ & \\
\hline & \multirow{2}{*}{$C-745-G$} & Top & & & $9(33-36)$ & $137(18-37)$ & \\
\hline & & Bottom & & & $17(33-36)$ & $98(5-37)$ & $2(37)$ \\
\hline & \multirow{2}{*}{$\mathrm{C}-745 \cdot \mathrm{K}$} & Top & & & $16(15-18)$ & & \\
\hline & & Bottom & & & $23(15-19)$ & $6(16-37)$ & \\
\hline & \multirow{2}{*}{ C-745-L } & Top & & & $1(13)$ & & \\
\hline & & Bottom & & & $2(14)$ & & $1(38)$ \\
\hline \multirow{2}{*}{ PORTS } & \multirow{2}{*}{$X-745-C$} & Top & & & & $221(6-40)$ & $56(20-36)$ \\
\hline & & Bottom & & & & $252(6-40)$ & $29(8-36)$ \\
\hline
\end{tabular}

- These are the two cylinders that were determined to breach from external corrosion (Barber et al. 1994). 
Table 4. Summary of thick-walled cylinder data utilized, not including data at the head/skirt interface (numbers in parenthesis are the ages, or range of ages, of the cylinders when evaluated).

\begin{tabular}{llllll}
\hline \multirow{2}{*}{ Site } & Yard & Row & 1992 & \multicolumn{3}{c}{ Number of Cylinders } & 1994 & 1995 & 1996 & 1997 \\
\hline \multirow{2}{*}{ PGDP } & C-745-C & Top & Bottom & & $1(42)$ \\
& & & & $1(44)$ \\
\hline \multirow{2}{*}{ PORTS } & \multirow{2}{*}{ X-745-C } & Top & Bottom & $50(42-45)$ \\
& & & $65(42-45)$ \\
\hline
\end{tabular}

Summary of Data Collection Efforts by Fiscal Year

In this section the data collection efforts are summarized in order by fiscal year in which they were obtained. Summaries by yard and/or subpopulation are discussed below.

\section{Data Collected FY1992}

These data consist of two breached cylinders discovered in 1992 in K-1066-K yard, for which it was deemed that external corrosion was the cause of the breach. There have been five other breaches discovered (two at K-25 in 1992, two at PORTS in 1990, and one at PGDP in 1992), but it was concluded that the breaches were induced by mechanical damage at the time of stacking rather than to external corrosion. In particular, the breaches were caused by a lifting lug of an adjacent cylinder that induced a small crack near a stiffening ring. While it is challenging to determine the best manner in which to include these data, it is felt that it is critical that these data be included. This is because the existence of these data show that extremely accelerated corrosion is possible (but rare), and hence any model utilized must incorporate this feature.

\section{Data Collected FY1994}

During the six month period $12 / 93$ to $5 / 94$, pit depth and wall thickness measurements were made for 136 cylinders in K-1066-K yard (Philpot 1995) using an automated scanner. It was intended that the cylinders selected for measurement be chosen at random, although a random number generator was not used to select the cylinders, and there were limitations imposed by the automated scanner (e.g.; length of power cord, clearance between adjacent cylinders). For these reasons, it is not possible to objectively conclude that the cylinders selected are a representative sample from the population, although this actually may be the case. For the first 21 cylinders evaluated, only minimum wall thickness data were recorded, while pit depth data were also recorded for the rest of the cylinders. There is concern about the accuracy of the wall thickness data for the first group of cylinders. Further, since no pit depth data were recorded for these cylinders that would allow estimating how much corrosion had occurred, these cylinders are not included in this analysis.

\section{Data Collected FY1995}

During FY 1995, data were collected for 100 thin-walled cylinders at PGDP using the automated scanner (Blue 1995a). The primary purpose of this effort was to assess "the condition of the more vulnerable portion" of the cylinder population at PGDP (Blue 1995a). The cylinders were selected from the C-745$\mathrm{B} / \mathrm{F} / \mathrm{G} / \mathrm{K} / \mathrm{L}$ yards based on the judgement of the personnel involved, and do not defensibly constitute a random sample from any of these yards. 


\section{Data Collected FY1996}

During FY1996, almost 900 cylinders were evaluated with the automated scanner at the PORTS and PGDP sites. Both thin-walled (nominal initial wall thickness 312.5 mils) and thick-walled cylinders were evaluated (nominal initial wall thickness 625 mils).

At PORTS, $10 \%$ of the cylinders that were relocated were selected using a random number generator to evaluate the wall thickness using ultrasonic thickness (UT) measurements. The $10 \%$ evaluation criterion was required based on a Consent Decree with the Ohio Environmental Protection Agency.

Most of the cylinders evaluated at PGDP were from C-745-G yard, and had been set aside as part of the relocation efforts performed during FY1995 and FY1996. These cylinders were a subset of the approximately 390 cylinders set aside from the first 3900 cylinders moved out of the C-745-G yard. Because of the manner in which these cylinders were selected, these cylinders are a systematic sample only from the first 3900 cylinders moved out of $G$ yard. An additional 6 cylinders from both $C-745-F$ and $C-745-K$ yard were also evaluated. For C-745-F yard, single stacked cylinders from the north end were selected, while the $\mathrm{C}-745-\mathrm{K}$ yard cylinders were selected based on the ease of accessibility with the equipment. In both cases, these samples are not considered to be a random sample.

\section{Data Collected FY1997}

During FY1997, data were collected for cylinders both at the head/skirt interface and for overall minimum wall thickness. Cylinders were evaluated at PORTS and PGDP. The head/skirt data were collected from cylinders that had been evaluated with the automated scanner in FY1996 at PORTS, and from two cylinders at PGDP (Lykins and Pawel 1997). The cylinders at PORTS had originally been systematically set aside as part of the $10 \%$ criterion for evaluation. No specific criteria were used for the selection of cylinders from this subset, thereby weakening the defensibility of assuming that the sample is random; however, more than $75 \%$ of those cylinders originally set aside were evaluated.

The cylinders evaluated at PORTS with the automated scanner were randomly selected from those cylinders moved during the year. Originally, it was suggested that approximately 250 cylinders be evaluated (Lykins 1996). However, budget constraints allowed only 85 evaluations with the PSCAN.

Two cylinders that had been in the bottom row of C-745-G yard, and one cylinder from C-745-L bottom row, were also evaluated with the PSCAN during FY1997. These were located in the north end of C-745-F yard when evaluated.

\section{Summary of Data Utilized by Subpopulation}

In this section the data utilized are discussed relative to the subpopulation to which they are assumed to belong. Some of the information is redundant with that in the previous section, but is included for clarity. 
K Yard at Oak Ridge, Thin-Walled Cylinders

K-1066-K yard, located at the K-25 plant in Oak Ridge Tennessee, contains 2942 thin-walled cylinders, ranging in age (in 1996) from about 32 years to 39 years. These cylinders were initially stored at $\mathrm{K}-1066-\mathrm{G}$ yard at Oak Ridge starting at about 1966, and relocated in 1983 (Barber et al. 1994). During the six month period 12/93 to 5/94, pit depth and wall thickness measurements were made for 136 cylinders (Philpot 1995) using an automated scanner. It was intended that the cylinders selected for measurement were chosen at random, although a random number generator was not used to select the cylinders, and there were limitations imposed by the automated scanner (e.g., length of power cord, clearance between adjacent cylinders). For these reasons, it is not possible to objectively conclude that the cylinders selected are a representative sample from the population, although this actually may be the case. For the first 21 cylinders evaluated, only minimum wall thickness data were recorded, while pit depth data were also recorded for the rest of the cylinders. There is concern about the accuracy of the wall thickness data for the first group of cylinders. Further, since no pit depth data were recorded for these cylinders that would allow estimating how much corrosion had occurred, these cylinders are not included in this analysis.

It is noted that the accuracy of the equipment used when these data were collected was such that only increments of 5 mils were recorded for pit depth. As a result, there may be several cylinders with the same pit depth and this cannot be seen in Figure 3.

Also included in the dataset are two breached cylinders discovered on K-1066-K yard in 1992 (Barber et al. 1994).

\section{C-745-B Yard, Thin-Walled Cylinders}

This yard contains about 1500 thin-walled cylinders manufactured between 1954 and 1988. In 1995, six cylinders were inspected, all type $48 \mathrm{~T}$ and manufactured in the period 1956-57. These cylinders had been stored on 10" high concrete piers above the yard surface since April 1967 (Blue 1995a). Four top row and two bottom row cylinders were evaluated, this particular choice of cylinders being a matter of convenience for the material handlers (Blue 1995a).

\section{C-745-F Yard, Thin-Walled Cylinders}

C-745-F yard contains approximately 4500 cylinders. The top and bottom rows of this yard were interchanged in 1992 when all bottom row cylinders were put on concrete chocks, rather than wood as had been previously used (each row was also relocated south one row). It is likely that some fraction of the bottom row cylinders were in water contact for extended periods of time, although none are now.

In 1995 twenty-six (26) cylinders were evaluated, with 13 from both the bottom and top rows. Both the pit depths and wall thickness were recorded for these cylinders. It is noted that hand-held measurements using a $2 \mathrm{~mm}$ probe were made in 1994 to estimate the minimum wall thickness for 21 cylinders in C-745-F yard, but the pit depths were not recorded (Blue 1994). These data are not included in this analysis because it is not possible to reliably estimate the pit depths. These data were used in the analysis discussed in Lyon (1995) because these were the only data available for this yard at that time.

Six cylinders were also evaluated in FY1996 from C-745-F yard. 


\section{C-745-G Yard, Thin-Walled Cylinders}

The population modeled as $\mathrm{C}-745-\mathrm{G}$ yard actually consists of those cylinders that were originally in C$745-\mathrm{G}$ yard prior to construction of the new yard, and have not been painted. A painting program was initiated for the cylinders moved from C-745-G to C-745-S yard in 1996. All 2168 cylinders in C-745-S were painted during FY1996-1997.

There are three datasets available for C-745-G yard that were utilized, all of which were collected using the automated scanner. The first consists of data for 26 cylinders that were evaluated in 1995 (Blue 1995a, 1995b).

The second dataset consists of measurements made between March and September 1996 on cylinders set aside as part of the relocation efforts performed during 1995 and 1996 . A total of 235 cylinders were evaluated (137 from the top row, and 98 from the bottom row). These cylinders are a subset of the approximately 390 cylinders set aside from the first 3900 cylinders moved out of the C-745-G yard. Because of the manner in which these cylinders were selected, these cylinders are a systematic sample only from the first 3900 cylinders moved out of $\mathrm{G}$ yard. This weakens the statistical defensibility of statements made for the whole $C-745-G$ yard population based on the trends observed for these data. There was concern that the condition of the bottom row cylinders in C-745-G yard affected the accuracy of the equipment for the cylinders evaluated in FY1995, as material at the bottom of the pits can result in the equipment underestimating the actual pit depth (Blue 1995c). Checks with hand-held instruments indicated that the pit depths may be underestimated by about 15 mils (Blue 1995c), and for this reason a factor of 15 mils was added to the measured maximum pit depth for these cylinders.

The third data set consists of two bottom row cylinders that were evaluated in FY1997; these were located in the north end of C-745-F when evaluated.

It is noted that hand-held measurements using a $2-\mathrm{mm}$ probe were made in 1994 to estimate the minimum wall thickness for eight cylinders in C-745-G yard, but the pit depths were not recorded (Blue 1994). These data are not included in this analysis because it is not possible to reliably estimate the pit depths. These data were used in the analysis discussed in Lyon (1995) because these were the only data available for this yard at that time.

\section{C-745-K and L Yards, Thin-Walled Cylinders}

The C-745-K and C-745-L yards contain a total of about 9000 Type OM and G cylinders manufactured in the period 1958-1992. These cylinders have been stored on five-inch concrete saddles in gravel yards constructed with an underground drainage system. Data were collected from these yards in 1995, 1996 and 1997. The sampling in 1995 was limited to those cylinders that were manufactured during the period 19761982 that had lost large portions of their protective coating (Blue 1995a). A total of 42 cylinders were inspected ( 39 from $\mathrm{K}$ yard, 3 from L yard). Twenty-five cylinders were from the bottom row, and 17 were from the top row. In 1996, 6 cylinders from the bottom row of C-745-K yard were evaluated. In 1997, one cylinder that had been in the bottom row of C-745-L yard was evaluated; it was located in the north end of C-745-F yard when evaluated: 


\section{PORTS, Thin-Walled Cylinders}

There are approximately 14000 thin-walled cylinders ranging in age from a few years to over 40 years old located at the PORTS site. Prior to FY 1996, there were four cylinder storage yards at PORTS. These yards were designated X-745-A, X-745-C, X-745-E, and X-745-F. The X-745-A and X-745-C yards were essentially the same yard, but were separated into different sections. The $\mathrm{X}-745-\mathrm{C}$ yard had six sections, while the X-745-A yard had three sections. The X-745-A and X-745-C yards had a two tier stacking configuration. The cylinders from the $\mathrm{X}-745-\mathrm{F}$ yard were single stacked cylinders. The $\mathrm{X}-745-\mathrm{E}$ yard was a compacted gravel storage area, but was reconstructed during FY 1995-1996 to a reinforced concrete storage yard. In FY 1996, a total of 5708 cylinders were relocated at PORTS to meet the new storage requirements.

Cylinders at PORTS were moved from single row storage to a two tiered arrangement around 1976. Prior to this, there were no top row cylinders at PORTS. The cylinders had been in their current location until movement activities in FY 1996. Thus, the "top" row cylinders at PORTS discussed here have only been in the top row for about 20 years.

In FY 1996, 10\% of the cylinders that were relocated were selected using a random number generator to evaluate the wall thickness using ultrasonic thickness (UT) measurements. The $10 \%$ evaluation criterion was required based on the Consent Decree with the Ohio Environmental Protection Agency. These cylinders, as well as other cylinders with handling or storage damage, were evaluated using the automated scanner $\mathrm{P}$ Scan system and hand-held measurements. A total of 609 cylinders were evaluated at PORTS in FY 1996.

For the purpose of modeling, all of the thin-walled cylinders at PORTS are considered as one yard, and the top and bottom rows are treated separately. During FY 1996, 473 thin-walled (i.e., nominal thickness 312.5 mils) were evaluated ( 221 from the top row, 252 from the bottom row), with an age range of $6-40$ years.

In Lyon (1995), a different dataset was used for the PORTS site. These data consisted of hand-held ultrasonic thickness measurements made in 1994 on 125 cylinders. These data are not used in the present analysis because the measurements were not taken at areas known to have accelerated corrosion, such as the saddle interface. Further, the evaluation techniques currently used are more stringent and provide more accurate data than that obtained previously.

\section{Thick-Walled Cylinders}

There are approximately 1800 thick-walled cylinders (nominal wall thickness 625 mils) located at the three sites: During FY1996, 137 thick-walled cylinders were evaluated with the PSCAN as part of the relocation efforts (135 at PORTS, 2 at PGDP). At this time, row location when evaluated (top vs. bottom) is uncertain for 20 of the cylinders evaluated at PORTS, and these data are not included in the present analysis. The cylinders evaluated at PORTS were randomly selected .

\section{Skirted Cylinders}

There are about 1500 thin- and thick-walled 48" cylinders at the three sites that have skirted ends. Most of these cylinders were manufactured before 1970. There is a concern that accelerated corrosion in the head/skirt crevice is possible due to a combination of extended time of wetness and differential aeration (Lykins and Pawel 1997). In order to comply with the Director's Findings and Orders with the Ohio EPA 
at PORTS for cylinder movements performed in FY1996, wall thickness data were taken during FY 1997 at the head/skirt interface for both thin-walled (233) and thick-walled (115) cylinders. These data are used to project the conditions at the head/skirt interface for the entire population of skirted cylinders. Two thickwalled cylinders were also evaluated at PGDP. These cylinders were selected based on their ease of accessibility (Lykins and Pawel 1997).

\section{DATA ANALYSIS}

Tables 5 and 6 show the basic groupings made with the current data. These groupings are then applied to larger populations that include unsampled cylinder populations. The median maximum pit depth for each of the models used is provided in Figures 1 and 2 (figures are presented in Appendix A). Scatterplots for the data for each population are shown in Figures 3-13. A discussion of each dataset is provided below. 
Table 5. Summary of population datasets and modeling assumptions for thin-walled cylinders.

\begin{tabular}{|c|c|c|c|c|c|c|c|c|}
\hline Dataset & $\begin{array}{l}\text { Sample } \\
\text { Size }\end{array}$ & $\begin{array}{l}\text { Population Dataset } \\
\text { Is Used for } \\
\end{array}$ & Comment & $\begin{array}{l}\text { Model for Penetration } \\
\text { Depth } P(t)^{\dagger}\end{array}$ & $\begin{array}{l}\text { Predicted Median } \\
\text { Pit Depth }\end{array}$ & $\begin{array}{l}\text { Model for Initial } \\
\text { Thickness }^{\dagger \dagger}\end{array}$ & $\overline{\operatorname{Ln}(t)}$ * & $\begin{array}{l}\text { Sum of } \\
\text { Squares* }\end{array}$ \\
\hline $\mathrm{K}-1066-\mathrm{K}$ & 117 & K-1066-K & $\begin{array}{l}\text { Narrow age range of cylinders } \\
\text { (manufacture dates } 1956-1964 \text { ), many of } \\
\text { which were previously in ground } \\
\text { contact for at least } 15 \text { years while in K- } \\
\text { 1066-G yard }\end{array}$ & $\mathrm{t} \times \log (0.53,0.46)$ & $1.70 \mathrm{t}$ & $\begin{array}{l}\mathrm{N}(315.1,9.8) \text { on } \\
{[302.5,340]}\end{array}$ & NA & NA \\
\hline $\begin{array}{l}\text { C-745-B/F/K/L } \\
\text { bottom row }\end{array}$ & 53 & $\begin{array}{l}\text { C-745- } \\
\text { B/C/D/F/K/L/M/N/P } \\
\text { bottom row }\end{array}$ & $\begin{array}{l}\text { Bottom row PGDP cylinders that, for } \\
\text { the most part, have not been in ground } \\
\text { contact }\end{array}$ & $\begin{array}{l}\log (1.79+0.6 \operatorname{Ln} t \\
0.37)\end{array}$ & $6.0 \mathrm{t}^{0.60}$ & $\begin{array}{l}\mathrm{N}(332.0,9.5) \text { on } \\
{[302.5,357]}\end{array}$ & 3.1 & 7.2 \\
\hline $\begin{array}{l}\text { C-745-G bottom } \\
\text { row }\end{array}$ & 117 & C-745-G bottom row & $\begin{array}{l}\text { Many cylinders were in ground contact } \\
\text { for extended periods }\end{array}$ & $\begin{array}{l}\log (1.85+0.71 \operatorname{Ln} t \\
0.37)\end{array}$ & $6.4 \mathrm{t}^{0.71}$ & $\begin{array}{l}N(336.3,10.0) \text { on } \\
{[302.5,363]}\end{array}$ & 3.4 & 9.5 \\
\hline $\begin{array}{l}\mathrm{C}-745- \\
\mathrm{B} / \mathrm{F} / \mathrm{G} / \mathrm{K} / \mathrm{L} \text { top } \\
\text { row }\end{array}$ & 180 & $\begin{array}{l}\text { C-745- } \\
\text { B/C/D/F/G/K/L/M/N/ } \\
\text { P top row }\end{array}$ & $\begin{array}{l}\text { Cylinders primarily in top row for most } \\
\text { of their storage history }\end{array}$ & $\begin{array}{l}\log (2.04+0.50 \operatorname{Ln} t \\
0.25)\end{array}$ & $7.7 \mathbf{t}^{0.50}$ & $\begin{array}{l}\mathrm{N}(332.8,8.6) \text { on } \\
{[302.5,356]}\end{array}$ & 3.3 & 13.0 \\
\hline PORTS top row & 277 & $\begin{array}{l}\text { PORTS and K-1066- } \\
\text { B/E/J top row }\end{array}$ & $\begin{array}{l}\text { Cylinders primarily in top row for most } \\
\text { of their storage history }\end{array}$ & $\begin{array}{l}\log (2.42+0.41 \operatorname{Lnt} \\
0.22)\end{array}$ & $11.3 \mathrm{t}^{0.41}$ & $\begin{array}{l}N(331.4,13.2) \text { on } \\
{[302.5,378]}\end{array}$ & 3.4 & 45.9 \\
\hline $\begin{array}{l}\text { PORTS bottom } \\
\text { row }\end{array}$ & 281 & $\begin{array}{l}\text { PORTS and } \\
\text { K-1066-B/E/J bottom } \\
\text { row }\end{array}$ & $\begin{array}{l}\text { Cylinders primarily in bottom row, but } \\
\text { not ground contact, for most of their } \\
\text { storage history }\end{array}$ & $\begin{array}{l}\log (2.58+0.42 \operatorname{Ln} t \\
0.28)\end{array}$ & $13.2 \mathrm{t}^{0.42}$ & $\begin{array}{l}N(333.4,13.8) \text { on } \\
{[302.5,375]}\end{array}$ & 3.3 & 66.8 \\
\hline
\end{tabular}

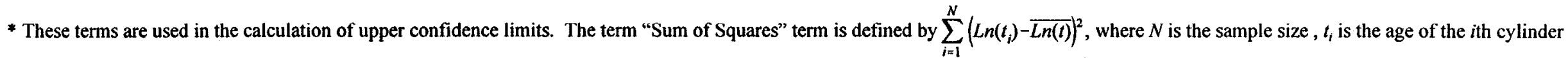
evaluated, and $\overline{\operatorname{Ln}(t)}$ is the mean of the natural logarithm of the ages. How these values are used in determining confidence limits is shown in Appendix $C$.

$+\quad \log (\mathrm{a}, \mathrm{b})$ denotes a lognormal distribution with mean and standard deviation of the natural logarithm of the values of $a$ and $b$, respectively.

it "N( $\mu, \sigma)$ on $[a, b] "$ denotes a normal distribution with mean $\mu$ and standard deviation $\sigma$ defined on the range [a,b]. 
Table 6. Summary of population datasets and modeling assumptions for thick-walled cylinder populations, skirted cylinder populations.

\begin{tabular}{|c|c|c|c|c|c|c|c|c|}
\hline Dataset & $\begin{array}{l}\text { Sample } \\
\text { Size }\end{array}$ & $\begin{array}{l}\text { Population Dataset Is } \\
\text { Used for }\end{array}$ & Comment & $\begin{array}{l}\text { Model for Penetration } \\
\text { Depth } P\left(t^{\dagger}\right.\end{array}$ & $\begin{array}{l}\text { Predicted Median } \\
\text { Pit Depth }\end{array}$ & $\begin{array}{l}\text { Model for Inltial } \\
\text { Thickness }{ }^{\dagger}\end{array}$ & $\overline{\operatorname{Ln}(t)}$ * & $\begin{array}{l}\text { Sum of } \\
\text { Squarest }\end{array}$ \\
\hline $\begin{array}{l}\text { PORTS thick-walled, top row } \\
\text { C-745-C, top row } \\
\text { PORTS thin-walled, top row }\end{array}$ & $\begin{array}{l}328(=50 \\
+1+ \\
277)\end{array}$ & $\begin{array}{l}\text { All yards, Thick-walled, top } \\
\text { row }\end{array}$ & $\begin{array}{l}\text { The combined dataset is used for estimating the } \\
\text { penetration depth and associated factors. The } \\
\text { thick-walled population alone is used to estimate } \\
\text { initial thickness distribution. }\end{array}$ & $\log (2.33+0.44 \operatorname{Ln} t, 0.23)$ & $10.3 t^{0.4}$ & $\begin{array}{l}N(641.7,13.0) \text { on } \\
{[615,680]}\end{array}$ & 3.4 & 52.8 \\
\hline $\begin{array}{l}\text { PORTS thick-walled, bottom } \\
\text { row } \\
\text { C- } 145-C \text {, bottom row } \\
\text { PORTS thin-walled, bottom } \\
\text { row }\end{array}$ & $\begin{array}{l}347(=65 \\
+1+281)\end{array}$ & $\begin{array}{l}\text { All yards, Thick-walled, } \\
\text { bottom row }\end{array}$ & $\begin{array}{l}\text { The combined dataset is used for estimating the } \\
\text { penetration depth and associated factors. The } \\
\text { thick-walled population alone is used to estimate } \\
\text { initial thickness distribution. }\end{array}$ & $\log (2.72+0.37 \operatorname{Ln} t, 0.27)$ & $15.2 \mathrm{t}^{0.37}$ & $\begin{array}{l}N(641.7,13.7) \text { on } \\
{[615,697]}\end{array}$ & 3.4 & 79.7 \\
\hline $\begin{array}{l}\text { PORTS thin-walled, head/skirt } \\
\text { interface, top row }\end{array}$ & 105 & $\begin{array}{l}\text { All yards, top row, thin- } \\
\text { walled, skirted cylinders }\end{array}$ & Narrow age range of cylinders evaluated & $t \times \log (-0.04,0.47)$ & $1.05 \mathrm{t}$ & $\begin{array}{l}\mathrm{N}(340.9,11.0) \text { on } \\
{[302.5,366]}\end{array}$ & NA & NA \\
\hline $\begin{array}{l}\text { PORTS thin-walled, head/skirt } \\
\text { interface, bottom row }\end{array}$ & 128 & $\begin{array}{l}\text { All yards, bottom row, thin- } \\
\text { walled, skitted cylinders }\end{array}$ & Narrow age range of cylinders evaluated & $t \times \log (0.11,0.47)$ & $1.18 \mathrm{t}$ & $\begin{array}{l}N(340.9,11.0) \text { on } \\
{[302.5,366]}\end{array}$ & NA & NA \\
\hline $\begin{array}{l}\text { PORTS thick-walled, } \\
\text { head/skirt interface }\end{array}$ & 115 & $\begin{array}{l}\text { All yards, thick-walled, } \\
\text { skinted cylinders }\end{array}$ & Narrow age range of cylinders evaluated & $t \times \log (0.21,0.67)$ & $1.24 \mathrm{t}$ & $\begin{array}{l}\mathrm{N}(767.4,22.4) \text { on } \\
{[615,835]}\end{array}$ & NA & NA \\
\hline
\end{tabular}

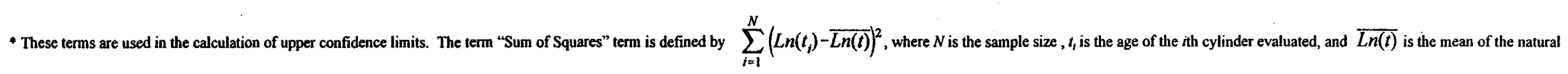

logarithm of the ages. How these values are used in determining confidence limits is shown in Appendix $C$.

1. Log $(a, b)$ denotes a lognormal distribution with mean and standard deviation of the natural logarithm of the values of $a$ and $b_{z}$ respectively.

" $" \mathrm{~N}(\mu, \sigma)$ on $[a, b] "$ denotes a nommal distribution with mean $\mu$ and standard deviation $\sigma$ defined on the range $[a, b]$. 


\section{$K-1066-K$ Yard}

This population is treated separately from the other populations. A large portion of these cylinders were in ground contact for extended periods while they were in a previous yard (K-1066-G yard). The narrow age range, coupled with a lack of data for the same cylinders at significantly different times, makes it difficult to determine and/or defend any dependence of corrosion on age. In fact, it may be that the age of the cylinder is no longer relevant for predicting future corrosion. However, given that cylinders were evaluated in 1994 on this yard, it may be possible with additional sampling to determine what this current corrosion rate may be (this is suggested in Lyon and Lykins 1996).

When utilizing these data, there are two features of this dataset that require assumptions to be made: (1) how to incorporate the two cylinders discovered in 1992 that were deemed to breach due to external corrosion (Barber et al. 1994), and (2) whether or not the top and bottom row populations should be modeled separately. In this report, the breaches are included and the top and bottom row populations are combined. More discussion is provided below.

It is not clear how the two breached cylinders discovered in 1992 should best be incorporated in the analyses. One of these cylinders was in the top row and one was in the bottom row at the time they were discovered, but the prior location of these cylinders in K-1066-G yard is not known. Because these two cylinders were not evaluated as part of a random sample, it is natural to deem them as the most extreme cases, and hence exclude them. However, this then omits potentially important information about this population of cylinders; namely, that extremely high corrosion rates did occur. For conservative purposes, it is considered appropriate to include these cylinders in the analysis, and that is what is assumed here.

An analyses of the top and bottom row cylinders suggests that there is little statistical difference between the two populations, although the average corrosion rate is slightly higher for the bottom row cylinders. The main reason that this difference is not larger may be a reflection of the nature of the relocation efforts that were conducted when K-1066-G yard was moved to K-1066-K yard in 1982. In particular, if the top and bottom row cylinders were not kept together, then "different" populations (from a corrosion standpoint) may have been effectively "shuffled", thereby obscuring any row-effects that may have been present.

The statistics for the corrosion rates for the different subpopulations within K-1066-K yard are shown in Table 7.

Table 7. Comparison of statistics for corrosion rate for $\mathrm{K}-1066-\mathrm{K}$ subpopulations.

\begin{tabular}{llcc}
\hline & & & \multicolumn{2}{c}{$\begin{array}{c}\text { Log of Age-Averaged Corrosion Rate } \\
\text { Mean, St.Dev. }\end{array}$} \\
\hline \multirow{2}{*}{ Top Row } & without breach & 60 & $0.48,0.40$ \\
& with breach & 61 & $0.51,0.47$ \\
\multirow{2}{*}{ Bottom Row } & without breach & 55 & $0.53,0.39$ \\
& with breach & 56 & $0.56,0.45$ \\
\multirow{2}{*}{ Top and Bottom Row } & without breaches & 115 & $0.50,0.39$ \\
& with breaches & 117 & $0.53,0.46$ \\
\hline
\end{tabular}


Using the $F$-test (sce, e.g., Snedecor and Cochran 1978, pp.116-117), one can accept that the variances of the logarithms of the pit depths for the top and bottom row populations are equal with $5 \%$ significance, whether or not the breaches are included. Similarly, using the same test as described in Lyon (1996), namely the t-test with unequal variances (Casella and Berger 1990), one can conclude that the medians of the distributions are the same; i.e., there is not a statistically significant difference between the medians of the distributions for the top and bottom row cylinders. Both of these results support treating the top and bottom rows as a single population, whether or not the breaches are included.

When a power law is fit to the maximum pit depths, the resulting model is unrealistic, whether or not the breaches are included: the median maximum pit depth would then be given by $P(t)=0.5 t^{l .4}$ (with breaches included) or $P(t)=0.1 t^{d .7}$ (without breaches included). This would imply that the corrosion rate is increasing for these cylinders at a very high rate, which seems unlikely (note that an example has been found in the literature where a value above 1 is reported', but the conditions do not seem relevant).

For the present analysis, the same method for pit depth discussed in Lyon $(1995,1996)$ is used for the K$1066-\mathrm{K}$ yard cylinders. With this method, the distribution of penetration depth is given by $P(t)=R t$, where $R$ is the distribution of age-averaged corrosion rates. This method is most applicable for short-term prediction due to the uncertainty about the current corrosion rates and the narrow age range for the cylinders: any model that would fit the current data should agree for near-term predictions since they must agree with the data available. If long-term predictions are a priority for this yard, then it is imperative that advantage be taken of the fact that cylinders were evaluated in 1994 and hence the current corrosion rates may be estimated. This would possibly eliminate much of the uncertainty regarding long-term prediction for this population, assuming that the yard conditions do not substantially change. This is not necessary if it is rather certain that the condition of the cylinders is going to be improved in the near future (e.g., by painting).

\section{C-745-B/F/K/L Yards, Bottom Row}

This population is used to represent cylinders at PGDP that were not in ground contact for extended periods. The dataset consist of two basic age groups: cylinders between 11 and 18 years old (from $\mathrm{K}$ and $\mathrm{L}$ yards), and cylinders between 31 and 39 years old (from $\mathrm{B}$ and $\mathrm{F}$ yards). If data for older cylinders were available for $\mathrm{K}$ or $\mathrm{L}$ yard bottom row (or any of the other better condition yards, such as $\mathrm{M}$ or $\mathrm{N}$ yard), then the $F$ yard cylinders would not be included in this dataset. Use of the F yard bottom row cylinders is conservative because some may have been in water contact, and hence more corrosion may have occurred. C-745-G yard, which was the only other population of cylinders from PGDP for which data are available, was not considered appropriate due to the poorer conditions of the yard compared to the C-745-F yard.

A power law model that fits (via least squares) the pit depth data is $\log (1.79+0.60 \log t, 0.37)$, which has a median predicted pit depth of $6.0 t^{0.60}$. This is slightly different than the fitted model for this population in the previous report, where the pit depth model was $\log (1.87+0.57 \log t, 0.37)$, which has a median predicted pit depth of $6.5 t^{0.57}$. The difference is due to the additional of one data point for a cylinder from C-745-L yard evaluated in FY1997.

'A value above 1 was reported for galvanized steel in an industrial environment in Chicago Pourbaix (1982). 


\section{C-745-G Yard, Bottom Row}

The C-745-G yard cylinders represent the worst conditions at the PGDP site. Many of these cylinders were in ground contact for extended periods. Unlike K-1066-K yard at Oak Ridge, there is a wide range of ages for these cylinders, and cylinders from the entire range were evaluated as part of the most recent data collection efforts.

A power law model that fits (via least squares) the pit depth data is $\log (1.85+0.71 \log t, 0.37)$, which has a median predicted pit depth of $6.4 t^{0.71}$. This is slightly different from the fitted model in the previous report (Lyon 1997), where the penetration model used was $\log (1.89+0.69 \log t, 0.37)$, which has a median predicted pit depth of $6.6 t^{0.69}$. This difference is the addition of two cylinders evaluated during FY1997.This is interesting when compared to the other PGDP bottom row cylinders because the "spread" of both distributions and the predicted first year corrosion are essentially the same. The only difference is the power, with the higher power for C-745-G yard bottom row due to the poorer conditions for this yard.

\section{C-745-B/F/G/K/L Yards, Top Row}

Few, if any, of the cylinders in the top rows of these yards were ever in extended ground contact, and this is assumed to be the case for all of the top row cylinders at PGDP (note that what is modeled here as the C$745-\mathrm{F}$ top row cylinders are currently in the bottom row, and vice versa, due to the relocation that took place in 1992).

A power law model that fits (via least squares) the pit depth data is $\log (2.04+0.50 \log t, 0.25)$, which has a median predicted pit depth of $7.7 t^{0.50}$. The power 0.50 is smaller than the similar power for both of the bottom row populations at PGDP discussed above, indicative of the lower corrosion rates for these cylinders. This is the same model used in the previous report, as there are no new data for this population.

\section{PORTS thin-walled cylinders, Top Row}

As for the top row cylinders at PGDP, few of the PORTS top row cylinders have ever been in extended ground contact. The data collected for the top row cylinders at PORTS are used to represent both the PORTS top row cylinders as well as the top row cylinders in the K-1066-B/E/J yards at the K-25 site at Oak Ridge until data for the K-25 yards are collected. There are data for 277 cylinders available.

A power law model that fits (via least squares) the pit depth data is $\log (2.42+0.41 \log t, 0.22)$, which has a median predicted pit depth of $11.3 t^{0.41}$. In the previous report, based on 221 cylinders, the pit depth model was $\log (2.48+0.39 \log t, 0.20)$, which had a median predicted pit depth of $11.9 t^{0.39}$.

The power 0.41 is smaller than the similar power for the top row population at PGDP discussed above, and this implies a lower corrosion rate eventually; however, the higher value of 11.3 can result in higher predicted corrosion in the short-term. This is also closer to the value for the bottom row cylinders at PORTS.

\section{PORTS thin-walled cylinders, Bottom Row}

Few of the PORTS bottom row cylinders have ever been in extended ground contact. The data collected for the bottom row cylinders at PORTS are used to represent both the PORTS bottom row cylinders as well as the bottom row cylinders in the K-1066-B/E/J yards at the K-25 site at Oak Ridge until data for the K-25 
yards are collected. There are data for 281 cylinders available.

A power law model that fits (via least squares) the pit depth data is $\log (2.58+0.42 \log t, 0.28)$, which has a median predicted pit depth of $13.2 t^{0.42}$. The previous model, based on 252 cylinders, was $\log (2.63+0.41 \log t, 0.27)$, which had a median predicted pit depth of $13.9 t^{0.41}$. The power is essentially the same as that for the top row cylinders at PORTS, although the power is slightly higher for the bottom row cylinders $(0.42$ versus 0.31$)$.

The difference between the power curves for the PORTS and PGDP cylinders bears noting. The higher value for the " $\mathrm{A}$ " term in $P(t)=A t$ " for the PORTS cylinders implies a higher predicted corrosion rate early in the life of the cylinder, while the lower value for " $n$ " implies that the long-term corrosion rate will be smaller for the PORTS cylinders (see Figure 1). Because this behavior occurs for both the top and bottom row cylinder populations when comparing across sites, there may be something peculiar to one of the sites that can account for this interesting difference. At this time it is not clear what specific factors could defensibly explain these interesting differences.

\section{Thick-walled cylinders, Top Row}

There were 51 thick-walled cylinders from the top row evaluated in FY1996 (50 from PORTS, 1 from C$745-C$ ), with an age range of $42-45$ years. Due to a concern about using such a narrow age, and since it is expected that the penetration depth for the thin-walled cylinders will be similar to that for the thick-walled cylinders, the data for the thin-walled cylinders in the top row at PORTS (277 cylinders) were added to the dataset, and a model for penetration depth was derived. This model was applied for top row thick-walled cylinders at all yards. It is noted that there are approximately 420 thick-walled cylinders at $\mathrm{K} 25$ in the K1066-B/E/J yards, 275 at PGDP in the C-745-B/C/D yards, and 1166 thick-walled cylinders at PORTS. Using the combined dataset, the resulting power law model that fits (via least squares) these pit depth data is is $\log (2.33+0.44 \log t, 0.23)$, which has a median predicted pit depth of $10.3 t^{0.44}$.

\section{Thick-walled cylinders, Bottom Row}

There were 66 thick-walled cylinders from the bottom row evaluated in FY1996 (65 from PORTS, 1 from C-745-C), with an age range of 42-45 years. As for the top row thick-walled cylinders, the data for the thinwalled cylinders in the bottom row at PORTS ( 277 cylinders) were added to the dataset, and a model for penetration depth was derived. This model was applied for bottom row thick-walled cylinders at all yards. Using the combined dataset, the resulting power law model that fits (via least squares) these pit depth data is $\log (2.72+0.37 \log t, 0.27)$, which has a median predicted pit depth of $15.2 t^{0.44}$.

\section{Thin-walled Skirted Cylinders}

The wall thickness in the head/skirt interface was evaluated for 233 thin-walled skirted cylinders at PORTS during FY 1997 (Lykins and Pawel 1997). As for the thick-walled cylinders, an extremely narrow age range (38-40 yr) precluded fitting a time-dependent model for penetration depth. As there are similar issues with the thick-walled skirted cylinders, combining the thin- and thick-walled datasets (as is done for the thick-walled cylinders above) is not considered. Instead, the penetration depth is modeled as $P(t)=R t$, where $R$ is the distribution of age-averaged corrosion rates (this is the same method currently used for the $\mathrm{K}-1066-\mathrm{K}$ yard cylinders). The fitted model for the top row cylinders is $\log (-0.04,0.47) t$, which has a 
median predicted pit depth of $1.05 t$. The median wall loss for the bottom row cylinders is slight larger, although the variability is similar; the fitted model for the top row cylinders is $\log (0.11,0.47) t$, which has a median predicted pit depth of $1.18 \mathrm{t}$. In both cases it could be accepted at the 0.05 level of significance that the distribution of age-averaged corrosion rates were lognormally distributed, using the method described in Lilliefors (1967; also see Appendix B)

\section{Thick-walled Skirted Cylinders}

The wall thickness in the head/skirt interface was evaluated for 115 thick-walled skirted cylinders at PORTS during FY1997 (Lykins and Pawel 1997); for 45 of these cylinders the row location was not available. The available data could not be fit with a power law, although the age range (36-45) was larger than that for the thin-walled skirted cylinders. As for the thin-walled skirted cylinders, the penetration depth is modeled as $P(t)=R t$, where $R$ is the distribution of age-averaged corrosion rates (this is the same method currently used for the $\mathrm{K}-1066-\mathrm{K}$ yard cylinders). The top and bottom row populations ( $35 \mathrm{in}$ each) have a similar fit using this approach: $\log (0.32,0.63) t$ for top row, $\log (0.34,0.71) t$ for bottom row. Application of the $F$-test (see, e.g., Snedecor and Cochran 1978, pp.116-117) indicated that one can accept that the variances of the logarithms of the pit depths for the top and bottom row populations are equal with $5 \%$ significance. Similarly, application of the t-test with unequal variances (Casella and Berger 1990), one can conclude that the medians of the distributions are the same at the same level of significance. These results did not suggest that it was inappropriate to treat the top and bottom rows as a single population. Thus, in order to allow inclusion of the cylinders for which the row is unknown, the top and bottom rows are combined, and the other cylinders were added to the dataset. The fitted model is $\log (0.21,0.67) t$, which has a median predicted pit depth of $1.24 t$. The goodness-of-fit tests indicated that the use of a lognormal distribution must be considered a conservative approximation, as the fitted lognormal distribution has a slightly higher probability of obtaining age-averaged corrosion rates above $2.25 \mathrm{mils} / \mathrm{yr}$.

\section{RESULTS}

Using the assumptions discussed above, projections were made of the number of cylinders with a minimum wall thickness less than preliminary criteria values. These minimum wall thickness criteria are:

1. A wall thickness that indicates a possible loss of material (a breach)

2. A wall thickness above which safe handling and stacking operations are indicated (62.5 mils)

3. A wall thickness representing applicable standards for off-site transport and contents transfer (based on ANSI 14.1 1995;250 mils for thin-walled cylinders, 500 mils for thick-walled cylinders)

It is important to note that, in general, these criteria are based on area of wall thinning. However, the minimum thickness predicted in this report is for a region with an area of about $0.01 \mathrm{sq}$. in, because this is the type of data used. Using a point thickness adds a considerable degree of conservatism to the results in this report.

The predicted number of cylinders with a minimum wall thickness below the three thickness criteria for the thin- and thick-walled cylinders are shown in Tables 8 and 9, respectively. These populations include 
skirted cylinders, but the results do not specifically apply to the thickness at the head/skirt interface because the data used do not address the thickness there. The results for the skirted cylinders, using the data specifically collected at the head/skirt interface are shown in Table 10. These results are based on grouping unsampled cylinder populations with similar populations that have been sampled (e.g., K-1066-B yard is added to the PORTS population).

The numbers in the columns labeled "Estimate" are the expected values based on the maximum likelihood estimate of the parameters for K-1066-K yard and the skirted cylinders, and the least squares estimate for the other populations. This difference is due to the different assumptions regarding the model used to predict penetration depth.

The confidence limits are upper bounds on the upper $95 \%$ confidence limit. How these confidence limits are calculated is described in Appendix B. For the populations other than the K-1066-K yard and skirted cylinders, the differences between the upper confidence limits and the estimates depends on two factors: the total number of cylinders sampled, and the ages of the cylinders sampled. Basically, the larger the "spread" in ages of the cylinders sampled, the smaller the difference between the confidence limits and the estimated values. The confidence limits for the K-1066-K yard and skirted cylinders depend on the number of samples but not on the spread of the ages of the cylinders sampled. 
Table 8. Summary results for thin-walled cylinder populations (nominal initial thickness 312.5 mils).

\begin{tabular}{|c|c|c|c|c|c|c|c|c|c|c|c|c|c|c|c|}
\hline \multirow[b]{2}{*}{ Population } & \multirow[b]{2}{*}{$\begin{array}{c}\text { Sample } \\
\text { Size }\end{array}$} & \multicolumn{14}{|c|}{ Predicted Number of Cylinders with Minimum Thickness Below 250.0 mils } \\
\hline & & $\begin{array}{c}1998 \\
\text { Estimate }\end{array}$ & $\begin{array}{l}\text { Upper } \\
\text { CL* }\end{array}$ & $\begin{array}{c}2000 \\
\text { Estimate }\end{array}$ & $\begin{array}{l}\text { Upper } \\
\mathrm{CL}^{*}\end{array}$ & $\begin{array}{c}2004 \\
\text { Estimate }\end{array}$ & $\begin{array}{l}\text { Upper } \\
\text { CL* }\end{array}$ & $\begin{array}{c}2008 \\
\text { Estimate }\end{array}$ & Upper & $\begin{array}{c}2012 \\
\text { Estimate }\end{array}$ & $\begin{array}{c}\text { Upper } \\
\mathrm{CL}^{*}\end{array}$ & $\begin{array}{c}2016 \\
\text { Estimate }\end{array}$ & $\begin{array}{l}\text { Upper } \\
\mathrm{CL}^{*}\end{array}$ & $\begin{array}{c}2020 \\
\text { Estimate }\end{array}$ & $\begin{array}{c}\text { Upper } \\
\mathrm{CL}^{*}\end{array}$ \\
\hline K-1066-K yard, top and bottom rows(2942 cylinders) & 117 & 1417 & 2101 & 1543 & 2206 & 1775 & 2381 & {$[977$} & 2516 & 2149 & 2620 & 2294 & 2698 & 2414 & 2758 \\
\hline C-745-G yard, bottom row, unpainted(2700 cylinders) & 117 & 1047 & 1702 & 1150 & 1808 & 1348 & 1997 & 1531 & 2156 & 1696 & 2286 & 1842 & 2389 & 1970 & 2469 \\
\hline C-745-B/C/D/F/K/LM/N/P yards, bottom row, thin-walled(10299 cylinders) & 53 & 369 & 1760 & 445 & 2023 & 632 & 2627 & 866 & 3317 & 1146 & 4061 & 1465 & 4830 & 1815 & 5579 \\
\hline C-745-B/C/D/F/G/K/L/M/N/P yards, top row, thin-walled(12668 cylinders) & 180 & 84 & 332 & 107 & 419 & 164 & 631 & 242 & 890 & 344 & 1189 & 473 & 1572 & 631 & 2017 \\
\hline K-1066-B/E/J and all PORTS yards, bottom row, thin-walled(8014 cylinders) & 281 & 461 & 942 & 543 & 1091 & 732 & 1415 & 951 & 1761 & 1194 & 2117 & 1452 & 2499 & 1721 & 2880 \\
\hline \multirow{4}{*}{\begin{tabular}{|} 
K-1066-B/E/J and all PORTS yards, top row, thin-walled(8014 cylinders) \\
Total
\end{tabular}} & 277 & 71 & 206 & 87 & 250 & 129 & 347 & 184 & 475 & 254 & 630 & 339 & 805 & 439 & 988 \\
\hline & 1025 & 3449 & & 3875 & & 4780 & & 5752 & & 6783 & & 7865 & & 8989 & \\
\hline & & \multicolumn{14}{|c|}{ Predicted Number of Cylinders with Minimum Thickness Below 62.5 mils } \\
\hline & $\begin{array}{l}\text { Sample } \\
\text { Size }\end{array}$ & $\begin{array}{c}1998 \\
\text { Estimate }\end{array}$ & $\begin{array}{l}\text { Upper } \\
\mathrm{CL}^{*}\end{array}$ & $\begin{array}{c}2000 \\
\text { Estimate }\end{array}$ & $\begin{array}{c}\text { Upper } \\
\text { CL* }\end{array}$ & $\begin{array}{c}2004 \\
\text { Estimate }\end{array}$ & $\begin{array}{l}\text { Upper } \\
\mathrm{CL}^{*}\end{array}$ & $\begin{array}{c}2008 \\
\text { Estimate }\end{array}$ & $\begin{array}{l}\text { Upper } \\
\text { CL. }\end{array}$ & $\begin{array}{c}2012 \\
\text { Estimate }\end{array}$ & $\begin{array}{l}\text { Upper } \\
\mathrm{CL}^{*}\end{array}$ & $\begin{array}{c}2016 \\
\text { Estimate }\end{array}$ & $\begin{array}{l}\text { Upper } \\
\text { CL* }^{*}\end{array}$ & $\begin{array}{c}2020 \\
\text { Estimate }\end{array}$ & $\begin{array}{c}\text { Upper } \\
\text { CL }^{*}\end{array}$ \\
\hline K-1066-K yard, top and bottom rows(2942 cylinders) & 117 & 5 & 36 & 7 & 48 & 12 & 68 & 21 & 102 & $\overline{33}$ & 146 & 49 & 201 & 70 & 264 \\
\hline C-745-G yard, bottom row, unpainted(2700 cylinders) & 117 & 1 & 23 & 2 & 31 & 4 & 36 & 6 & 53 & 10 & 83 & 15 & 123 & 21 & 165 \\
\hline C-745-B/C/D/F/K//M/N/P yards, bottom row, thin-walled(10299 cylinders) & 53 & 0 & 16 & 0 & 23 & 0 & 39 & 0 & 56 & 0 & 68 & 0 & 78 & 0 & 112 \\
\hline C-745-B/C/D/F/G/K/L/M/N/P yards, top row, thin-walled(12668 cylinders) & 180 & 0 & 0 & 0 & 0 & 0 & 0 & 0 & 0 & 0 & 0 & 0 & 0 & 0 & 0 \\
\hline $\mathrm{K}-1066-\mathrm{B} / \mathrm{E} / \mathrm{J}$ and all PORTS yards, bottom row, thin-walled(8014 cylinders) & 281 & $\mathbf{0}$ & $\mathbf{0}$ & 0 & 0 & 0 & 0 & 0 & 0 & 0 & 0 & 0 & 0 & 0 & 0 \\
\hline $\mathrm{K}-1066-\mathrm{B} / \mathrm{E} / \mathrm{J}$ and all PORTS yards, top row, thin-walled(8014 cylinders) & 277 & 0 & 0 & 0 & 0 & 0 & 0 & 0 & o & 0 & 0 & 0 & 0 & 0 & 0 \\
\hline \multirow[t]{3}{*}{ [" } & 1025 & 6 & & 9 & & 16 & & 27 & & 43 & & 64 & & 92 & \\
\hline & & \multicolumn{14}{|c|}{ Predicted number of breached cylinders } \\
\hline & $\begin{array}{l}\text { Sample } \\
\text { Size }\end{array}$ & $\begin{array}{c}1998 \\
\text { Estimate }\end{array}$ & $\begin{array}{l}\text { Upper } \\
\mathrm{CL}^{*}\end{array}$ & $\begin{array}{c}2000 \\
\text { Estimate }\end{array}$ & $\begin{array}{l}\text { Upper } \\
\text { CL* }^{*}\end{array}$ & $\begin{array}{c}2004 \\
\text { Estimate }\end{array}$ & $\begin{array}{l}\text { Upper } \\
\text { CL*}^{*}\end{array}$ & $\begin{array}{c}2008 \\
\text { Estimate }\end{array}$ & $\begin{array}{c}\text { Upper } \\
\text { CL* }^{*}\end{array}$ & $\begin{array}{c}2012 \\
\text { Estimate }\end{array}$ & $\begin{array}{c}\text { Upper } \\
\mathrm{CL}^{*}\end{array}$ & $\begin{array}{c}2016 \\
\text { Estimate }\end{array}$ & $\begin{array}{l}\text { Upper } \\
\mathrm{CL}^{*}\end{array}$ & $\begin{array}{c}2020 \\
\text { Estimate }\end{array}$ & $\begin{array}{l}\text { Upper } \\
\mathrm{CL}^{*}\end{array}$ \\
\hline K-1066-K yard, top and bottom rows ( 2942 cylinders) & 117 & $\mathbf{T}$ & 9 & $\mathrm{~T}$ & 14 & 3 & 28 & 5 & 39 & 8 & 58 & 13 & 73 & 20 & 102 \\
\hline C-745-G yard, bottom row, unpainted(2700 cylinders $)$ & 117 & 0 & 3 & 0 & 4 & 1 & 9 & 1 & 18 & 2 & 31 & 3 & 35 & 4 & 53 \\
\hline C-745-B/C/D/F/K/L/MNN/P yards, bottom row, thin-walled(10299 cylinders) & 53 & 0 & 1 & $\mathbf{0}$ & 1 & 0 & 3 & 0 & 10 & 0 & 22 & 0 & 36 & 0 & 51 \\
\hline $\mathrm{C}-745-\mathrm{B} / \mathrm{C} / \mathrm{D} / \mathrm{F} / \mathrm{G} / \mathrm{K} / \mathrm{L} / \mathrm{M} / \mathrm{N} / \mathrm{P}$ yards, top row, thin-walled(12668 cylinders) & 180 & 0 & 0 & $\mathbf{0}$ & 0 & 0 & 0 & 0 & 0 & 0 & 0 & 0 & 0 & 0 & 0 \\
\hline $\mathrm{K}-1066-\mathrm{B} / \mathrm{E} / \mathrm{J}$ and all PORTS yards, bottom row, thin-walled(8014 cylinders) & 281 & 0 & 0 & $\mathbf{0}$ & 0 & 0 & 0 & 0 & 0 & 0 & 0 & 0 & 0 & 0 & 0 \\
\hline K-1066-B/E/J and all PORTS yards, top row, thin-walled(8014 cylinders) & 277 & 0 & 0 & 0 & 0 & 0 & 0 & 0 & 0 & 0 & 0 & 0 & 0 & 0 & 0 \\
\hline Total! & 1025 & T & & 2 & & $\overline{3}$ & & 6 & & 10 & & 16 & & 25 & \\
\hline
\end{tabular}

These are bounds on the upper $95 \%$ confidence limit. The details about how they are calculated are provided in Appendix $\mathbf{B}$.

Apparent discrepancies between the totals and the summands are due to fractional contributions of the summands. 
Table 9. Summary results for thick-walled cylinder populations (nominal initial thickness 625 mils).

\begin{tabular}{|c|c|c|c|c|c|c|c|c|c|c|c|c|c|c|c|c|}
\hline \multirow[b]{2}{*}{ Population } & \multirow[b]{2}{*}{$\begin{array}{l}\text { Sample } \\
\text { Size }\end{array}$} & & \multicolumn{2}{|c|}{1998} & \multicolumn{2}{|c|}{2000} & \multicolumn{2}{|c|}{2004} & \multicolumn{2}{|c|}{2008} & \multicolumn{2}{|c|}{2012} & \multicolumn{2}{|c|}{2016} & \multicolumn{2}{|c|}{2020} \\
\hline & & & Estimate & $\begin{array}{l}\text { Upper } \\
\text { CL* }^{*}\end{array}$ & Estimate & $\begin{array}{l}\text { Upper } \\
\text { CL* }\end{array}$ & Estimate & $\begin{array}{l}\text { Upper } \\
\text { CL* }\end{array}$ & Estimate & $\begin{array}{l}\text { Upper } \\
\mathrm{CL}^{*}\end{array}$ & Estimate & $\begin{array}{l}\text { Upper } \\
\text { CL* }^{*}\end{array}$ & Estimate & $\begin{array}{l}\text { Upper } \\
\mathrm{CL}^{*}\end{array}$ & Estimate & $\begin{array}{c}\text { Upper } \\
\mathrm{CL}^{*}\end{array}$ \\
\hline \multirow{3}{*}{\begin{tabular}{|l|} 
All Yards, bottom row, \\
thick-walled(931 cylinders)
\end{tabular}} & \multirow[t]{3}{*}{347} & Minimum Thickness Below 500.0 mils & 2 & 6 & 2 & 8 & 3 & 10 & 4 & 14 & 6 & 17 & 7 & 22 & 9 & 27 \\
\hline & & Minimum Thickness Below 62.5 mils & 0 & $\mathbf{0}$ & 0 & 0 & 0 & $\mathbf{0}$ & 0 & o & 0 & 0 & 0 & 0 & 0 & 0 \\
\hline & & Minimum Thickness Below 0.0 mils & 0 & 0 & 0 & 0 & $\mathbf{0}$ & 0 & 0 & 0 & $\mathbf{0}$ & $\mathbf{0}$ & 0 & 0 & 0 . & 0 \\
\hline \multirow{3}{*}{$\begin{array}{l}\text { All Yards, top row, thick- } \\
\text { wallcd(931 cylinders) }\end{array}$} & \multirow[t]{3}{*}{328} & Minimum Thickness Below 500.0 mils & $\mathbf{0}$ & 0 & 0 & 0 & 0 & 1 & 0 & 1 & 0 & 1 & 0 & 2 & 1 & 3 \\
\hline & & Minimum Thickness Below 62.5 mils & $\mathbf{0}$ & $\mathbf{0}$ & $\mathbf{0}$ & 0 & 0 & 0 & $\mathbf{0}$ & $\mathbf{0}$ & 0 & 0 & 0 & 0 & 0 & $\mathbf{0}$ \\
\hline & & Minimum Thickness Below 0.0 mils & 0 & $\mathbf{0}$ & $\mathbf{0}$ & 0 & 0 & $\mathbf{0}$ & 0 & 0 & 0 & 0 & 0 & 0 & 0 & $\mathbf{0}$ \\
\hline
\end{tabular}

Table 10. Summary results for skirted cylinder populations.

\begin{tabular}{|c|c|c|c|c|c|c|c|c|c|c|c|c|c|c|c|c|}
\hline \multirow[b]{2}{*}{ Population } & \multirow[b]{2}{*}{$\begin{array}{c}\text { Sample } \\
\text { Size }\end{array}$} & & \multicolumn{2}{|c|}{1998} & \multicolumn{2}{|c|}{2000} & \multicolumn{2}{|c|}{2004} & \multicolumn{2}{|c|}{2008} & \multicolumn{2}{|c|}{2012} & \multicolumn{2}{|c|}{2016} & \multicolumn{2}{|c|}{2020} \\
\hline & & & \begin{tabular}{|l|} 
Estimate \\
\end{tabular} & $\begin{array}{l}\text { Upper } \\
\text { CL** }\end{array}$ & Estimate & $\begin{array}{c}\text { Upper } \\
\mathrm{CL}^{*}\end{array}$ & Estimate & $\begin{array}{l}\text { Upper } \\
\mathrm{CL}^{*}\end{array}$ & Estimate & $\begin{array}{l}\text { Upper } \\
\text { CL.* }\end{array}$ & Estimate & $\begin{array}{l}\text { Upper } \\
\text { CL** }\end{array}$ & Estimate & $\begin{array}{l}\text { Upper } \\
\mathrm{CL}^{*}\end{array}$ & Estimate & $\begin{array}{c}\text { Upper } \\
\mathrm{CL}^{*}\end{array}$ \\
\hline $\begin{array}{l}\text { All Yards, bottom row, } \\
\text { skirted, thin-walled(3574 } \\
\text { cylinders) }\end{array}$ & 128 & $\begin{array}{r}\text { Minimum Thickness Below } 250.0 \text { mils } \\
\text { Minimum Thickness Below } 62.5 \text { mils } \\
\text { Minimum Thickness Below } 0.0 \text { mils }\end{array}$ & $\begin{array}{c}267 \\
0 \\
0\end{array}$ & $\begin{array}{c}706 \\
3 \\
1\end{array}$ & $\begin{array}{c}318 \\
0 \\
0\end{array}$ & $\begin{array}{c}804 \\
4 \\
1\end{array}$ & $\begin{array}{c}433 \\
1 \\
0\end{array}$ & $\begin{array}{c}1003 \\
8 \\
2\end{array}$ & $\begin{array}{c}562 \\
1 \\
0\end{array}$ & $\begin{array}{c}1209 \\
13 \\
4\end{array}$ & $\begin{array}{c}704 \\
2 \\
1\end{array}$ & $\begin{array}{c}1415 \\
25 \\
6\end{array}$ & $\begin{array}{c}854 \\
4 \\
1\end{array}$ & $\begin{array}{c}1616 \\
41 \\
9\end{array}$ & $\begin{array}{c}1009 \\
6 \\
1\end{array}$ & $\begin{array}{c}1809 \\
58 \\
14\end{array}$ \\
\hline $\begin{array}{l}\text { All Yards, top row, skinted, } \\
\text { thin-walled(3485 cylinders) }\end{array}$ & 105 & $\begin{array}{r}\text { Minimum Thickness Below } 250.0 \text { mils } \\
\text { Minimum Thickness Below } 62.5 \text { mils } \\
\text { Minimum Thickness Below } 0.0 \text { mils }\end{array}$ & $\begin{array}{c}131 \\
0 \\
0\end{array}$ & $\begin{array}{c}447 \\
1 \\
0\end{array}$ & $\begin{array}{c}161 \\
0 \\
0\end{array}$ & $\begin{array}{c}519 \\
2 \\
1\end{array}$ & $\begin{array}{c}230 \\
0 \\
0\end{array}$ & $\begin{array}{c}683 \\
3 \\
1\end{array}$ & $\begin{array}{c}313 \\
0 \\
0\end{array}$ & $\begin{array}{c}847 \\
5 \\
2\end{array}$ & $\begin{array}{c}409 \\
1 \\
0\end{array}$ & $\begin{array}{c}1021 \\
10 \\
2\end{array}$ & $\begin{array}{c}515 \\
1 \\
0\end{array}$ & $\begin{array}{c}1200 \\
20 \\
4\end{array}$ & $\begin{array}{c}630 \\
2 \\
0\end{array}$ & $\begin{array}{c}1376 \\
36 \\
6\end{array}$ \\
\hline $\begin{array}{l}\text { All Yards, skirted, thick- } \\
\text { walled(1861 cylinders) }\end{array}$ & 115 & $\begin{array}{c}\text { Minimum Thickness Below } 500.0 \text { mils } \\
\text { Minimum Thickness Below } 62.5 \text { mils } \\
\text { Minimum Thickness Below } 0.0 \text { mils }\end{array}$ & $\begin{array}{l}19 \\
0 \\
0\end{array}$ & $\begin{array}{c}81 \\
2 \\
1\end{array}$ & $\begin{array}{c}22 \\
0 \\
0\end{array}$ & $\begin{array}{c}93 \\
2 \\
2\end{array}$ & $\begin{array}{c}30 \\
0 \\
0\end{array}$ & $\begin{array}{c}118 \\
3 \\
2\end{array}$ & $\begin{array}{c}39 \\
0 \\
0\end{array}$ & $\begin{array}{c}145 \\
5 \\
3 \\
\end{array}$ & $\begin{array}{c}50 \\
1 \\
0\end{array}$ & $\begin{array}{c}188 \\
6 \\
4\end{array}$ & $\begin{array}{c}62 \\
1 \\
1\end{array}$ & $\begin{array}{c}207 \\
8 \\
6\end{array}$ & $\begin{array}{c}76 \\
1 \\
1\end{array}$ & $\begin{array}{c}241 \\
12 \\
7\end{array}$ \\
\hline
\end{tabular}


Results for Thin-Walled Cylinders

The results for predicted cylinders with minimum thickness below 250 mils show that the populations can be naturally divided into three groups: (1) K-1066-K yard and C-745-G yard bottom row, (2) C-745-B/F/K/L and PORTS bottom row, and (3) C-745-B/F/G/K/L and PORTS top row. The results for the number of cylinders with minimum thickness below 62.5 mils or breaches are similar, although there is a more pronounced difference between the $\mathrm{K}-1066-\mathrm{K}$ and $\mathrm{C}-745-\mathrm{G}$ yard bottom row cylinders.

For two cylinder populations, K-1066-K at K-25 and the cylinders that were in the bottom row of C-745-G at PGDP, a large number of cylinders are predicted to have a minimum point thickness below 250 mils at present. Both of these populations have had a large fraction of cylinders that were in ground contact at one time, although they are no longer in ground contact. For the other cylinder populations, bottom row cylinders are generally predicted to have a greater number less than 250 mils than top row cylinders.

The impact of the small sample size is shown when the results for the $\mathrm{C}-745-\mathrm{B} / \mathrm{F} / \mathrm{K} / \mathrm{L}$ bottom row cylinders ( 53 samples) are compared to the results for the PORTS bottom row cylinders ( 281 samples) in Table 9. For example, although the expected number of cylinders with a minimum point thickness below 62.5 mils or a breach is zero for both these populations through the year 2020 , the upper confidence limits for the $\mathrm{C}-745-\mathrm{B} / \mathrm{F} / \mathrm{K} / \mathrm{L}$ population are significantly larger than that for the PORTS cylinders. Generally, the confidence limits will increase with increasing time in a manner that depends on the number of samples and the spread of the ages of the cylinders evaluated. Increasing either the sample size or the spread of the ages will result in a decrease in the difference between the expected value and the upper confidence limit.

Despite the fact that a more sophisticated approach is used for the C-745-G yard bottom row cylinders, the predicted median maximum pit depth is higher than that for the $\mathrm{K}-1066-\mathrm{K}$ yard cylinders until after they reach 60 years of service (see Fig. 1). Given that the oldest cylinders on both yards are about 40 years old (in 1998), this means that the median predicted pit depth will be higher for the C-745$\mathrm{G}$ yard cylinders until after 2020 . However, the available data also suggest that the $\mathrm{K}-1066-\mathrm{K}$ yard cylinders are, on average, about 18 mils thicker on uncorroded areas. Since the estimate of the initial thickness is based on the wall thickness on uncorroded areas of the cylinder, this results in slightly fewer thinner cylinders predicted for the $\mathrm{C}-745-\mathrm{G}$ yard bottom row than for $\mathrm{K}-1066-\mathrm{K}$ yard.

\section{Results for Thick-Walled Cylinders}

The results for the thick-walled cylinders (nominal wall thickness 625 mils) are similar to those for the PORTS yard. Few are predicted to have a minimum point thickness below the ANSI N14.1 standard (ANSI 1995) of 500 mils, and none are predicted to have a thickness below 62.5 or have a breach, through 2020 . It is recalled that the data available for the thick-walled cylinders are for a narrow age range that precluded finding a fit with a power law model (data are for thick-walled cylinders at PORTS). For this reason, the maximum pit data for the thin-walled cylinders at PORTS were included with the data for the thick-walled cylinders in order to derive the model for penetration depth.

\section{Results at the Head/Skirt Interface for Skirted Cylinders}

The results for the predicted minimum wall thickness at the head/skirt interface, shown in Table 10, present some noteworthy differences, compared to the other results. In particular, for thick- 
walled cylinders, all of which are skirted, more cylinders are predicted to have minimum thickness below the various criteria thicknesses, when compared to the results using the data for the body of the cylinder. However, it is noted that the narrow age range of cylinders evaluated precluded a power law fit for the penetration depth, and a model of the form $P(t)=R t$ was utilized. This form of model will generally be more conservative than one using a power law, $P(t)=A t^{n}$. For the wall thickness data from the body of the cylinder, a power law model was used for most of the thin-walled cylinder populations, and all of the thick-walled populations.

\section{Comparison with Results in Previous Report}

The results for the thin-walled cylinders are similar to those presented in last year's report (Lyon 1997). In general, there is either no change, or a slight decrease in the total number of thin-walled cylinders that do not meet the various thickness criteria, when compared to the previous year's report. The main difference concerns the results for the unpainted $\mathrm{C}-745-\mathrm{G}$ bottom row cylinders, as approximately 1000 of these cylinders were painted during the last year. This difference, and other minor ones, are discussed below.

\section{Impact of Cylinder Painting}

The painting program initiated in FY1997 has resulted in reducing the forecasted number of cylinders with wall thicknesses below the specified criteria levels, with the more substantial reduction occurring for the C-745-G yard bottom row population. Table 11 summarizes one aspect of the potential impact of the painting program, assuming that the painting will essentially halt corrosion for approximately 10 years.

Table 11. Illustration of impact of current painting program on C-745-G yard bottom row cylinders.

\begin{tabular}{|c|c|c|c|c|}
\hline & \multicolumn{4}{|c|}{$\begin{array}{l}\text { Predicted number of cylinders with minimum point wall thickness } \\
\text { below } 250 \text { mils }\end{array}$} \\
\hline & 1998 & 2000 & 2004 & 2008 \\
\hline C-745-G bottom row, if no painting had occurred & 1387 & 1528 & 1800 & 2053 \\
\hline C-745-G bottom row, accounting for painting completed in $1998^{*}$ & 1387 & 1490 & 1688 & 1872 \\
\hline $\begin{array}{l}\text { Predicted number of cylinders that painting prevents from reaching } \\
\qquad 250 \text { mil minimum point thickness }\end{array}$ & 0 & 38 & 112 & 181 \\
\hline \multicolumn{5}{|c|}{$\begin{array}{l}\text { * For } 1998 \text {, this number is the total for the unpainted cylinders alone as well as the cylinders that have been painted by } 1998 \text {. After } 1998 \text {, it } \\
\text { is the number of unpainted cylinders that fail the criterion during each time period., estimated using Table } 8 \text {. For example, referring to } \\
\text { Table } 8 \text { the number of cylinders in } 2000 \text { is } 1490=1387+(1150-1047) \text {. In this illustration, it is assumed that after } 1998 \text { the corrosion on the } \\
\text { painted cylinders will be halted for a ten year period. }\end{array}$} \\
\hline
\end{tabular}

As the painting program for C-745-G yard is completed, the impact will be larger; however, the results for this population may not ever be as significant as one may expect, as painting will not prevent a cylinder from failing a thickness criterion unless it is painted before the cylinder in fact fails the criterion. 


\section{Other Differences}

The availability of more data for the PORTS cylinders, which are applied to the K-1066-B/E/J and PORTS yards, has resulted in slightly more cylinders being predicted to have a minimum point wall thickness below 250 mils (about 60 more in 1998, and 200 more in 2020). The results for breaches and wall thicknesses below 62.5 mils are unchanged, with none being predicted before 2020 . The difference occurs despite the fact that the total population assumed is smaller (16424 cylinders in 1997 report, 16028 cylinders here). The difference is due to the updated model fits for penetration depth, although the difference is slight. For example, the fitted median penetration depth for the top row cylinders in the 1997 report was $P(t)=11.9 t^{0.39}$, while the fit using the data collected during the last year is $P(t)=11.3 t^{0.4 t}$. The larger value of the power coefficient $(0.41 \mathrm{vs.} 0.39)$ implies that the updated fit will predict more corrosion on older cylinders. The differences in the confidence limits are smaller, because the updated model is based on more samples, and hence the confidence limits are closer to the estimates.

There are other slight differences due to the inclusion of a few new data points for the other populations, or due to the minor adjustments in the age distributions used. One difference that will be noted is that for the $\mathrm{K}-1066-\mathrm{K}$ yard cylinders. The dataset and age distribution used are identical as that used in the previous report; however, there are slightly more cylinders predicted to have a minimum thickness below the various criteria (about 6 more for the 250 mil criterion). The reason for this difference is that in the previous report the fitted parameters were inadvertently truncated to two decimal places before being applied in the model, while 16 digits of precision were used here. This small change results in the observed differences.

\section{UNCERTAINTIES AND LIMITATIONS}

The purpose of this report is to estimate the extent of corrosion on populations of cylinders as a function of time, and this requires that assumptions be made regarding the dependence of the distribution of corrosion rates on time. The data currently available consist of wall thickness measurements made on different cylinders of different ages. There are no data from the same cylinder at substantially different times. This makes defensibly using more realistic and less conservative models difficult, and one is forced to either make conservative assumptions regarding the change of corrosion with time or to use measurements from different cylinders at different ages to estimate corrosion with time. Implicit in any trend derived from the current data is the assumption that the older cylinders had similar corrosion as the younger cylinders when they were younger; i.e., the distribution of pit depths for 10 year old cylinders in a given population is the same no matter when it is measured. This assumption is unavoidable without data for a fixed cylinder at different ages.

Another area of uncertainty is that the storage conditions have changed, thereby altering the corrosion characteristics of the steel. This complicates predicting corrosion when the cylinders have been moved numerous times throughout their history.

The results are also based on the assumption that the data are representative of the population from which they are taken, which is difficult to ascertain for some populations (e.g., data for C-745-B and L yard cylinders). The PORTS data are probably most representative because they were randomly sampled when the cylinders were relocated during FY 1996. Implementation of a statistically-based sampling plan could reduce this uncertainty. 


\section{CONCLUSIONS AND RECOMMENDATIONS}

The United States Department of Energy (DOE) currently manages depleted uranium hexafluoride that is stored in approximately 50,000 carbon steel cylinders located at three DOE sites. Using either a hand-held ultrasonic transducer or an automated scanner, wall thickness and corrosion pit depth data have been collected for several subpopulations of cylinders.

In this report, the most recently collected wall thickness data were utilized, along with previously collected data, to make projections about the condition of the cylinders located at K-25, PGDP, and PORTS. The results presented here are intended to supercede and enlarge the scope of those presented previously (Lyon 1995,1996, 1997). In particular, projections are made for thin-walled cylinders (nominal initial thickness 312.5 mils) and thick-walled cylinders (nominal initial thickness $625 \mathrm{mils}$ ). In addition, a preliminary analysis is conducted for the minimum thickness at the head/skirt interface for skirted cylinders.

The most recently collected data, which were not available for last year's report (Lyon 1997), consisted of evaluations of the wall loss in the head/skirt interface of skirted 48" thin- and thick-walled cylinders, and additional cylinder body evaluations. The head/skirt data had no impact on the previous results, as this was the first effort to collect data of this type. Inclusion of the other data resulted in minor modifications of the fitted curves for penetration depth. When combined with the impacts of the cylinder painting program and refinement of the relevant age distributions for the modeled cylinders, there is either no change, or a slight decrease in the total number of thin-walled cylinders that do not meet the various thickness criteria, when compared to the previous year's report.

Most of the thin-walled cylinders predicted to have a minimum point thickness less than 250 mils in 1998 are located in K-1066-K yard at K-25 or were in the bottom row of C-745-G yard at PGDP. Of the few cylinders predicted to have a minimum thickness less than $62.5 \mathrm{mils}$ or have a point breach in 1998 (using expected values), all are in these two yards. Both of these yards have had a large fraction of cylinders that were in ground contact at one time, although they have been relocated. Using conservative upper confidence limits, a single breach is predicted by 1998 in the PGDP bottom row population that is treated separately from $\mathrm{C}-745-\mathrm{G}$ yard; however, this is an implication of the small sample size for this population.

The painting program has reduced the predicted number of cylinders that do not meet the specified wall thickness criteria. For example, for the C-745-G yard bottom row cylinders, it is predicted that the painting already completed will prevent almost 200 cylinders from failing the ANSI 14.1 thickness criterion by 2008 (assuming that painting halts corrosion for approximately 10 years).

Few of the approximately 2000 thick-walled cylinders are predicted to have a minimum point thickness below any of the thickness criteria by 2020 . In particular, less than 50 are predicted to have a minimum wall thickness below 500 mils by 2020 , and none are predicted to have a breach or minimum point thickness less than 62.5 mils by 2020 .

A preliminary analysis of data specifically collected at the head/skirt interface during FY1997 tentatively confirmed the accelerated nature of corrosion in the skirt crevice compared to the general body. In particular, some thick-walled cylinders, all of which are skirted, were predicted to have a minimum thickness below 62.5 mils, or even a breach, at the interface by 2020 . 


\section{Recommendations}

1. Given the changes in the location and condition of some of the cylinder populations, and due to significant changes in the funding levels available for collecting data, it is suggested that the cylinder thickness sampling plan discussed in Lyon and Lykins (1996) be revised.

2. There are few data for many of the older populations at PGDP, and sampling should be directed towards these populations in order to better characterize their condition.

3. More wall thickness evaluations are needed in the head/skirt interface for skirted cylinders. In particular, a wider age range of skirted cylinders should be evaluated.

4. The values in this report are based on the assumption that the historical trends will continue, and thus represent all baseline projections. Many of the yards are being improved, in which case the corrosion rates will probably be reduced. It is suggested that future analyses incorporate these changes, if they can be defensibly quantified. This will require additional discussion with the site technical personnel.

\section{REFERENCES}

American National Standards for Nuclear Materials-Uranium Hexafluoride-Packaging for Transport, ANSI N14.1, American National Standards Institute, New York, 1995 edition.

Barber, E.J., J.H. DeVan, J.M. Googin, and M.S. Taylor (1994). Investigation of Breached Depleted UF Cylinders at the K-25 Site. ORNL/TM-12840, Oak Ridge, Tennessee, October 1994.

Blue, S.C. (1994). Facsimile from S.C. Blue to M. Taylor, October 27, 1994.

Blue, S.C. (1995a). Memorandum from S.C. Blue to A.K. Balding, September 25, 1995.

Blue, S.C. (1995b). Facsimile from S.C. Blue to B.F. Lyon, October 30, 1995.

Casella, G. And R.L. Berger (1990). Statistical Inference. Wadsworth and Brooks/Cole Advanced Books and Software, Pacific Grove, California.

Feliu, S., M. Morcillo and S. Feliu, Jr. (1993a). The Prediction of Atmospheric Corrosion from Meteorological and Pollution Parameters--Ii. Annual Corrosion in Corrosion Science, Vol. 34, No.3, pp.403-414.

Feliu, S., M. Morcillo and S. Feliu, Jr. (1993b). The Prediction of Atmospheric Corrosion from Meteorological and Pollution Parameters--II. Long-term Forecasts in Corrosion Science, Vol. 34, No.3, pp.415-422.

Horton, J.B. (1964). The Composition, Structure and Growth of the Atmospheric Rust on Various Steels. 
Thesis Lehigh University 1964, Bethlehem, PA.

Lawless, J.F. (1982). Statistical Models and Methods for Lifetime Data. John Wiley and Sons, New York.

Legault, R.A. and G. Preban (1975). Corrosion-NACE, Vol. 31, p.117.

Lockheed Martin Energy Systems, Inc. (LMES) (1997a). UF6 Cylinder Project System Requirements Document (SRD). K/TSO-001, Rev.3. May 1997. U.S. Department of Energy.

Lockheed Martin Energy Systems, Inc. (LMES) (1997b). UF6 Cylinder Project System Engineering Management Plan (SEMP). KJTSO-017. July 1997. U.S. Department of Energy.

Lykins, M.L. and S.J. Pawel (1997). Evaluation of Wall Thickness in the Cylinder Head/Skirt Interface on Skirted Cylinders. Memorandum from M.L Lykins and S.J. Pawel to M.S. Taylor, ORNL/CST-SP-102297-1, October 22, 1997.

Lyon, B.F. (1995). Prediction of External Corrosion for UF ${ }_{6}$ Cylinders: Results of an Empirical Method, ORNL/TM-13012. June 1995. Oak Ridge National Laboratory, Oak Ridge, Tennessee.

Lyon, B.F. (1996). Prediction of External Corrosion for Steel Cylinders at the Paducah Gaseous Diffusion Plant: Application of an Empirical Method, ORNL/TM-13192. February 1996. Oak Ridge National Laboratory, Oak Ridge, Tennessee.

Lyon, B.F. and M.L. Lykins (1996). Ultrasonic Thickness Sampling Plan for the Depleted Uranium Hexafluoride Program, ORNL/TM-13280. July 1996. Oak Ridge National Laboratory, Oak Ridge, Tennessee.

Lyon, B.F. (1997). Prediction of External Corrosion for Steel Cylinders, ORNL/TM-13359. February 1997. Oak Ridge National Laboratory, Oak Ridge, Tennessee.

Mughabghab, S.F. and T.M. Sullivan (1989). Evaluation of the Pitting Corrosion of Carbon Steels and Other Ferrous Metals in Soil Systems. Waste Management, Vol. 9, pp. 239-251.

Philpot, H.E. (1995). Memorandum from Halen Philpot to Valerie Newman, February 17, 1995.

Pourbaix, M. (1982). The Linear Bilogarithmic Law for Atmospheric Corrosion, in Atmospheric Corrosion (W.H. Ailor, ed.). John Wiley and Sons, New York.

Romanoff, M. (1957). Underground Corrosion. NBS Circular 579, National Bureau of Standards, Washington, D.C.

Rosen, R.S. and R.E. Glaser (1995). Letter to C.E. Bradley from R.S. Rosen and R.E. Glaser, November 8, 1995.

Rosen, R.S. and R.E. Glaser (1996). Letter to B.F. Lyon from R.S. Rosen and R.E. Glaser, April, 10, 1996. 
Schmidt, M.A., J.K. Harper, and J.A. Broders (1996). A Comparison of Wall Thickness Measurements on UF $F_{6}$ Cylinders using Scanning vs Hand-held Ultrasonic Probes. K/TSO-019, November 1996. Oak Ridge National Laboratory, Oak Ridge, Tennessee.

Snedecor, G.W. and W.G. Cochran. (1978). Statistical Methods, Sixth Edition, Iowa State University Press, Ames, lowa. 


\section{APPENDIX A: FIGURES}

Fig. 1. Median of fitted models for modeling maximum pit depth $\ldots \ldots \ldots \ldots \ldots \ldots \ldots \ldots \ldots$ A-2

Fig. 2. Median of fitted models for modeling wall loss at head/skirt interface $\ldots \ldots \ldots \ldots \ldots \ldots$ A-2

Fig. 3. Measured pit depths (mils) for K-1066-K yard, yard top and bottom rows $\ldots \ldots \ldots \ldots \ldots$ A-3

Fig. 4. Measured pit depths (mils) for $\mathrm{C}-745-\mathrm{G}$ yard, bottom row $\ldots \ldots \ldots \ldots \ldots \ldots \ldots \ldots$

Fig. 5. Measured pit depths (mils) for $\mathrm{C}-745-\mathrm{B} / \mathrm{F} / \mathrm{K} / \mathrm{L}$ yards, bottom row $\ldots \ldots \ldots \ldots \ldots \ldots$

Fig. 6. Measured pit depths (mils) for $\mathrm{C}-745-\mathrm{B} / \mathrm{F} / \mathrm{G} / \mathrm{K} / \mathrm{L}$ yards, top row $\ldots \ldots \ldots \ldots \ldots \ldots$ A-6

Fig. 7. Measured pit depths (mils) for Portsmouth yards, top row $\ldots \ldots \ldots \ldots \ldots \ldots \ldots \ldots \ldots$ A-7

Fig. 8. Measured pit depths (mils) for Portsmouth yards, bottom row $\ldots \ldots \ldots \ldots \ldots \ldots \ldots \ldots$

Fig. 9. Measured pit depths (mils) for Portsmouth yards (thin- and thick-walled) and C-745-C yard

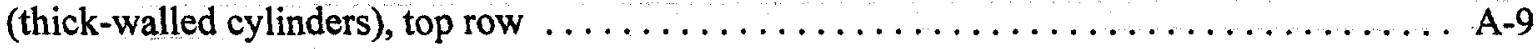

Fig. 10. Measured pit depths (mils) for Portsmouth yards (thin- and thick-walled) and C-745-C yard (thick-walled cylinders), bottom row $\ldots \ldots \ldots \ldots \ldots \ldots \ldots \ldots \ldots \ldots \ldots \ldots \ldots \ldots \ldots \ldots \ldots \ldots \ldots$

Fig. 11. Measured wall loss (mils) at head/skirt interface for Portsmouth yards (thin-walled),

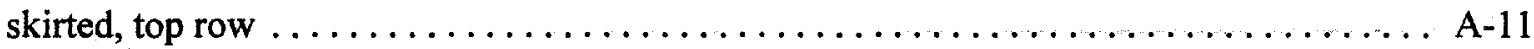

Fig. 12. Measured wall loss (mils) at head/skirt interface for Portsmouth yards (thin-walled),

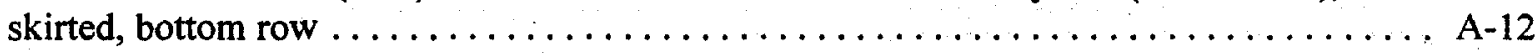

Fig. 13. Measured wall loss (mils) at head/skirt interface for Portsmouth yards (thick-walled), skirted, top and bottom rows

Fig. 14. Predicted number of cylinders with minimum point thickness below 250 mils ....... A-14

Fig. 15. Predicted number of cylinders with minimum point thickness below 62.5 mils ...... A-14

Fig. 16. Predicted number of cylinders with a point breach $\ldots \ldots \ldots \ldots \ldots \ldots \ldots \ldots \ldots \ldots$ 


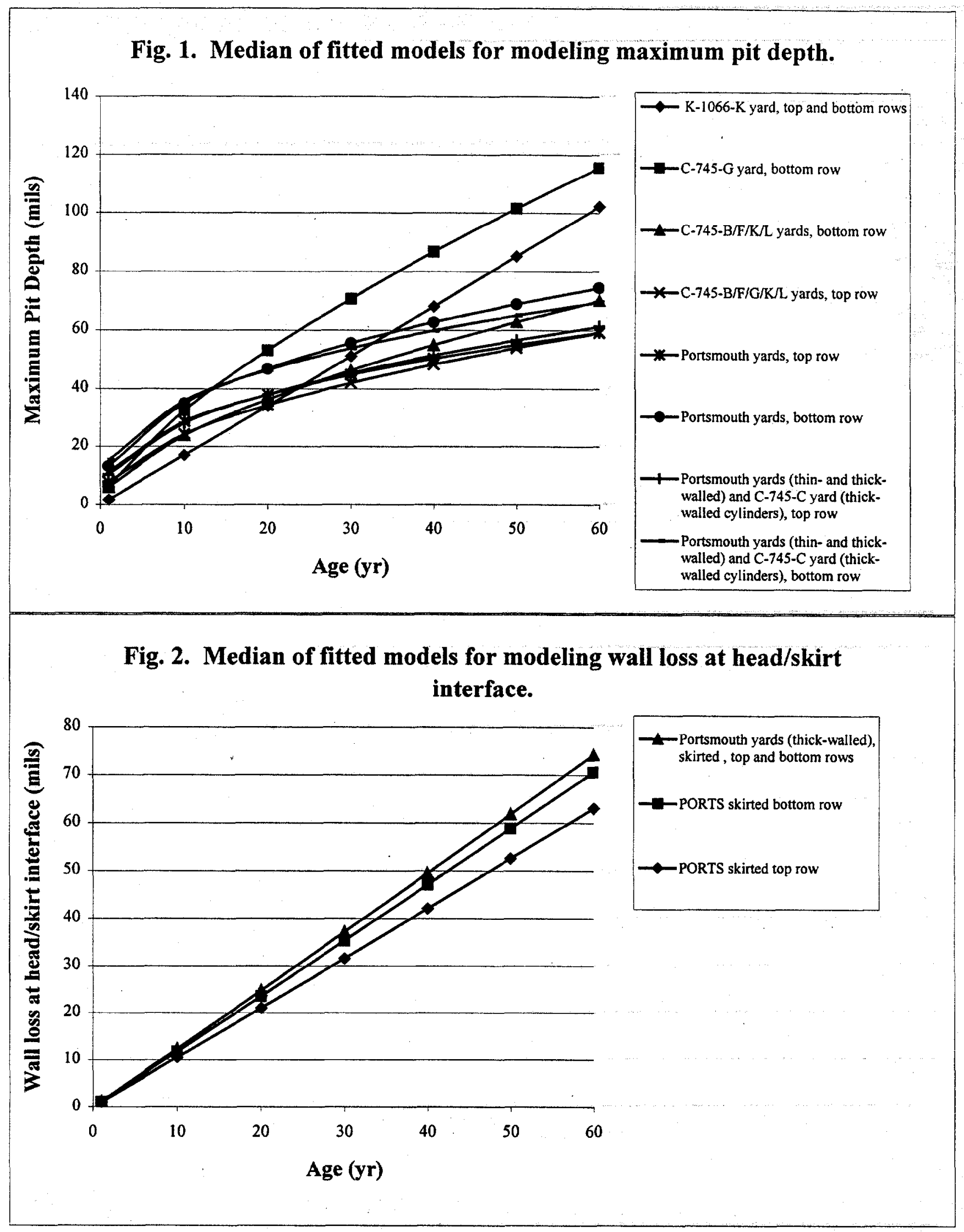


Fig. 3. Measured pit depths (mils) for K-1066-K yard, top and bottom rows (117 cylinders)

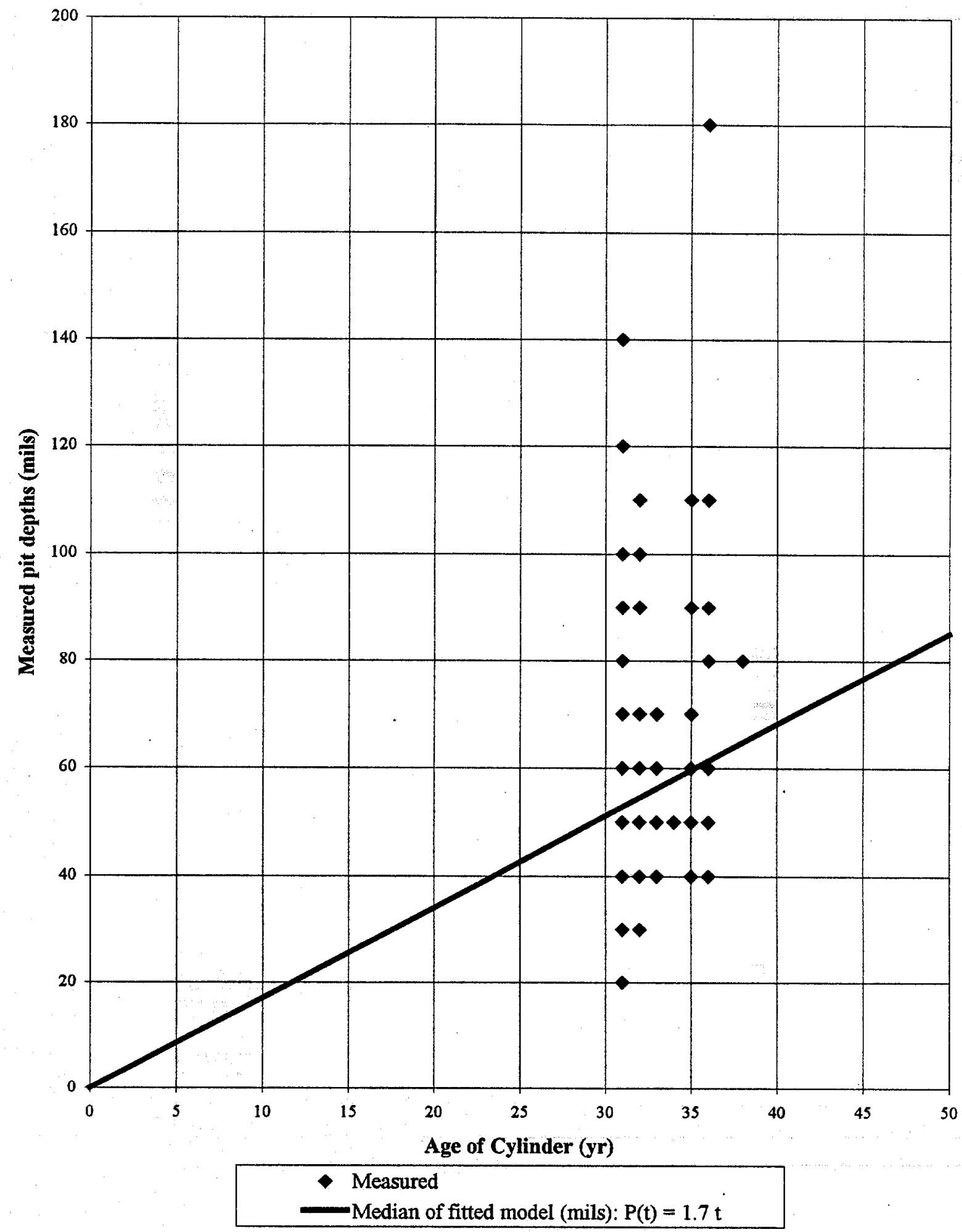


Fig. 4. Measured pit depths (mils) for C-745-G yard, bottom row (117 cylinders)

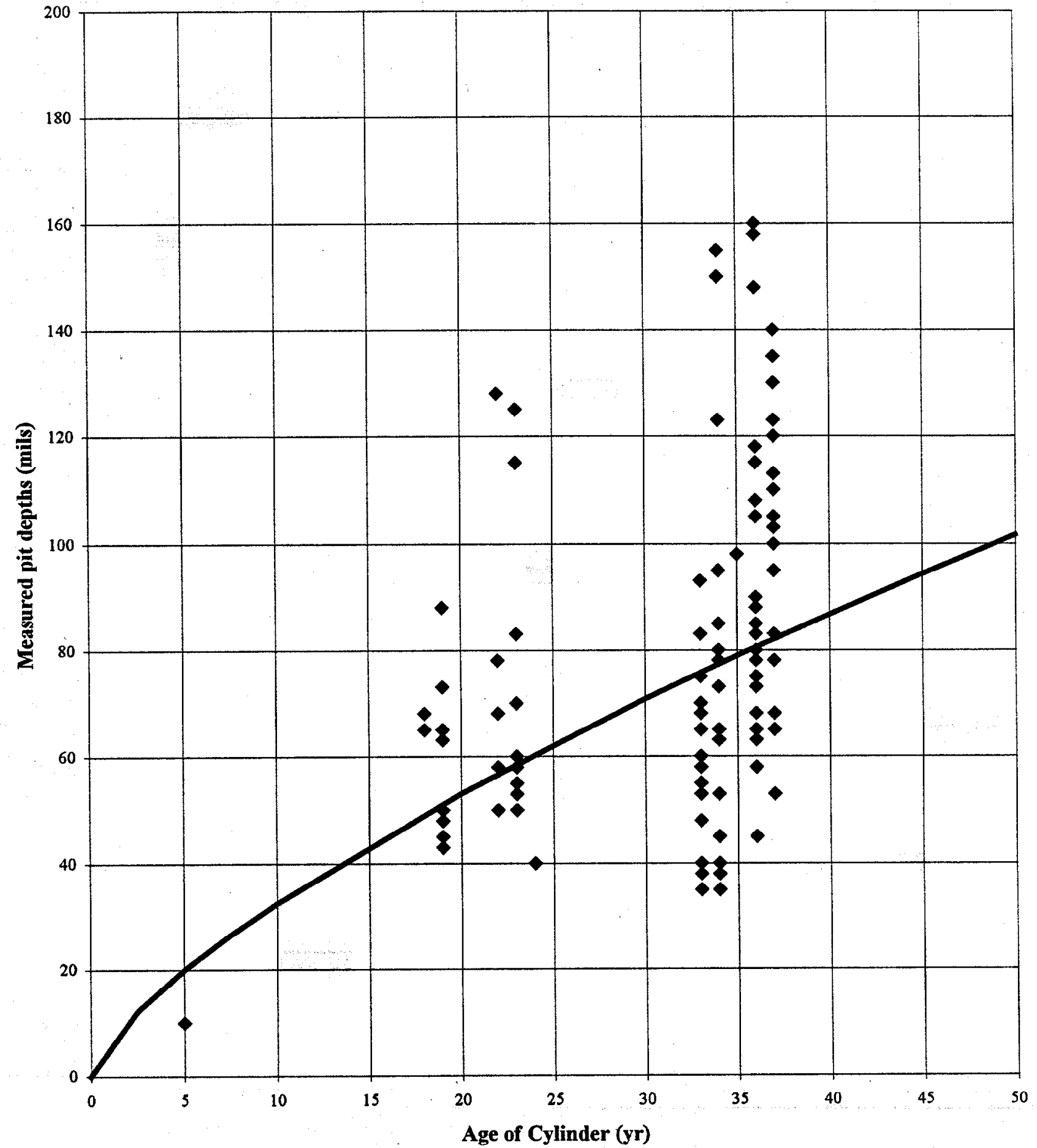

- Measured

Median of fitted model (mils): $P(t)=6.4 t^{\wedge} 0.7$ 


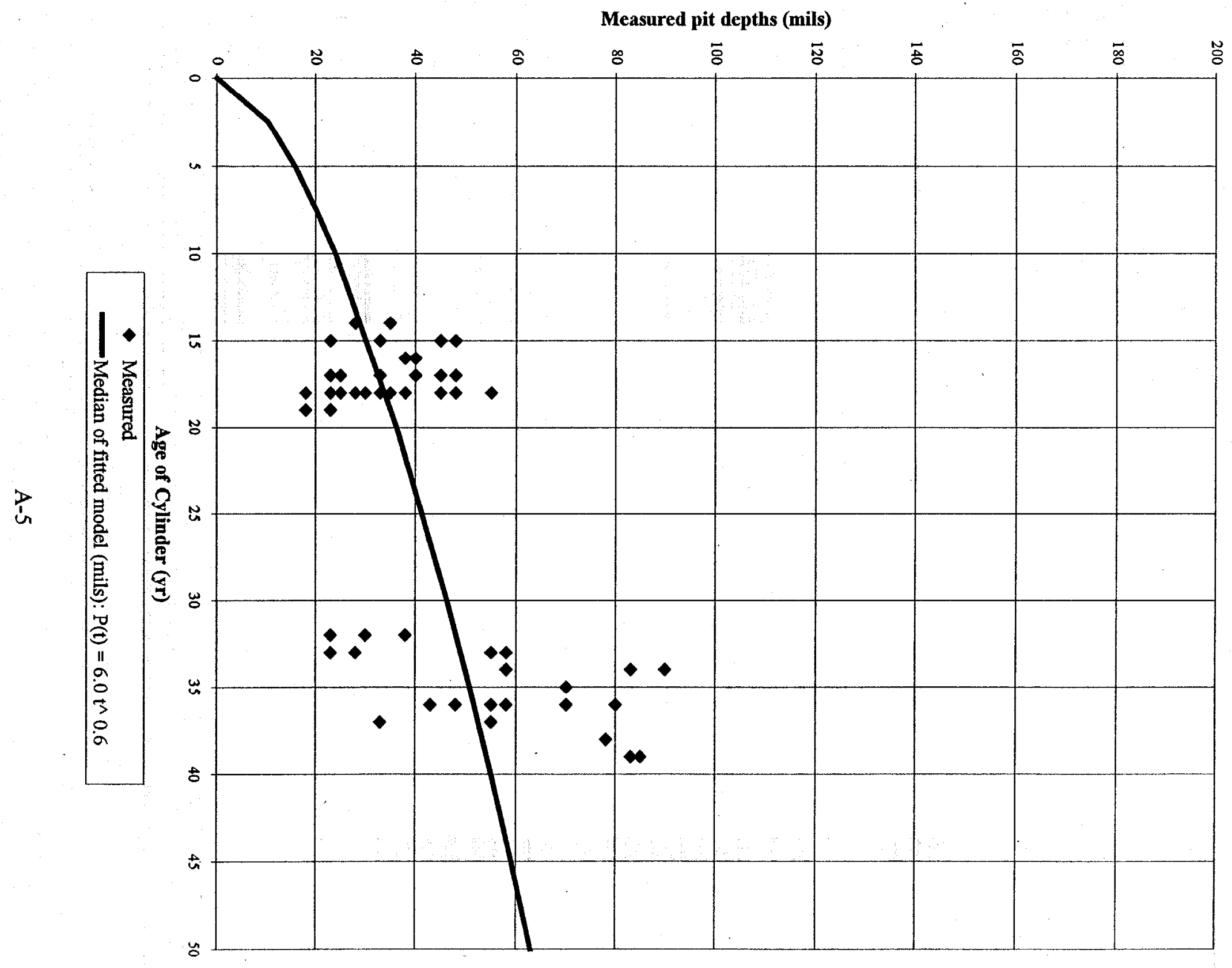

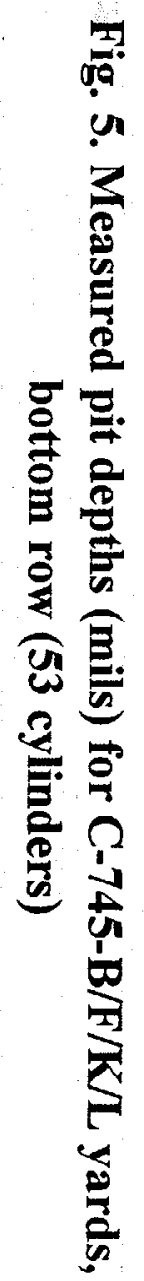


Fig. 6. Measured pit depths (mils) for C-745-B/F/G/K/L yards, top row (180 cylinders)

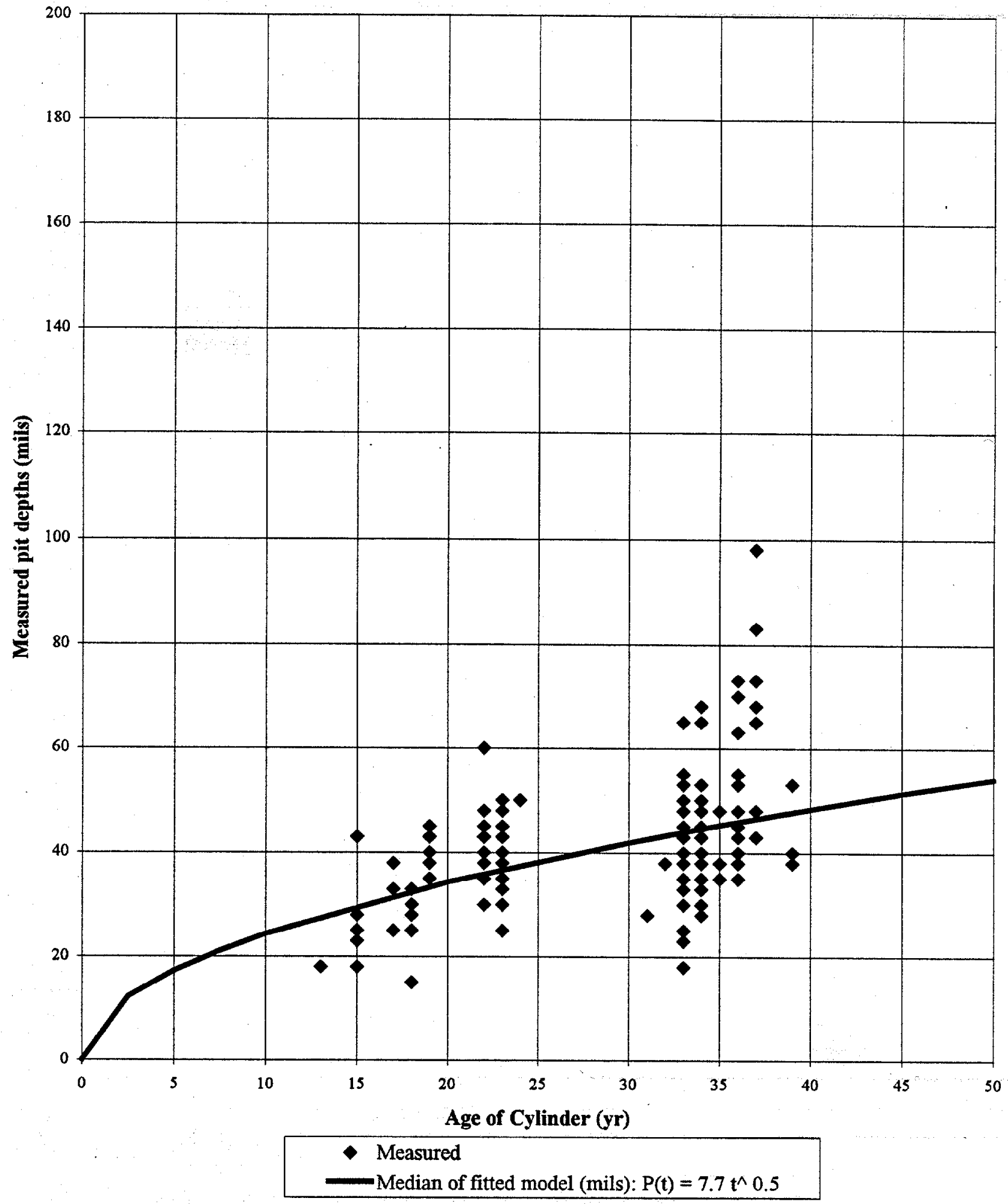


Fig. 7. Measured pit depths (mils) for Portsmouth yards, top row (277 cylinders)

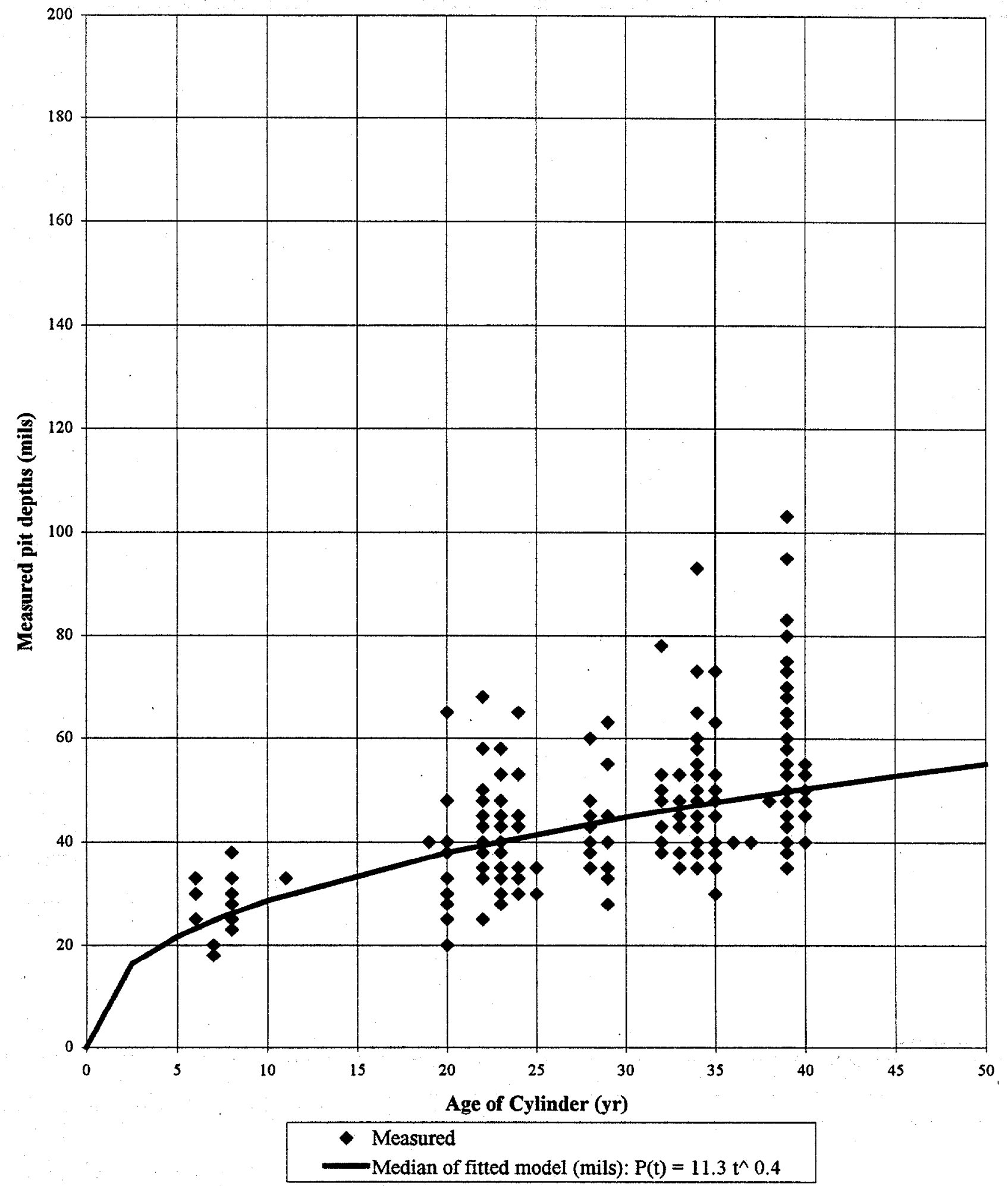


Fig. 8. Measured pit depths (mils) for Portsmouth yards, bottom row (281 cylinders)

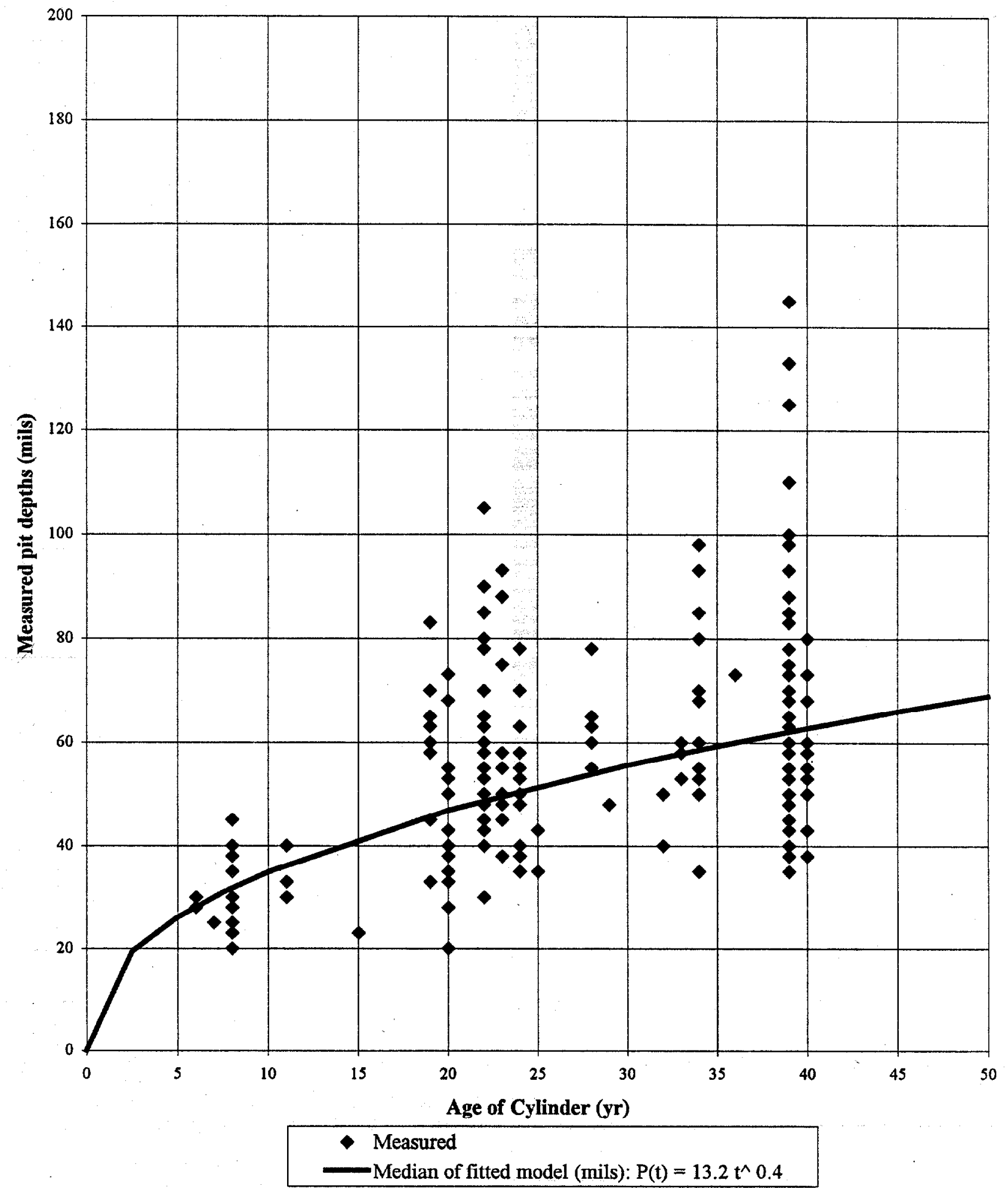


Fig. 9. Measured pit depths (mils) for Portsmouth yards (thinand thick-walled) and C-745-C yard (thick-walled cylinders), top row (328 cylinders)

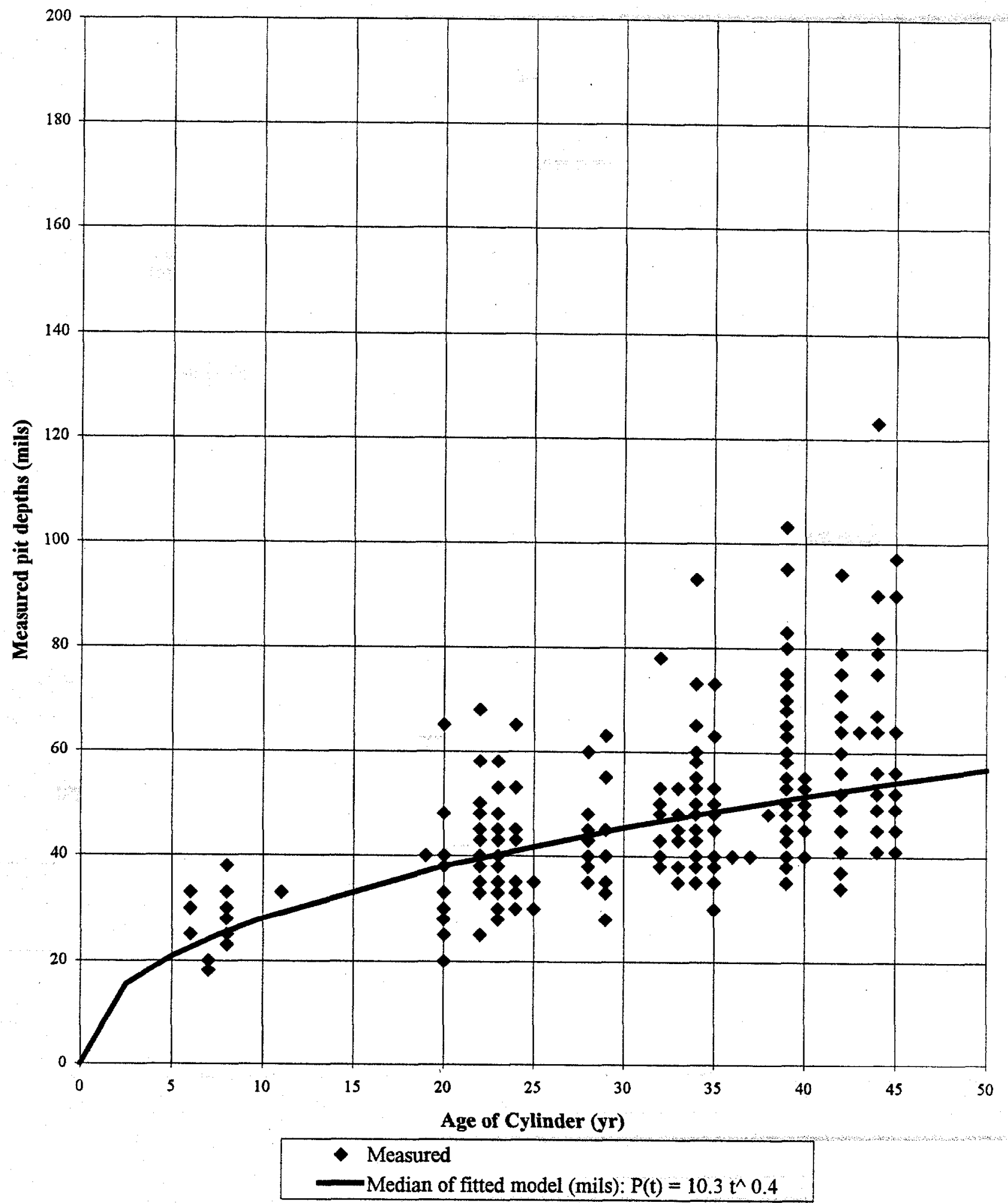


Fig. 10. Measured pit depths (mils) for Portsmouth yards (thinand thick-walled) and C-745-C yard (thick-walled cylinders),

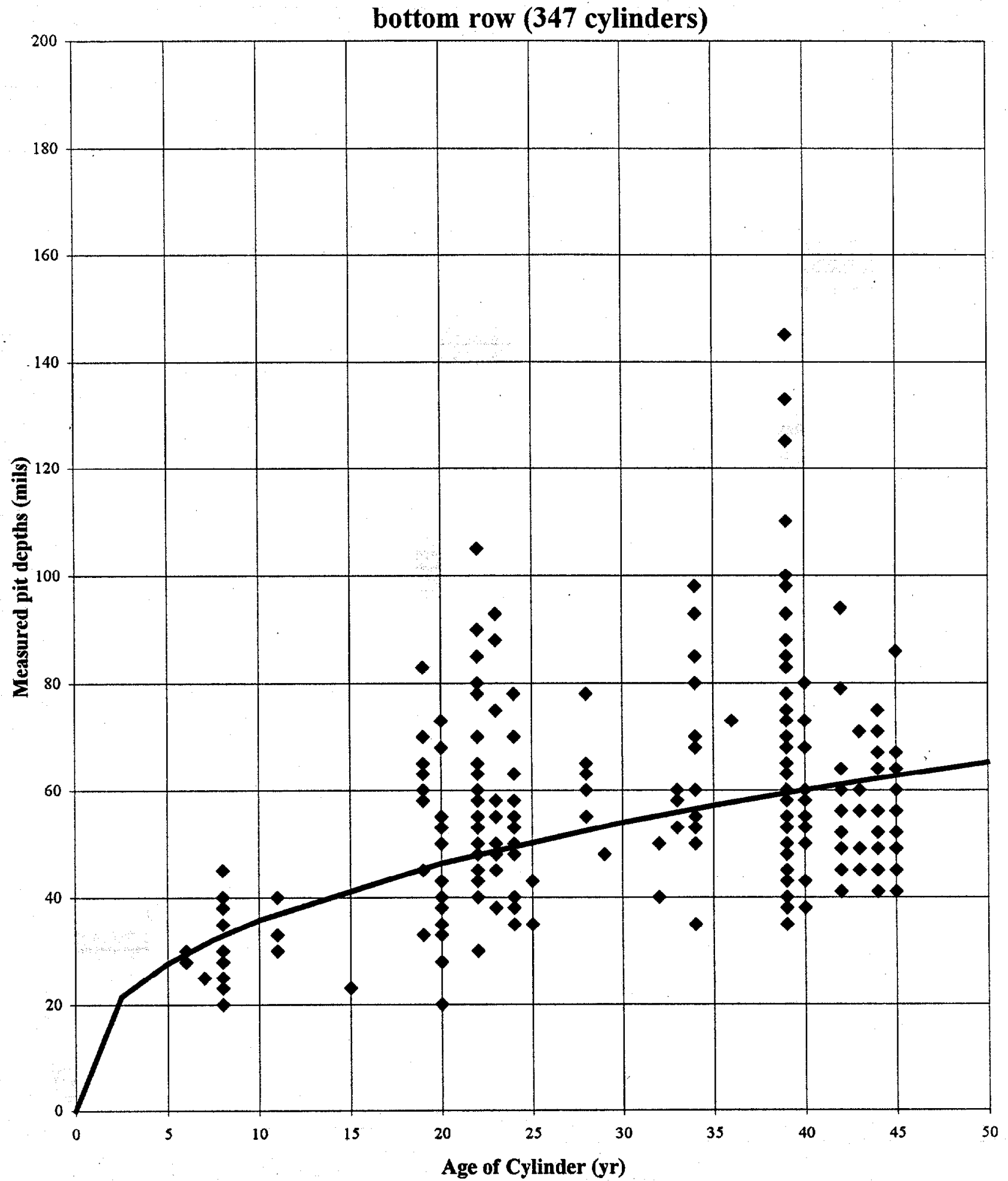

- Measured

Median of fitted model (mils): $P(t)=15.2 t^{\wedge} 0.4$ 
Fig. 11. Measured wall loss (mils) at head/skirt interface for Portsmouth yards (thin-walled), skirted, top row (105 cylinders)

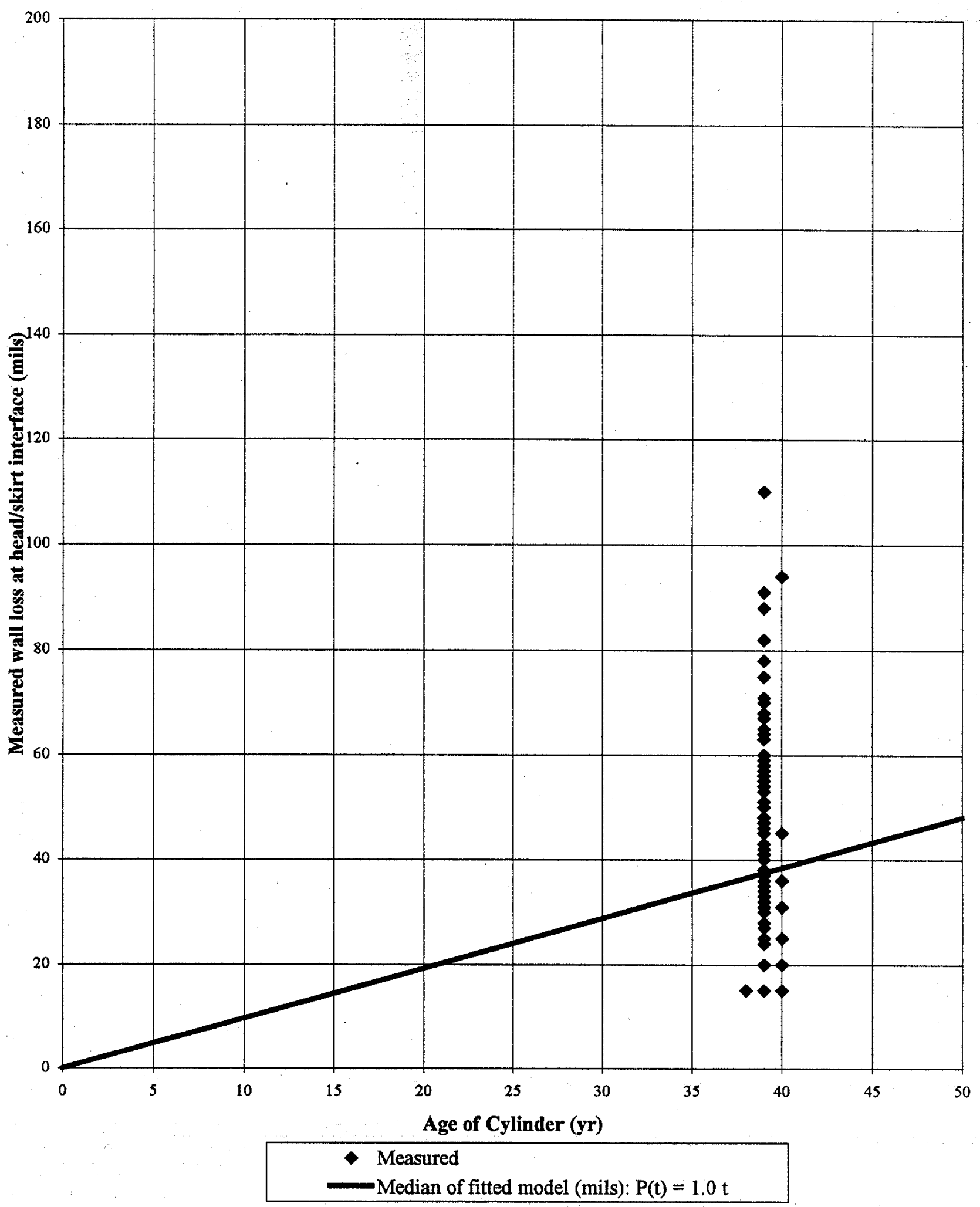


Fig. 12. Measured wall loss (mils) at head/skirt interface for Portsmouth yards (thin-walled), skirted, bottom row (128 cylinders)

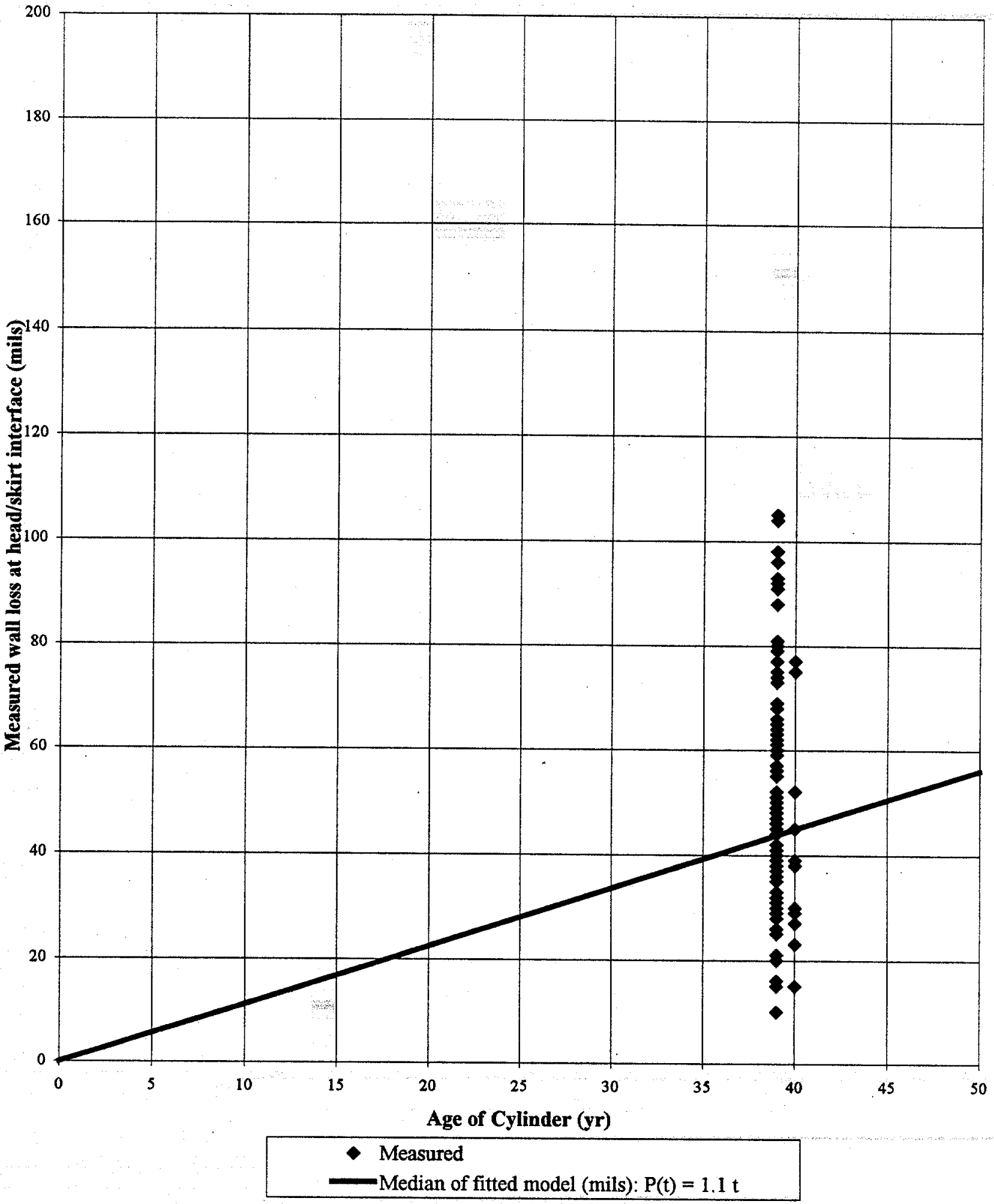


Fig. 13. Measured wall loss (mils) at head/skirt interface for Portsmouth yards (thick-walled), skirted, top and bottom rows (115 cylinders)

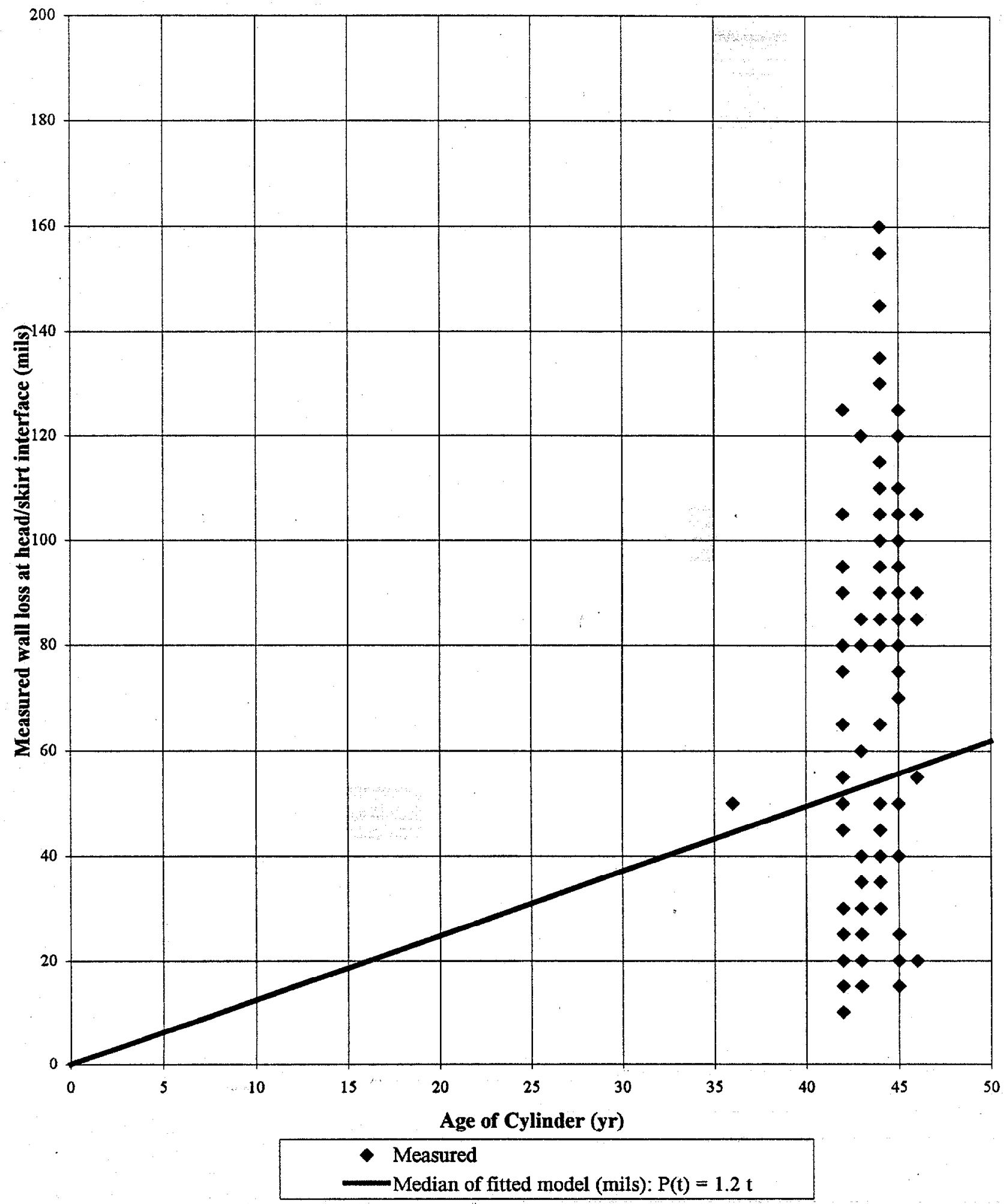




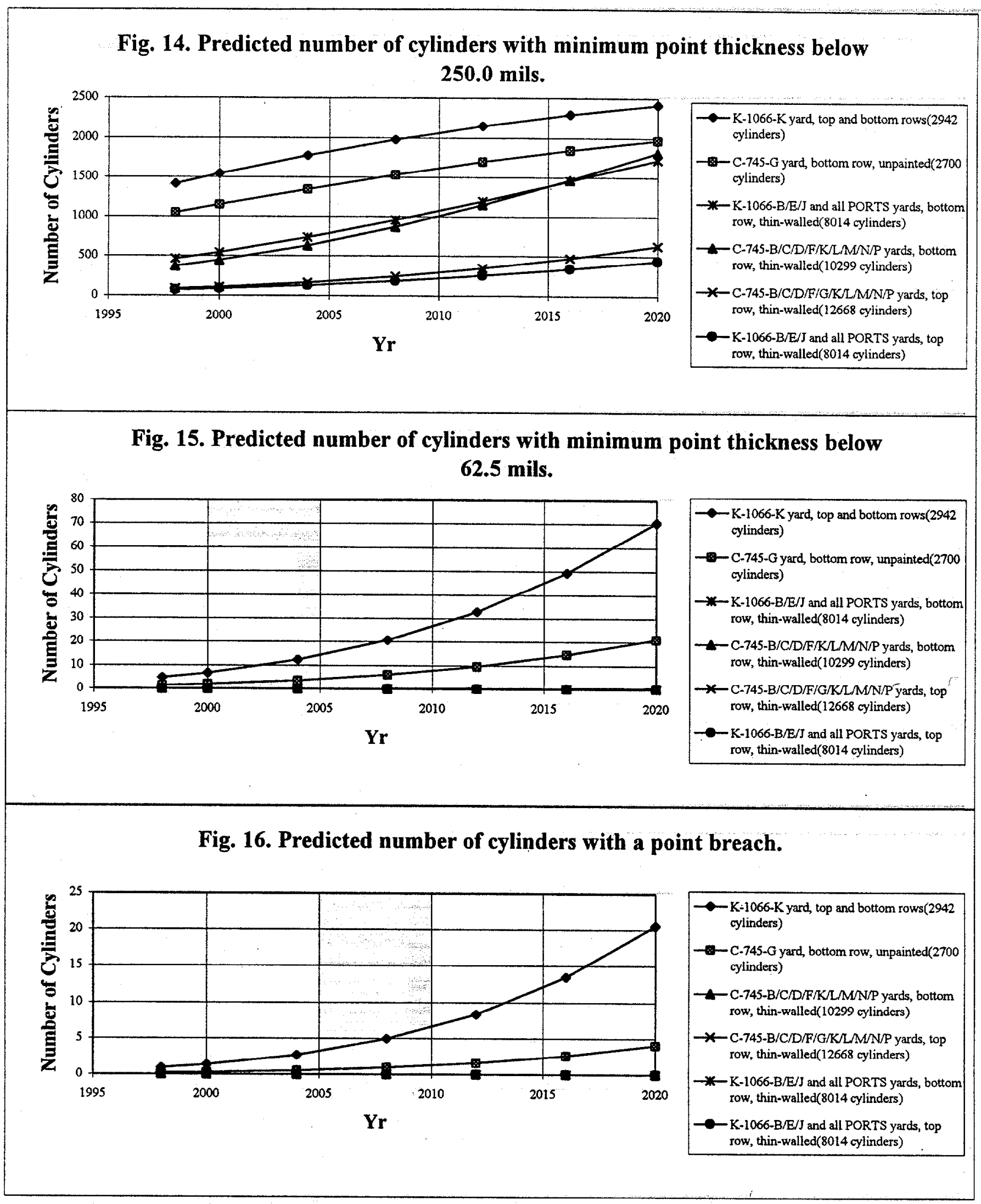




\section{APPENDIX B: METHODS}

\section{Calculating the cumulative distribution function for the difference of two distributions}

All of the methods discussed in this report are of the form

$$
M(t)=C_{0}-P(t)
$$

where $P(t)$ is the amount of corrosion that results in the minimum wall thickness (mils) at time $t$, and $C_{0}$ is the initial thickness (mils) where the minimum wall thickness occurs. Both $P(t)$ and $C_{0}$ are distributions, and calculation of the number of cylinders that have a minimum thickness below a certain thickness $z$ then requires calculating the probability that $M(t)<z$. Assuming a model of the form in Eq. 1, this is equivalent to calculating the probability that $C_{0}-P(t)<z$. Since both $C_{0}$ and $P(t)$ are distributions, calculation of this probability is not as straightforward as calculating the probabilities of $C_{n}$ and $P(t)$ separately, except for certain special cases (e.g., when $P(t)$ and $C_{0}$ are both normal distributions, in which case the difference is also a normal distribution). In this section, the method of calculating the needed probabilities are provided.

\section{General Formula}

If the random variable $W$ is defined by $W=X-Y$, where $X$ and $Y$ are independent random variables, then any sample $w$ from $W$ can be written in the form (not necessarily uniquely)

$$
w=F^{-1}(p)-G^{-1}(q)
$$

where $p, q$ are in $[0,1]$, and $F^{l}$ and $G^{\prime l}$ are the inverse cumulative distribution functions for $X$ and $Y$, respectively. Determination of the probability that $W<z$ is then equivalent to evaluating

$$
\iint_{A(z)} d p d q
$$

where $A(z)$ is the set defined by $A(z)=\left\{(p, q) \mid F^{-1}(p)-G^{-1}(q)<z\right\}$. Since $F^{-1}$ and $G^{-1}$ are inverse cumulative distribution functions, they are both nondecreasing functions, and so the function $h(p, q)=F^{-1}(p)-G^{-1}(q)$ is a nondecreasing function of $p$ and nonincreasing function of $q$. This makes evaluation of the integral in Eq. 3 relatively straightforward. First,

$$
\begin{aligned}
A(z) & =\left\{(p, q) \mid F^{-1}(p)-G^{-1}(q)<z\right\} \\
& =\left\{(p, q) \mid F^{-1}(p)<z+G^{-1}(q)\right\} \\
& =\left\{(p, q) \mid p<F\left(z+G^{-1}(q)\right)\right\}
\end{aligned}
$$


and so

$$
\begin{aligned}
\iint_{A(z)} d p d q & =\int_{0}^{1} \int_{0}^{F\left(z+G^{-1}(q)\right)} d p d q \\
& =\int_{0}^{1} F\left(z+G^{-1}(q)\right) d q
\end{aligned}
$$

Therefore,

$$
\operatorname{Prob}\{W=X-Y<z\}=\int_{0}^{1} F\left(z+G^{-1}(q)\right) d q
$$

The integral over the interval $[0,1]$ is evaluated using the adaptive quadrature method described in Burden and Faires (1989). With this method, subintervals are determined so that the integral is approximated with the desired accuracy using Simpson's rule on each subinterval. This method is generally faster than simpler integration methods to achieve the same accuracy because the ultimate subdivision that is used need not be uniformly spaced over the entire interval of integration; the subintervals can be selected based on the desired accuracy and the variability of the function to be integrated.

\section{Application}

In this report, $F$ is the cumulative distribution function (cdf) for the initial thickness $C_{0}$ which has a truncated normal distribution, and $G$ is the cdf for the penetration depth $P(t)$ at a fixed time $t$ which has a lognormal distribution with mean of the logarithm of the values of $\mu_{L}(t)$ and standard deviation of the logarithm of the values of $\sigma_{L}$.

Let $N(u)$ denote the cdf for the standard normal distribution (this is the normal distribution with mean 0 and standard deviation 1), and denote the qth quantile of the standard normal distribution by $n_{q}$. Then by the formula above it follows that

$$
\operatorname{Prob}\left\{C_{0}-P(t)<z\right\}=\int_{0}^{1} F\left(z+e^{\mu(t)+n_{q} \sigma(t)} ; \mu, \sigma\right) d q
$$

where 


$$
F_{[a, b]}(x ; \mu, \sigma)=\left\{\begin{aligned}
0 & \text { if } x<a \\
(N(x ; \mu, \sigma)-N(a ; \mu, \sigma)) /(N(b ; \mu, \sigma)-N(a ; \mu, \sigma)) & \text { if } a<x<b \\
1 & \text { if } x>b
\end{aligned}\right.
$$

where $N(x ; m, s)=N((x-m) / s)$, where $N(z)$ is the standard normal distribution.

\section{Calculation of Upper Confidence Limits}

In the methods used in this report, the maximum penetration depth $P(t)$ is modeled using a lognormal distribution, with $P(t) \sim \log \left(\mu_{L}, \sigma_{\nu}\right)^{*} t$ (for $\mathrm{K}-1066-\mathrm{K}$ yard) or $P(t) \sim \log \left(\log A+n \log t, \sigma_{L}\right)$ and the parameters are fit with the data available. The number of cylinders with a minimum thickness below a certain thickness $z$ by a given time $T$ is calculated by a sum of the form

$$
\sum_{i} \operatorname{Prob}\left\{C_{0}-P\left(t_{i}\right)<z\right\} \times\left\{\text { Number of cylinders of age } t_{i} \text { at time } T\right\}
$$

where the sum is over all age classes for the cylinder population of interest. An upper confidence limit is calculated for this sum by first determining a confidence level $\alpha$ such that if an upper $100 \alpha \%$ confidence limit is used for each term in the sum, then the final sum will be bounded with at least $95 \%$ confidence. For the purpose of this effort, the Bonferroni inequality is used to determine $\alpha$. This is conservative because there is structure in the model that is not exploited. If necessary, further analysis will investigate the implementation of less conservative methods (e.g., extension of Working-Hotelling Bands (Miller 1981)). The specific value of $\alpha$ depends on the number of age classes, and increases with the number of age classes; generally, $\alpha$ is at least 0.99 for the cases here.

Because a distribution is assumed for the initial thickness $C_{0}$, it is somewhat involved to calculate confidence limits for the terms $\operatorname{Prob}\left\{C_{0^{-}} P(t)<z\right\}$, even for a fixed time $t$. This is because one must obtain an upper confidence limit on an integral of the form

$$
\int_{0}^{1} F\left(z+G^{-1}(q, t)\right) d q
$$

where $F(z)$ is the cumulative distribution function for the initial thickness and $G(z, t)^{2}$ is the cumulative distribution function for the penetration depth at time $t$ (i.e., $G(z, t)=\operatorname{Prob}\{P(t)<z\})$.

In order to obtain an upper confidence limit on the integral above, it is not sufficient to use the confidence limits for $G^{-1}(q, t)$ for a fixed $q$. In particular, neglecting the uncertainty in the initial thickness distribution, a curve $H\left(q ; q_{1}, q_{2}\right)$ must found such that

${ }^{2}$ This is a slight abuse of notation that hopefully will help more than confuse the reader. 


$$
\operatorname{Prob}\left\{G^{-1}(q, t)<H\left(q ; q_{1}, q_{2}\right) \text { for } q \in\left(q_{1}, q_{2}\right)\right\}=\alpha
$$

where $\alpha$ is the desired confidence level (e.g., 0.95 for an upper $95 \%$ confidence limit). The details of calculating the function $H\left(q ; q_{1}, q_{2}\right)$ when $P(t)$ is either normally or lognormally distributed are provided in Appendix C.

It is not possible to obtain simultaneous confidence limits that hold for $q$ in the closed interval $[0,1]$ if $P(t)$ is normally or lognormally distributed. However, for arbitrary $q_{1}$ and $q_{2}$, it can be concluded with at least $1000 \%$ confidence that

$$
\int_{0}^{1} F\left(z+G^{-1}(q, t)\right) d q<\int_{0}^{q_{1}} F\left(z+G^{-1}(q, t)\right) d q+\int_{q_{2}}^{l} F\left(z+G^{-1}(q, t)\right) d q+\int_{q_{1}}^{q_{2}} F\left(z+H\left(q ; q_{1}, q_{2}\right)\right) d q
$$

Since $F(z) \leq 1$,

$$
\int_{0}^{1} F\left(z+G^{-1}(q, t)\right) d q<q_{1}+\left(1-q_{2}\right)+\int_{q_{1}}^{q_{2}} F\left(z+H\left(q ; q_{1}, q_{2}\right)\right) d q
$$

If it is assumed that $P(t)-\log (\ln A+n \ln t, \sigma)$, then

$$
H\left(q ; q_{1}, q_{2}\right)=\hat{A} t^{\hat{n}} e^{S_{L} z_{q}} e^{S_{L} r\left(l, \alpha, q_{l}, q_{2}\right)}
$$

where $\ln \hat{A}$ and $\hat{n}$ are the least squares estimates of $\ln A$ and $n$, respectively, $S_{L}$ is an unbiased estimate of $\sigma_{L}, z_{q}$ is the $q$ th percentile of the standard normal distribution, and $r_{U}\left(t, \alpha, q_{1}, q_{2}\right)$ is the factor that makes the curve $H\left(q ; q_{1}, q_{2}\right)$ an upper confidence limit valid over the entire interval $\left(q_{1}, q_{2}\right)$. In the end, one can conclude with at least $100 \alpha \%$ confidence that

$$
\operatorname{Prob}\left\{C_{0}-P(t)<z\right\}<q_{1}+\left(1-q_{2}\right)+\int_{q_{1}}^{q_{2}} F\left(z+\hat{A} t^{\hat{n}} e^{S_{L^{2}} e} e^{\left.S_{L^{r}} u^{\left(t, \alpha, q_{1}, q_{2}\right)}\right)}\right) d q
$$

Note that the practical effect is to "increase" the term $\hat{A}$, and this facilitates calculation of the confidence 
limits because previously implemented integration routines can be employed, after replacing $\hat{A}$ with $\hat{A} e^{S_{L} r_{U}\left(t, \alpha, q_{1}, q_{2}\right)}$, to calculate the integral.

The limits $q_{1}$ and $q_{2}$ are completely arbitrary, and can be chosen so as to minimize the upper confidence limit on the integral. The term $q_{1}+\left(1-q_{2}\right)$ becomes smaller the closer $\left(q_{1}, q_{2}\right)$ is to the whole interval $(0,1)$. However, this results in an increase of the term $H\left(q ; q_{1}, q_{2}\right)$ since the interval is wider. At the present, time constraints prevented a two-dimensional search algorithm for finding $q_{1}$ and $q_{2}$. Instead, $q_{1}$ is fixed and $q_{2}$ is found by finding where the derivative with respect to $q_{2}$ is zero.

\section{Statistical Tests}

\section{Kolmogorov-Smirnov Goodness-of-Fit Test}

The test used to determine if it was reasonable to assume that the distribution of average corrosion rates were lognormally distributed was a variant of the Kolmorogov-Smirnov test. This test uses the difference between the empirical (or sample) cumulative distribution function and that of the hypothesized distribution. If the difference is too large, then one rejects the hypothesis that the sample came from the hypothesized distribution.

The empirical cumulative distribution function evaluated at a given value $r$ is simply the fraction of the samples with value less than or equal to $r$. In particular, given $N$ samples $r_{1}, r_{2}, \ldots r_{N}$ from a distribution $R$, the empirical cumulative distribution function $F_{N}(r)$ is defined by

$$
F_{N}(r)=\frac{\# \text { samples } \leq r}{N}
$$

Let $F(r)$ denote the cumulative distribution of the hypothesized distribution. The Kolmogorov-Smirnov test statistic $D_{N}$ is defined by

$$
D_{N}=\max _{r}\left|F_{N}(r)-F(r)\right|
$$

If the cdf $F(r)$ is continuous, then this statistic is independent of the hypothesized distribution. A closed form has been derived for the distribution of this statistic (see, e.g., Vincze 1970), and so the calculated value $D_{N}$ can be compared to critical values of its distribution to perform hypothesis tests at a prescribed significant level; i.e., one can test the null hypothesis that $R$ has a specified distribution with cumulative distribution function $F(r)$ versus the alternative hypothesis that the distribution of $R$ is other than that specified. One accepts the null hypothesis if $D_{N}\left\langle D^{*}(\alpha)\right.$, where $D^{*}(\alpha)$ is such that $\operatorname{Prob}\left\{D_{N}>D^{*}(\alpha)\right\}=\alpha$. This test is called the Kolmogorov-Smirnov goodness-of-fit test (K-S test).

In contrast to the $\chi^{2}$ goodness-of-fit test, the K-S test is applicable for all sample sizes, and 
avoids the problem of the grouping of the data. However, the K-S test in the above form is not applicable if any of the parameters of the hypothesized distribution have been estimated from the data. For the standard $\chi^{2}$ test, this is addressed by reducing the degrees of freedom of the $\chi^{2}$ distribution used (one for each parameter estimated from the data). For the K-S test, it is recognized (e.g., Massey 1951) that if the parameters of the hypothesized distribution are estimated from the data, then the critical value $D^{*}(\alpha)$ should be reduced, but the amount of the reduction necessary is not known in general. This means that if the standard $D^{*}(\alpha)$ values are used, then one is more likely to falsely accept the null hypothesis that the distribution has the hypothesized form. Using Monte Carlo calculation, Lilliefors (1967) estimated the appropriate critical values $D^{*}(\alpha)$ for the case when the hypothesized distribution is a normal distribution with mean and variance estimated from the data. These values can be applied for lognormal distributions as well since the statistic in Eq. B-1 has the same value whether or not the data are transformed. As expected, the estimated critical values in Lilliefors (1967) are smaller than those for the more general K$\mathrm{S}$ test. Table B-1 shows the critical values $D^{*}(\alpha)$ from Lilliefors (1967), as well as the standard values (from Massey 1951).

Table B-1. Critical values for the statistic used for goodness-of-fit tests.

\begin{tabular}{ccc}
\hline Sample size $N$ & Critical $D^{*}(\alpha)$ for $\alpha=0.05^{\mathrm{A}}$ & Standard K-S Critical Value for $\alpha=0.05^{\mathrm{B}}$ \\
\hline 4 & 0.38 & 0.62 \\
5 & 0.34 & 0.57 \\
6 & 0.32 & 0.52 \\
7 & 0.30 & 0.49 \\
8 & 0.29 & 0.46 \\
9 & 0.27 & 0.43 \\
10 & 0.26 & 0.41 \\
11 & 0.25 & 0.39 \\
12 & 0.24 & 0.38 \\
13 & 0.23 & 0.36 \\
14 & 0.23 & 0.35 \\
15 & 0.22 & 0.34 \\
16 & 0.21 & 0.33 \\
17 & 0.21 & 0.32 \\
18 & 0.20 & 0.31 \\
19 & 0.20 & 0.30 \\
20 & 0.19 & 0.29 \\
25 & 0.18 & 0.27 \\
30 & 0.16 & 0.24 \\
Over 30 & $-0.886 \mathrm{~N}^{-1 / 2}$ & $-36 \mathrm{~N}^{-12}$ \\
\hline
\end{tabular}

A Calculated from Monte Carlo analysis in Lilliefors (1967).

${ }^{B}$ Massey (1951). 
The K-S test, using the appropriate critical values from Lilliefors (1967), was utilized here. If the sample size was not one of those in Table B-1, then the critical value for the next highest sample size in Table B- 1 was used for sample sizes $<30$, and the asymptotic approximation for sample sizes above 30.

\section{T-Test with Unequal Variances}

Before combining certain cylinder populations, statistical tests were performed to determine if it was likely that the populations were too "different" in a statistically meaningful sense. To this end, the $t$ test with unequal variances was used to determine if the medians were equal (the usual $t$-test requires that the variances of the populations being compared are equal). When the results of the goodness-of-fit tests indicated that it was reasonable to assume that the distribution of rates was lognormally distributed for each subpopulation considered, the $t$-test with unequal variances is applicable to the logarithm of the corrosion rates. The $t$-test is actually a test for means, but the median is equal to the mean for normal distributions. Thus, if we can accept or reject the hypothesis that the medians of the logarithms are not equal, then we can make the same conclusion for the exponential of the random variables.

For two normally distributed random variables $X$ and $Y$, let $m_{X}$ and $m_{Y}$ denote the sample means and $s_{X}$ and $s_{Y}$ denote the sample standard deviations from samples of sizes $n_{X}$ and $n_{Y}$ from the populations $X$ and $Y$, respectively. The purpose of the $t$-test is to test the null hypothesis that the means $\mu_{X}$ and $\mu_{Y}$ of $X$ and $Y$ are equal, versus the alternative hypothesis that they are not equal. The statistic used to test this hypothesis is given by

$$
t^{\prime}=\frac{m_{X}-m_{Y}}{\sqrt{s_{X}^{2} / n_{X}+s_{Y}^{2} / n_{Y}}}
$$

By Satterthwaite's approximation (see, e.g., Casella and Berger 1990), this random variable can be approximated by a $t$-distribution with degrees of freedom $\hat{v}$ given by

$$
\hat{v}=\frac{\left(s_{X}^{2} / n_{x}+s_{Y}^{2} / n_{Y}\right)^{2}}{\frac{s_{X}^{4}}{n_{X}^{2}\left(n_{X}-1\right)}+\frac{s_{Y}^{4}}{n_{Y}^{2}\left(n_{Y}-1\right)}}
$$

For a given confidence level $\alpha$, the hypothesis that the means are equal is rejected if $t^{\prime}$ is too large or too small. In particular, the hypothesis is rejected if $t^{\prime}<-t_{\hat{v}}(\alpha / 2)$ or $t^{\prime}>t_{\hat{v}}(\alpha / 2)$, where $t_{\hat{v}}(\alpha / 2)$ is the upper $\alpha / 2$ percentile of the $t$-distribution with $\hat{v}$ degrees of freedom; i.e., 


$$
\int_{t_{0}(\alpha / 2)}^{\infty} f(t, \hat{v}) d t=\alpha / 2
$$

where

$$
f(t, v)=\frac{\Gamma\left(\frac{v+1}{2}\right)}{\Gamma\left(\frac{v}{2}\right)}(\pi v)^{-1 / 2}\left(1+t^{2} / v\right)^{-(v+1) / 2}
$$

The slightly different test of testing the null hypothesis that the means are equal versus the alternative hypothesis that one mean is larger than the other can be performed using the one-tail probabilities from the $t$-distribution. For example, we would reject the hypothesis that the means are equal versus the alternative hypothesis that $\mu_{\mathrm{X}}>\mu_{\mathrm{Y}}$ if $t^{\prime}>t_{\mathrm{v}}(\alpha)$.

\section{References}

Burden, R.L. and J.D. Faires (1989). Numerical Analysis, Fourth Edition, PWS-Kent Publishing Company, Boston.

Casella, G. And R.L. Berger (1990). Statistical Inference. Wadsworth and Brooks/Cole Advanced Books and Software, Pacific Grove, California.

Evans, M., N. Hastings, and Brian Peacock (1993). Statistical Distributions. Second Edition, John Wiley \& Sons, New York.

Lilliefors, H.W. (1967). On the Kolomogorov-Smirnov test for normality with mean and variance unknown. American Statistical Association Journal, pp. 399-402, June 1967.

Massey, F.J., Jr. (1951). The Kolomogorov-Smirnov test for goodness of fit. American Statistical Association Journal, Vol. 46, pp. 68-79.

Miller, R.G., Jr. Simultaneous Statistical Inference. Second Edition, Springer-Verlag, New York..

Vincze, I. (1970). On Kolmogorov-Smirnov Type Distribution Theorems, in Nonparametric Techniques in Statistical Inference (ed. M.L Puri). Cambridge at the University Press. 


\section{APPENDIX C: SIMULTANEOUS CONFIDENCE LIMITS ON THE PERCENTILES OF A NORMAL DISTRIBUTION}

In order to calculate upper confidence limits for the case when both the penetration depth $P(t)$ and the initial thickness $\mathrm{C}_{0}$ are treated as a distribution, it is necessary to find a curve $h(q)$ such that the percentiles $P_{q}$ of $P(t)$ satisfy $P_{q}<h(q)$ for all $q$ in a given interval $[a, b]$ for a specified confidence. In this case, it is assumed that $P(t)$ is lognormally distributed, and so the $q$ th percentile of $P(t)$ is of the form $\exp \left[\mu_{L}(t)+\sigma_{L} z_{q}\right]$, where $z_{q}$ is the $q$ th percentile of the standard normal distribution. Since the exponential function is an increasing function, it is sufficient to find a curve that bounds the term $\mu_{L}(t)+$ $\sigma_{L} z_{q}$ for all $q$ in a given interval $[a, b]$ for a specified confidence. In this appendix, how this curve is determined is described, first for the special case when the mean $\mu_{L}(t)$ is constant, and then in the case for linear regression when $\mu_{L}(t)$ is assumed to be a linear function of $t$. The former case reduces to the problem of determining simultaneous confidence limits for the percentiles of a normal distribution. The latter case follows from the former with only a few modifications based on differences in the relevant sampling distributions.

\section{Simultaneous Confidence Limits for the Percentiles of a Normal Distribution}

If $\mu$ and $\sigma$ are the mean and standard deviation of a normal distribution, then the $p$ th percentile of the distribution is $\mu+\sigma z_{p}$, where $z_{p}$ is the $p$ th percentile of the standard normal distribution. If $m$ and $s$ are a sample mean and standard deviation from this distribution with a sample size of $n$, then an upper $100 \alpha \%$ confidence limit for $\mu+\sigma z_{p}$ is given by $m+s\left(z_{p}+e_{p}(\alpha)\right)$, where $e_{p}(\alpha)$ is calculated from the percentage points of the noncentral $t$-distribution (Owen 1968). A lower $100 \alpha \%$ confidence limit for $\mu+$ $\sigma \mathrm{Z}_{\mathrm{p}}$ is the same as an upper $100(1-\alpha) \%$; i.e., $m+s\left(z_{p}+e_{p}(1-\alpha)\right)$ These confidence limits are not simultaneous in $p$; i.e., one cannot state with $100 \alpha \%$ confidence that these bounds hold for a subinterval $[a, b]$. Here we describe determination of exact confidence limits that hold uniformly over a fixed interval. In particular, we describe how to determine numbers $\varepsilon_{\mathrm{U}}(\alpha, \mathrm{a}, \mathrm{b})$ and $\varepsilon_{\mathrm{L}}(\alpha, \mathrm{a}, \mathrm{b})$ such that

$$
\operatorname{Prob}\left\{\mu+\sigma z_{p} \leq m+s\left(z_{p}+\varepsilon_{U}(\alpha, a, b)\right) \text { for all } p \in[a, b]\right\}=\alpha
$$

and

$$
\operatorname{Prob}\left\{\mu+\sigma z_{p} \geq m+s\left(z_{p}+\varepsilon_{L}(\alpha, a, b)\right) \text { for all } p \in[a, b]\right\}=\alpha
$$

The numbers $\varepsilon_{U}(\alpha ; a, b)$ and $\varepsilon_{L}(\alpha ; a, b)$ can be determined using the distributions

$$
T_{U}=\max _{p \in[a, b]}\left[\frac{\left(\mu+\sigma z_{p}\right)-\left(m+s z_{p}\right)}{s}\right]
$$


and

$$
T_{L}=\min _{p \in[a, b]}\left[\frac{\left(\mu+\sigma z_{p}\right)-\left(m+s z_{p}\right)}{s}\right]
$$

respectively, because

$$
\begin{aligned}
\operatorname{Prob}\left\{\mu+\sigma z_{p} \leq m+s\left(z_{p}+\varepsilon_{U}(\alpha, a, b)\right) \text { for all } p \in[a, b]\right\} & =\operatorname{Prob}\left\{\max _{p \in[a, b]}\left[\frac{\left(\mu+\sigma z_{p}\right)-\left(m+s z_{p}\right)}{s}\right] \leq \varepsilon_{U}(\alpha, a, b)\right\} \\
& =\operatorname{Prob}\left\{T_{U} \leq \varepsilon_{U}(\alpha, a, b)\right\} \\
\operatorname{Prob}\left\{\mu+\sigma z_{p} \geq m+s\left(z_{p}+\varepsilon_{L}(\alpha, a, b)\right) \text { for all } p \in[a, b]\right\} & =\operatorname{Prob}\left\{\min _{p \in[a, b]}\left[\frac{\left(\mu+\sigma z_{p}\right)-\left(m+s z_{p}\right)}{s}\right] \geq \varepsilon_{L}(\alpha, a, b)\right\} \\
& =\operatorname{Prob}\left\{T_{L} \geq \varepsilon_{L}(\alpha, a, b)\right\}
\end{aligned}
$$

It is shown below that

$$
\begin{aligned}
& \operatorname{Prob}\left\{T_{U}<t\right\}=F_{n}(t ; a, b) \\
& \operatorname{Prob}\left\{T_{L}<t\right\}=F_{n}(t ; b, a)
\end{aligned}
$$

where

$$
F_{n}(t ; a, b)=\int_{0}^{\infty} H_{n}(u ; t, a) d u+\int_{0}^{\sqrt{v}}\left[H_{n}(u ; t, b)-H_{n}(u ; t, a)\right] d u
$$

the integrand is defined by

$$
H_{n}(u ; t, a)=\frac{1}{\Gamma(v / 2) 2^{v / 2-1}} G\left(\frac{u}{\sqrt{v}}\left(t+z_{a}\right) \sqrt{n}-z_{a} \sqrt{n}\right) e^{-u^{2} / 2} u^{v-1}
$$


$v=n-I$, and $G(u)$ is the cumulative distribution function for the standard normal distribution, given by

$$
G(w)=\frac{1}{\sqrt{2 \pi}} \int_{-\infty}^{w} e^{-w^{2} / 2} d w
$$

Therefore, the numbers $\varepsilon_{U}(\alpha ; a, b)$ and $\varepsilon_{L}(\alpha ; a, b)$ are found by solving the equations

$$
\begin{aligned}
& F_{n}\left(\varepsilon_{U}(\alpha, a, b) ; a, b\right)=\alpha \\
& F_{n}\left(\varepsilon_{L}(\alpha, a, b) ; b, a\right)=1-\alpha
\end{aligned}
$$

Note that this implies, at least formally, that

$$
\varepsilon_{L}(\alpha, a, b)=\varepsilon_{U}(1-\alpha, b, a)
$$

When $a=b=p$ these limits reduce to the usual factors used to calculate confidence limits on the percentile of a normal distribution, and

$$
F_{n}(t ; p, p)=\operatorname{Prob}\left\{t_{n-1}\left(z_{p} \sqrt{n}\right)<\left(t+z_{p}\right) \sqrt{n}\right\}
$$

where $t_{v}(\delta)$ is the noncentral $t$-distribution with noncentrality parameter $\delta$. Denoting the upper $\alpha$ th percentile by $t^{(\alpha)}(\delta)$, we have that

$$
\begin{aligned}
& \varepsilon_{U}(\alpha, p, p)=t_{n-1}^{(\alpha)}\left(z_{p} \sqrt{n}\right) / \sqrt{n}-z_{p} \\
& \varepsilon_{L}(\alpha, p, p)=t_{n-1}^{(1-\alpha)}\left(z_{p} \sqrt{n}\right) / \sqrt{n}-z_{p}
\end{aligned}
$$

in which case the upper and lower confidence $100 \alpha \%$ limits on $\mu+\sigma z_{p}$ reduce to $m+s t_{n-1}^{(\alpha)}\left(z_{p} \sqrt{n}\right) / \sqrt{n}$ and $m+s t_{n-1}^{(1-\alpha)}\left(z_{p} \sqrt{n}\right) / \sqrt{n}$, respectively. and hence

Finally, using the elementary fact that $G(-w)=1-G(w)$, we have that $F_{n}(t ; a, b)=1-F_{n}(-t ; 1-a, 1-b)$,

$$
\varepsilon_{L}(\alpha, a, 1-a)=-\varepsilon_{U}(\alpha, a, 1-a)
$$

that is, the upper and lower confidence limits are symmetric about the curve $m+s z_{p}$ when $b=1-a$. 


\section{Numerical Methods}

The first integral in Eq. 8 is that for the cumulative distribution of the noncentral $t$-distribution. In particular,

$$
\int_{0}^{\infty} H_{n}(u ; t, a) d u=\operatorname{Prob}\left\{t_{v}\left(z_{a} \sqrt{n}\right)<t+z_{a} \sqrt{n}\right\}
$$

where $t_{v}(\delta)$ is the noncentral $t$-distribution with noncentrality parameter $\delta$. This integral is evaluated using the method discussed in Owen (1968).

The second integral in Eq. 8 is evaluated using adaptive quadrature. However, this integral is first split into several pieces and adaptive quadrature is applied to each piece. This is done because the integrand has a maximum value near the upper limit of integration and is close to zero over most of the integration range. As a result, the adapative quadrature integration routine will terminate prematurely unless the endpoints of the first few subintervals are close to where the maximum occurs. For this reason, the integral is broken up into integrals over the regions $[0, \sqrt{v} / 2],[\sqrt{v} / 2, \sqrt{v}-1]$, and $[\sqrt{v}-1, \sqrt{v}]$.

A combination of the bisection method and the secant method is used to solve the equation

$$
F_{n}(\varepsilon, a, b)=\alpha
$$

Two initial guesses are required for the secant method. Since $z_{b}>z_{a}$, the inequality $H_{n}(u ; t, b)-$ $H_{n}(u ; t, a) \leq 0$ holds for $0 \leq u \leq \sqrt{v}$. Using Eq. 8, this means that $\varepsilon_{U}(\alpha, a, b)>L=\zeta_{\alpha} / \sqrt{n}-z_{a}$, where $\operatorname{Prob}\left\{t_{n-1}\left(z_{a} \sqrt{n}\right)<\zeta_{\alpha}\right\}=\alpha$, and so $L$ can serve as a lower bound for $\varepsilon_{U}(\alpha, a, b)$. An upper bound $U$ is determined by adding 0.2 to the lower limit $L$ until $F_{n}(U, a, b)>\alpha$. In this manner, $L<\varepsilon_{v}(\alpha, a, b)<U$. Similarly, $\varepsilon_{L}(\alpha, a, b)<\zeta_{1-\alpha} / \sqrt{n}-z_{a}$, and a lower bound is determined by subtracting 0.2 from the upper bound until an interval is found that contains the root $\varepsilon_{L}(\alpha, a, b)$. After an interval is found containing the root, the secant method is then used to generate the next approximation. If the approximation falls outside of the interval containing the root, then the bisection method is used to generate the next approximation. This procedure is continued until an approximation $\hat{\varepsilon}$ satisfies

$$
\left|F_{n}(\hat{\varepsilon}, a, b)-\alpha\right|<\text { Tolerance }
$$

for the upper confidence limit, and

$$
\left|F_{n}(\hat{\varepsilon}, b, a)-(1-\alpha)\right|<\text { Tolerance }
$$

for the lower confidence limit. 


\section{Derivation of Formula for Relevant Distribution}

In this section we derive the integral representation of the cumulative distribution for the functions $T_{U}$ and $T_{L}$ as shown in Eq. 8 above.

The function defined by

$$
\frac{\left(\mu+\sigma z_{p}\right)-\left(m+s z_{p}\right)}{s}
$$

has its maximum and minimum on $[a, b]$ at one of the endpoints since its derivative with respect to $p$ never vanishes (unless $s=\sigma$, in which case it is a constant, an event with probability 0 ). Further, this function is an increasing function of $p$ if $\sigma>s$ and decreasing if $\sigma<s$ because $z_{p}$ is an increasing function of $p$. Thus, the maximum will occur at the left endpoint if $\sigma$ is overestimated by $s$, and vice versa. This means that

$$
\begin{array}{r}
\max _{p \in[a, b]}\left[\frac{\left(\mu+\sigma z_{p}\right)-\left(m+s z_{p}\right)}{s}\right]=\frac{\sigma}{s}\left(\frac{\mu-m}{\sigma}\right)+\left(\frac{\sigma}{s}-1\right)\left\{\begin{array}{l}
z_{b} \text { if } \sigma / s>1 \\
z_{a} \text { if } \sigma / s<1
\end{array}\right. \\
\min _{p \in[a, b]}\left[\frac{\left(\mu+\sigma z_{p}\right)-\left(m+s z_{p}\right)}{s}\right]=\frac{\sigma}{s}\left(\frac{\mu-m}{\sigma}\right)+\left(\frac{\sigma}{s}-1\right)\left\{\begin{array}{l}
z_{a} \text { if } \sigma / s>1 \\
z_{b} \text { if } \sigma / s<1
\end{array}\right.
\end{array}
$$

This shows that once we have found the distribution for the maximum, the distribution for the minimum can be obtained by simply interchanging $a$ and $b$. Subsequent derivations are only shown for the maximum.

The random variable $W=(\mu-m) / \sigma$ is normally distributed with mean 0 and standard deviation $1 / \sqrt{n}$, and the random variable $X=s / \sigma$ is distributed as $1 / \sqrt{\chi_{v}^{2} / v}$, and the distributions $W$ and $X$ are independent. Let $G(w)$ denote the cumulative distribution function for the standard normal distribution $(=\sqrt{n} W)$ and $f(x)$ denote the probability density function for $X$. Then

$$
\begin{aligned}
G(w) & =\frac{1}{\sqrt{2 \pi}} \int_{-\infty}^{w} e^{-w^{2} / 2} d w \\
f(x) & =\frac{2 v}{x^{3}} \frac{1}{\Gamma(v / 2) 2^{v / 2}}\left(v / x^{2}\right)^{v / 2-1} e^{-v /\left(2 x^{2}\right)}
\end{aligned}
$$

Therefore we have that 


$$
\begin{aligned}
\operatorname{Prob}\left\{\frac{\sigma}{s}\left(\frac{\mu-m}{\sigma}\right)+\left(\frac{\sigma}{s}-1\right)\left\{\begin{array}{l}
z_{b} \text { if } \sigma / s>1 \\
z_{a} i f \sigma / s<1
\end{array}\right\}<t\right\} & =\operatorname{Prob}\left\{X W+(X-1)\left\{\begin{array}{l}
z_{b} \text { if } X>1 \\
z_{a} \text { if } X<1
\end{array}\right\}<t\right\} \\
& =\operatorname{Prob}\left\{X W \sqrt{n}+(X-1)\left\{\begin{array}{l}
z_{b} \sqrt{n} i f X>1 \\
z_{a} \sqrt{n} i f X<1
\end{array}\right\}<t \sqrt{n}\right\} \\
& =\int_{0}^{1} f(x) G\left(\frac{t \sqrt{n}-(x-1) z_{a} \sqrt{n}}{x}\right) d x+\int_{1}^{\infty} f(x) G\left(\frac{t \sqrt{n}-(x-1) z_{b} \sqrt{n}}{x}\right) d x \\
& =\int_{0}^{\infty} f(x) G\left(\frac{t \sqrt{n}-(x-1) z_{a} \sqrt{n}}{x}\right) d x+ \\
& \left.\int_{1}^{\infty} f(x)\left[\frac{t \sqrt{n}-(x-1) z_{b} \sqrt{n}}{x}\right)-G\left(\frac{t \sqrt{n}-(x-1) z_{a} \sqrt{n}}{x}\right) d x\right]
\end{aligned}
$$

Making the substitution $u=\sqrt{v} / x$ yields

$$
\operatorname{Prob}\left\{\frac{\sigma}{s}\left(\frac{\mu-m}{\sigma}\right)+\left(\frac{\sigma}{s}-1\right)\left\{\begin{array}{l}
z_{b} \text { if } \sigma / s>1 \\
z_{a} \text { if } \sigma / s<1
\end{array}\right\}<t\right\}=\int_{0}^{\infty} H_{n}(u ; t, a) d u+\int_{0}^{\sqrt{v}}\left[H_{n}(u ; t, b)-H_{n}(u ; t, a)\right] d u
$$

where

$$
H_{n}(u ; t, a)=\frac{1}{\Gamma(v / 2) 2^{v / 2-1}} G\left(\frac{u}{\sqrt{v}}\left(t+z_{a}\right) \sqrt{n}-z_{a} \sqrt{n}\right) e^{-u^{2} / 2} u^{v-1}
$$

\section{Application to Linear Regression}

Assume that we have pairs of samples $p_{i}$ at various ages $t_{i}:\left(t_{i} p_{i}\right), I=1, \ldots, N$, and we assume that $p(t)=N(a t+b, \sigma)$. Estimates of the regression coefficients $a$ and $b$ are given by 


$$
\begin{aligned}
& \hat{a}=\frac{\sum_{i=1}^{N} p_{i} t_{i}-\frac{1}{N}\left(\sum_{i=1}^{N} p_{i}\right)\left(\sum_{i=1}^{N} t_{i}\right)}{\sum_{i=1}^{N} t_{i}^{2}-\frac{1}{N}\left(\sum_{i=1}^{N} t_{i}\right)^{2}} \\
& \hat{b}=\bar{p}-\hat{a} \bar{t}
\end{aligned}
$$

where $\bar{p}=\frac{1}{N} \sum_{i=1}^{N} p_{i}$ and $\bar{t}=\frac{1}{N} \sum_{i=1}^{N} t_{i}$. An unbiased estimate of the standard deviation $\sigma$ is

$$
S^{2}=\frac{1}{N-2} \sum_{i=1}^{N}\left(p_{i}-\hat{a} t_{i}-\hat{b}\right)^{2}
$$

Assuming that $p(t) \sim N(a t+b, \sigma)$, the following is known about the sampling distributions for the estimates of the parameters (Casella and Berger, 1990; pp. 569-575):

$$
\begin{gathered}
\hat{a}+t \hat{b} \sim N\left(a+b t, \sigma e_{N}(t)\right) \\
S^{2} \sim \sigma^{2} \frac{\chi_{N-2}^{2}}{N-2}
\end{gathered}
$$

where we define $e_{N}(t)$ by

$$
e_{N}(t)=\sqrt{\frac{1}{N}+\frac{(t-\bar{t})^{2}}{S_{t t}}}
$$

and

$$
S_{t t}=\sum_{i=1}^{N}\left(t_{i}-\bar{t}\right)^{2}
$$

and $\chi^{2}{ }_{v}$ is the $\chi$-squared distribution with $v$ degrees of freedom. 
Based on similarities in the sampling distributions, the preceding discussion can be applied with only slight modifications to derive simultaneous confidence limits for the $p$ th percentile for $N(a t+b, \sigma)$ valid uniformly for $p$ in the range $\left(q_{1}, q_{2}\right)$. In particular, all that changes is that we replace $1 / \sqrt{n}$ with $e_{n}(t)$ and $v=n-2$ instead of $v=n-1$. The result is that an upper and lower $100 \alpha \%$ confidence limit on the $p$ th percentile for $N(a t+b, \sigma)$ are given by

$$
\begin{aligned}
& \left\{\text { Upper } 100 \alpha \% \text { confidence limit on } a t+b+\sigma z_{p}, p \in\left(q_{1}, q_{2}\right)\right\}=\hat{a} t+\hat{b}+S\left(z_{p}+r_{U}\left(\alpha, q_{1}, q_{2}\right)\right) \\
& \left\{\text { Lower } 100 \alpha \% \text { confidence limit on at }+b+\sigma z_{p}, p \in\left(q_{1}, q_{2}\right)\right\}=\hat{a} t+\hat{b}+S\left(z_{p}+r_{L}\left(\alpha, q_{1}, q_{2}\right)\right)
\end{aligned}
$$

where

$$
\begin{gathered}
\left.F_{n}^{(r e g)}\left(r_{U}\left(\alpha, q_{1}, q_{2}\right) ; q_{1}, q_{2}\right)\right)=\alpha \\
\left.F_{n}^{(r e g)}\left(r_{L}\left(\alpha, q_{1}, q_{2}\right) ; q_{2}, q_{1}\right)\right)=\alpha \\
F_{n}^{(r e g)}(\omega ; a, b)=\int_{0}^{\infty} R_{n}(u ; \omega, a) d u+\int_{0}^{\sqrt{n-2}}\left[R_{n}(u ; \omega, b)-R_{n}(u ; \omega, a)\right] d u
\end{gathered}
$$

and

$$
R_{n}(u ; \omega, a)=\frac{1}{\Gamma((n-2) / 2) 2^{(n-2) / 2-1}} G\left(\frac{u}{\sqrt{n-2}}\left(\omega+z_{a}\right) / e_{n}(t)-z_{a} e_{n}(t)\right) e^{-u^{2} / 2} \cdot u^{n-2-1}
$$

Finally, if in the case that $\ln p(t) \approx N(a \ln (t)+b, \sigma)$, i.e., $p(t)$ is lognormally distributed, then this same method can be applied, replacing $t$ with $\ln (t)$ and taking the exponential of the upper confidence limits.

\section{References}

Lawless, J.F. (1982). Statistical Models and Methods for Lifetime Data. John Wiley and Sons, New York.

Owen, D.B. (1968). A survey of properties and applications of the noncentral $t$-distribution.

Technometrics, Vol. 10, No.3. 
ORNL/TM-13359

\section{DISTRIBUTION}

1-50. B.F. Lyon

51. Central Research Library

52. Document Reference Center

53. ORNL Patent Section

54-55. ORNL Laboratory Records

56. ORNL Laboratory Records, RC

57. Office of Assistant Manager, Energy Research and Development, DOE-ORO, P.O. Box 2008; Oak Ridge, TN 37831-6269

58-59. Office of Science and Technical Information, P.O. Box 62, Oak Ridge, TN 37831 